\title{
A Revised Validation Process for Ice Accretion Codes
}

\author{
William B. Wright * Vantage Partners, LLC \\ Cleveland, Ohio 44135
}

\author{
Christopher E. Porter NASA Glenn Research Center \\ Cleveland, Ohio 4435
}

\begin{abstract}
I. Abstract
A research project is underway at NASA Glenn to produce computer software that can accurately predict ice growth under any meteorological conditions for any aircraft surface. This report will present results from the newest LEWICE, version 3.5. This program differs from previous releases in its ability to model mixed phase and ice crystal conditions such as those encountered inside an engine. It also has expanded capability to use structured grids and a new capability to use results from unstructured grid flow solvers. A quantitative comparison of the results against a database of ice shapes that have been generated in the NASA Glenn Icing Research Tunnel (IRT) has also been performed. This paper will extend the comparison of ice shapes between LEWICE 3.5 and experimental data from a previous paper. Comparisons of lift and drag are made between experimentally collected data from experimentally obtained ice shapes and simulated (CFD) data on simulated (LEWICE) ice shapes. Comparisons are also made between experimentally collected and simulated performance data on select experimental ice shapes to ensure the CFD solver, FUN3D, is valid within the flight regime. The results show that the predicted results are within the accuracy limits of the experimental data for the majority of cases.
\end{abstract}

\section{Nomenclature}

$\begin{array}{ll}\text { AOA } & \text { angle of attack (degrees) } \\ \mathrm{c} & \text { chord (in) } \\ \text { LWC } & \text { Liquid Water content }\left(\mathrm{g} / \mathrm{m}^{3}\right) \\ \mathrm{MVD} & \text { median volume diameter }(\mu \mathrm{m}) \\ \mathrm{T} & \text { temperature }\left({ }^{\circ} \mathrm{F}\right) \\ \mathrm{t} & \text { time }(\mathrm{min})\end{array}$

A. Subscripts
orral

III. Introduction

The NASA Glenn Icing Branch has produced software ${ }^{1-3}$ over the last several years for performing icing simulation in two dimensions. Currently, as part of the Advanced Air Transport Technology (AATT) Project, NASA is conducting research toward future generations of advanced airplane configurations with ambitious goals to improve efficiency while reducing emissions and noise. This research relies on the development of advanced icing simulation tools in order to realize these design goals. Therefore, NASA Glenn has worked toward expanding the capabilities of their LEWICE 2D code to produce software that can accurately predict ice growth under any meteorological conditions for any aircraft surface to assess these advanced airplane configurations. A new version of LEWICE, version 3.5, has been developed. This version differs from previous releases in its ability to model mixed phase and ice crystal conditions such as those encountered inside an engine. It also has expanded capability to use structured grids and a new capability to use results from unstructured grid flow solvers. 
Prior to the release of each new version of LEWICE, a validation process is followed to assess the accuracy of the simulation $^{4-6}$. While this validation process has been followed with LEWICE 3.5, additional validation steps are required to assess the accuracy of new capabilities. Previous validation efforts focused on the geometric comparison of ice shape features. Since the new version can produce multi-time step results using a Naviér-Stokes flow solver, comparisons can also be made to the aerodynamic degradation produced by the ice shape. Ideally, this validation would involve a comparison of the calculated lift and drag values against experimental data. However, since only a small number of ice shapes meet this criterion there are a large number of icing conditions to consider, this was not possible. Instead, the flow field is calculated on the ice shape produced from the experiment and the lift and drag values for those results are compared to the lift and drag values produced by the ice shape calculated by LEWICE 3.5. The previous year's report ${ }^{7}$ showed geometric comparisons for 105 cases. Naviér-Stokes comparisons were attempted for these cases but the demands on computational effort proved to be too high. The current report reduces the number of cases even further with the intent of developing a standard database for validation that could be used by others who develop icing tools.

There have been a large number of papers in recent years that predict ice accretions using Naviér-Stokes flow solvers ${ }^{8-35}$, but comparisons are typically limited to a small number of cases. Frequently, a comparison is made to a NACA0012 shape with the following conditions: $c=21^{\prime}, \mathrm{V}=130 \mathrm{kts}, \mathrm{T}_{\mathrm{o}}=28^{\circ} \mathrm{F}, \mathrm{AOA}=4^{\circ}, \mathrm{LWC}=1 \mathrm{~g} / \mathrm{m}^{3}, \mathrm{MVD}=20 \mu \mathrm{m}$. However, the comparison is often shown for only one of the NASA Icing Research Tunnel (IRT) ice shapes collected using this condition. In fact, this case is one of the most frequently repeated icing conditions as it is part of a calibration test used to confirm that the IRT produces similar ice shapes over time. There are 46 ice shape tracings available for this condition, including offcenterline tracings. Given the large number of cases available, a more proper comparison would show the prediction as compared to the variability of the experiment as shown in Fig. 1 using LEWICE. This figure shows the average of the 46 profiles along with the maximum and minimum ice shape as determined by the upper horn height. It should also be noted that since this is a very warm glaze condition, the repeatability is not as good as the repeatability of the IRT for other cases. This comparison also shows that the LEWICE prediction falls within the experimental variability. It is therefore desirable to find cases that would properly test the capabilities of ice accretion software. The current study selects 12 conditions that produce large glaze and large mixed ice shapes for evaluation of LEWICE 3.5. Previous comparisons have been made using NaviérStokes solvers with LEWICE ${ }^{36-38}$ but this is the first comprehensive comparison involving a large number of conditions and to apply the AIAA standard for verification and validation ${ }^{39}$.

The report is divided into four sections. The first section will cover the updates to this new version of LEWICE. The second section will provide a description of the Naviér-Stokes flow solver FUN3D ${ }^{40}$ that was used for this effort and the python scripts that manage the time stepping process. The third section will describe the experimental data and the parameters used for quantifying the comparisons. The last section will provide validation results along with a statistical comparison of those parameters with the available experimental data.

\section{Existing Computational Tools}

\section{A. LEWICE}

The computer program, LEWICE, embodies an analytical ice accretion model that evaluates the thermodynamics of the freezing process that occur when supercooled droplets impinge on a body. The atmospheric parameters of temperature, pressure, and velocity, and the meteorological parameters of liquid water content (LWC), droplet diameter, and relative humidity are specified and used to determine the shape of the ice accretion. The surface of the clean (un-iced) geometry is defined by segments joining a set of discrete body coordinates. The software consists of four major modules. They are 1) the flow field calculation, 2) the particle trajectory and impingement calculation, 3) the thermodynamic and ice growth calculation, and 4) the modification of the current geometry by addition of the ice growth.

LEWICE applies a time-stepping procedure to "grow" the ice accretion. Initially, the flow field and droplet impingement characteristics are determined for the clean geometry. The ice growth rate on each segment defining the surface is then determined by applying the thermodynamic model. When a time increment is specified, this growth rate can be transformed into an ice thickness and the body coordinates are adjusted to account for the accreted ice. This procedure is repeated, beginning with the calculation of the flow field about the iced geometry, then continued until the desired icing time has been reached. The results shown in this report are from version 3.5 of LEWICE.

There are two major updates that pertain to LEWICE 3.5. First a capability was added to model mixed phase and ice crystal conditions such as those existing in engines. This modification consists of three sub-models. First, there are the modifications to the particle trajectory routine that track the energy transfer to and from a particle. Second, there is a model for mass loss due to erosion in a mixed phase environment. Finally, there are changes to the mass and energy balance whereby the incoming ice particles can add to the ice mass at the surface. The second major modification was to expand the 
type of grids that could be handled by LEWICE. In the previous release, only single block structured grids could be used for single body geometries. Multi-block chimera grids could be used when analyzing multi-element airfoils. The new version can use unstructured grid input as well as multi-block structured grids including chimera grids and Cartesian grids. However, in order to use LEWICE in an automated fashion similar to the process used for potential flow solvers, a python script was created in order to manage the process. The script calls the grid generator, which in this case was Pointwise ${ }^{41}$, using the glyph scripting language ${ }^{42}$. Once the grid is generated, the script calls the flow solver to calculate the flow field. The grid and flow solver files were converted to a form that LEWICE can use with a utility program called catersian.exe. This process is similar to the process used by LEWICE3D to convert various grids and flow solutions to a format supported by LEWICE3D ${ }^{43}$. Once the grid and flow solutions are in a usable format, then LEWICE is run in single time step mode to produce an interim ice shape. Then the process is repeated for the number of time steps needed. The number of time steps used by the python script is determined by the same formula used in LEWICE when calculating automated time steps when using the potential flow solver. The results shown in this paper use ice shapes generated by LEWICE with potential flow. However, the performance data for these ice shapes were extracted from Navier-Stokes based simulations.

\section{B. FUN3D and Grid Generation}

FUN3D can perform both two-dimensional (2D) and three-dimensional (3D) node-based finite volume Naviér-Stokes simulations and has been parallelized with Message Passing Interface (MPI) communication for distributed computing. It can handle both compressible and incompressible simulations as well as time accurate simulations. It has several turbulence models, including Spalart-Allmaras, Menter k-omega SST, Wilcox k-omega, detached eddy simulation and others. The solver can also model implicit time stepping, boundary conditions for internal flows and grid motion. The Wilcox 2006 turbulence model ${ }^{44}$ was used in this report.

Grids were generated for airfoils and ice shapes using the commercial software Pointwise. This software was chosen because it could create the variety of grids necessary for testing the capabilities of LEWICE but also because of its ease of use and amenability to automated scripting. The user interface for Pointwise was built using the Glyph 2 scripting language. Glyph2 is an extension to the tcl programming language that allows access to the commands and entities of the Pointwise application. Unstructured grids were used in this report, as this would allow for a higher quality mesh for complex ice shapes. Previously, a system for automating a single LEWICE run using a single block structured grid was developed ${ }^{36}$. This process worked well in a general sense, but for large ice shapes the grids generated were warped, leading to less accurate flow solutions. For this study, rectangular elements were used near the surface of the geometry, with triangular elements further away. This was accomplished by using a feature in Pointwise called T-rex ${ }^{45}$. This allowed for the specification of a y+ of 1 at the wall. The T-rex layer was specified as being twenty cells thick, although this could be changed if it were found to be necessary. The outer grid was an unstructured O-grid with the freestream boundary placed 20 chord lengths from the airfoil. For all of the cases in this report, the grid resolution was doubled from the initial grid resolution to ensure the fidelity of the results.

\section{Experimental Data}

The experimental data described in this paper are the result of a wide variety of tests performed in the NASA IRT over the last twenty-five years. This database consists of over 3000 experimental ice shapes and has been reported on previously ${ }^{4-7}$. Twelve conditions were selected for this validation. The criteria used were to select large glaze ice shapes, with a representative case from each airfoil and each chord size of that airfoil. Within that subset, conditions that had the most repeats were selected in order to evaluate the variability of the tunnel data. The twelve conditions result in forty-six experimental ice tracings for comparison. The list of conditions is shown in Table 1. Experimental flow data ${ }^{46}$ was available for three of the ice shapes.

The six airfoils are as follows: a NACA 23012, a Large Transport Horizontal Stabilizer (LTHS), a business jet airfoil, a NACA 0012, a NACA 0015, and a NLF 0414 laminar flow general aviation wing. The airfoils are shown in Figure 2. If more than one chord size was used for an airfoil, the profile for the 36" chord was shown in the figure. Many of these models were described in an earlier report on the LEWICE 2.0 validation effort ${ }^{4}$. The complete set of conditions can be analyzed using LEWICE with a potential flow solver. The flow fields over the ice tracings and LEWICE shapes were calculated using the FUN3D solver. For those runs, the Mach number and Reynolds number from the aero tests was taken such that the airspeed was closest to the airspeed of the icing condition. An angle of attack sweep from $-6^{\circ}$ to $8^{\circ}$ was performed for each ice shape whether it came from LEWICE or from experiment. For the three conditions that have experimental data from an aerodynamic tunnel, the shapes from repeat runs in the IRT and from different span wise locations were also analyzed with the flow solver to assess the variability of aerodynamic performance with slight variations in shape.

3

American Institute of Aeronautics and Astronautics 


\section{Results and Comparison Methodology}

As mentioned previously there are three distinct sets of aerodynamic performance data that are discussed below: 1) Experimentally obtained aerodynamic data on an experimentally accreted ice shape, 2) Computationally obtained aerodynamic data on an experimentally accreted ice shape, and 3) Computationally obtained aerodynamic data on a computational ice shape generated from LEWICE. In order to maintain clarity of the figures presented, three sets of comparisons are made.

The first compares the experimental and computational performance data of the experimentally accreted ice shape. This grounds the simulations to reality and serves as a level of validation adding confidence to the computational results across the tested flight regime. It should be noted that none of the computational ice shapes from LEWICE have experimental performance data, so these validation comparisons only occur on the experimentally accreted ice shapes. Also note that not all airfoils and ice shapes have experimentally measured aerodynamic performance data, so these comparisons will only occur when applicable. The second comparison made is between the computationally obtained performance data of an experimentally accreted ice shape and the analogous ice shape generated by LEWICE. This effort is to extend the validation of LEWICE shapes from simple geometric comparisons to a more rigorous quantitative comparison of a parameter of interest, the aerodynamic performance data. The last set compares the computational performance data of various experimentally accreted ice shapes at the same flight conditions (i.e. repeat runs). This is to test whether experimental variability can significantly affect the performance of an iced airfoil.

The first set of comparisons presented are those for condition 9 in Table 2. This condition was selected because experimental wind tunnel data was available for the ice shape accreted in the IRT. This ice shape along with the LEWICE comparison is shown in Figure 3. Based on geometric comparisons presented previously, there is a $1.2 \mathrm{~cm}$ difference in horn height and a $30^{\circ}$ difference in horn angle between the LEWICE shape and the average of the IRT ice shapes for this condition. In order to assess whether or not this variation is significant, the flow was calculated for each ice shape at angles of attack from $-6^{\circ}$ to $8^{\circ}$ as described previously. However, to increase confidence in the simulations and validate the flow solver over this flight regime, the simulated performance data is compared with experimental values measured in an aerodynamic wind tunnel. Those comparisons are shown in Figures 4 and 5. The results are consistent with the accuracy of Reynolds Averaged Naviér Stokes (RANS) solvers for clean airfoils. The computed results are accurate except right at stall. Now that the computed flow results can be considered accurate, the computed results for the IRT ice shape are compared to the computed flow results for the LEWICE ice shape. Those results are shown in Figures 6 and 7. The lift coefficient compares well between the two shapes except near stall. The drag coefficient for the IRT ice shape is higher than the LEWICE shape. This is most likely caused by the difference in horn angle as the other cases will show. The drag on the large shapes used in this study is mostly pressure drag, thus the roughness of the IRT shapes plays only a small part. While the difference in the aero performance of the two shapes is expected, the significance of the variation has to be considered. In order to establish a baseline, the IRT shapes from repeat runs and other span wise tracings are considered. The ice shapes from repeat runs are shown in Figure 8 and the performance results are shown in Figures 9 and 10. The geometric variation and aero performance variations are both smaller than the variation from the LEWICE case, especially for drag. This result does show that even small variations in geometry can cause a noticeable difference in drag. The difference in span wise results, shown in Figures 11-13 show a similar result. Quantitatively, the lift results from the LEWICE shape are within $10.4 \%$ of the experimental aero values while the variation in the IRT shapes produced a difference of $8.3 \%$ in lift on average while the predicted drag for the LEWICE shape is $68 \%$ lower than the experimental drag compared to an average difference of $15 \%$ for the IRT ice shapes.

The next set of results shown come from condition 3 which also has experimental aero performance data for one of the IRT ice shapes produced with that condition. The ice shape and LEWICE prediction are shown in Figure 14. Based on the previous geometric comparisons, there is a difference of $2 \mathrm{~cm}$ in horn height and $23^{\circ}$ difference in horn angle between the average of the IRT shapes and the LEWICE shape. Compared to the previous example, the horn angles are slightly better predicted but the horn height is under predicted. Once again, the first aero comparison is that between the FUN3D results and the experimental data as shown in Figures 15 and 16. As was shown in the first example, the CFD results match the experimental data for lift until it reaches stall. Figures 17 and 18 show the comparison between the CFD results on the LEWICE shape and the IRT shape. In this case, the lift computed on the LEWICE ice shape differs from the IRT shape more than the first example. However, an examination of the variability of the IRT shapes with repeatability (Figures 19-21) and span wise variability (Figures 22-24) show a similar difference in lift and drag with small variations in the ice shapes. These figures demonstrate that although the geometric variation of these shapes are similar to the variability of the previous example, the IRT shapes have a wider variation in the aerodynamic result. The variability of the IRT shapes with respect to lift is $10 \%$ compared to the experimental aero data while the variation in drag is $14.7 \%$. The LEWICE shape differs $28 \%$ in lift and $61 \%$ in drag compared to the experimental data.

4

American Institute of Aeronautics and Astronautics 
The third example case comes from condition 10 which also has experimental aero performance data for one of the IRT shapes produced with that condition. The same set of plots were produced for this condition as well. The ice shape and LEWICE prediction are shown in Figure 25. Based on previous geometric comparisons, there is a difference of $0.7 \mathrm{~cm}$ in horn height and $34^{\circ}$ difference in horn angle between the average of the IRT shapes and the LEWICE shape. Figure 26 shows the comparison of the lift measured in the experiment and that computed by FUN3D. Drag values were not available for this case. The results show a greater disparity between the computed results and the experimental measurements. It is believed that this is due to a greater sensitivity of this airfoil to variations in the iced geometry. There is an average difference of 0.05 in lift coefficient between the computed result and the experimental data and a difference of 0.092 at $\mathrm{C}_{\mathrm{L}, \max }$. Figures 27 and 28 show the comparison between the IRT shape and the LEWICE shape in lift and drag respectively. The average difference in predicted lift coefficient between the results on the LEWICE shape and experiment is 0.17 on the lift coefficient. The difference between the predicted drag on the IRT shapes and the predicted drag on the LEWICE shape is 0.025. This translates to an $11 \%$ difference in lift for the IRT shapes compared to experiment and a $22 \%$ difference in lift for the LEWICE shapes and a 39\% difference in drag for the LEWICE shape compared to the average prediction for the IRT shapes. The variation of the IRT shapes in repeatability is shown in Figure 29 with the lift and drag variation shown in Figures 30 and 31 respectively. The variation in span wise shape is shown in Figure 32 while the lift and drag variation of those shapes are shown in Figures 33 and 34. The average variability in lift coefficient is $4 \%$ due to the variation in ice shape and a variability of $14 \%$ in drag coefficient.

The next case shown comes from condition 1 . There is no experimental aerodynamic data for this condition nor for any of the remaining cases. Because of this reason, comparisons were limited to the computed aero performance of the main IRT shape and the LEWICE shape. Geometric variability of the ice shapes is available, but the aerodynamics of those shapes were not performed. The IRT ice shape and the LEWICE shape are shown in Figure 35. The difference between the average IRT horn height and the LEWICE result is $0.92 \mathrm{~cm}$ for this condition while the average variation in the measured heights is 0.22 $\mathrm{cm}$. The difference between the average IRT horn angle and the LEWICE shape is $9.5^{\circ}$ which compares favorably to the experimental variability of $8.5^{\circ}$. A qualitative assessment of the geometric comparison would rate this comparison as very good to excellent. Despite this, the computed lift and drag on the shapes is quite different as shown in Figures 36 and 37 . The degradation due to the IRT shape is much worse. The percentages are $184 \%$ for lift and $62 \%$ for drag. It should be noted that no experimental data on the aerodynamics of this shape is available. A plot of the Mach contours at $6^{\circ} \mathrm{AOA}$ as shown in Figure 38 suggests that the reattachment of the separation bubble is unrealistic and it might be necessary to perform unsteady analysis for this condition. A plot of the Mach contours for the LEWICE shape at the same angle of attack is shown in Figure 39 for comparison.

The next case shown comes from condition 2. The IRT ice shape and LEWICE shape are shown in Figure 40. There are only two IRT shapes for this condition and the difference in horn heights were less than $1 \mathrm{~mm}$ and the horn angles differed by $3^{\circ}$. The LEWICE shape differs by only $2 \mathrm{~mm}$ and $13^{\circ}$ in horn angle. The difference between the two shapes is the difference in the leading edge thickness. The aerodynamic predictions for these two shapes are shown in Figures 41 and 42 . The difference in lift coefficient at $8^{\circ}$ is $7.7 \%$ and the difference in drag is $21.6 \%$. These predictions suggest that the major geometric features that need to be matched are the horn height and angle and that other variations are less important.

The next case shown comes from condition 4. The ice shape prediction is shown in Figures 43 and the aerodynamic predictions are shown in Figures 44 and 45. The geometric comparison shows a difference of $1.4 \mathrm{~cm}$ in horn height and only $7^{\circ}$ difference in horn angle. There are only two IRT shapes for this condition, and once again the difference in the IRT shapes is minimal, just $3 \mathrm{~mm}$ difference in height and less than $1^{\circ}$ difference in horn angle. The lift curve for the two shapes are similar, but the computed drag on the IRT shape is higher. The difference in lift coefficient for this case is $13.6 \%$ while the difference in drag is $37 \%$.

The remaining cases are shown in Figures 46-63 where the plots for each condition consist of an ice shape comparison and comparison plots of lift coefficient and drag coefficient. The quantitative results for all conditions are shown in Table 2. For conditions 5 and 6 (Figs 46-51), the lift and drag comparisons are much better for condition 5, even though the geometric parameters are similar, perhaps due to the sharp turn of the horns on the IRT shape for condition 6 . For conditions 7 and 8 (Figs. 52-57), the lift and drag comparisons are better for condition 8. Once again, the geometric comparisons are similar, but the aero comparisons are different due to shape features that are not captured by the values measured. Condition 11 (Figs. 5860) shows an excellent comparison for both the geometry measurements and the aero results while the comparisons for condition 12 (Figs. 61-63) were not as good. In this last case, it is also possible that the aero results for the IRT shape would be better if an unsteady calculation were performed.

Overall, the results seem to indicate that in addition to measurements of horn height and angle, the curvature of the horns plays a role in the aero results. When the results of the 12 cases are averaged, they show that the LEWICE shapes differed on average by $0.7 \mathrm{~cm}$ and $19^{\circ}$ in horn height which resulted in an average difference of $36 \%$ in lift and $43 \%$ in drag. This level 
of comparison suggests that comparing the aero performance of computational shapes is a very strict criteria as even small changes in shape can result in large changes in the computed aero result.

\section{Discussion and Conclusions}

One of the primary goals of this report was to validate LEWICE 3.5, and its new mixed phase capabilities. While typical validation efforts center around purely geometric-based comparisons, this paper recommends extending ice-shape validation to include aerodynamic performance comparisons, since performance degradation of the aircraft is the primary concern in the icing world.

A means to compare computational shapes to tunnel ice shapes was developed by using computed flow results on both shapes. Quantitative comparisons were made for geometric measurements as well as the computed aero results. Where possible, the computed aero results were also compared to experimental aero data. The results showed that the variability of tunnel ice shapes resulted in a 10\% difference in computed lift and a 15\% difference in computed drag. The LEWICE shapes varied from $0.1 \mathrm{~cm}$ to $2 \mathrm{~cm}$ in height $\left(0.7 \mathrm{~cm}\right.$ average) and by $7^{\circ}$ to $38^{\circ}$ in angle ( $19^{\circ}$ average) in horn angle which resulted in a variation of lift $8 \%$ to $28 \%$ in lift. Two cases where the steady flow results calculated were suspect show a greater lift variation. The variation in drag was $7 \%$ to $61 \%$ difference. The results also suggest that horn curvature plays a role in the comparison. Overall, the comparisons between the experimentally accreted ice shapes and the LEWICE shapes were favorable, therefore LEWICE 3.5 and its mixed phase capabilities can be considered validated.

A secondary purpose of this effort was to propose a subset of airfoil geometries and test conditions to be used by the icing community for standardized code validation. The airfoils, test conditions, and ice shapes presented here are all open source, a necessity for standardization. The shapes include classic symmetric airfoils, such as the NACA 0012/0015, as well as airfoils that are more representative of those used in industry, such as the bizjet foil. While there is room to add an airfoil representative of a commercial large transport, the airfoils presented here are more than sufficient to test and validate the capabilities of ice accretion codes. 4

\section{Acknowledgements}

The first author would like to acknowledge the continued financial support from NASA Glenn for this research.

\section{References}

1. Wright., W. B., "User Manual for the NASA Glenn Ice Accretion Code LEWICE Version 2.0", NASA CR-1999209409, Dec. 1999.

2. Wright, W. B., "User Manual for the NASA Glenn Ice Accretion Code LEWICE Version 2.2.2, NASA CR-2002211723, Aug. 2002.

3. Wright, W. B., “User’s Manual for LEWICE 3.2”, NACA CR-2008-214255, Nov. 2008.

4. Wright, W. B. and Rutkowski, A., "Validation Results for LEWICE 2.0,” NASA CR 208690, Nov. 1998.

5. Wright, W. B., "Validation Methods and Results for a Two-Dimensional Ice Accretion Code,: J. of Aircraft, Vol. 35, No, 5, Sept. 1999.

6. Wright, W. B., "Validation Results for LEWICE 3.0", AIAA 2005-1243, Jan. 2005.

7. Wright, W. B., "Validation Process for LEWICE Coupled with a Naviér-Stokes Solver”, AIAA 2016-4349

8. Brahimi, M T; Tran, P; Tezok, F; Paraschivoiu, I, "Numerical simulation of in-flight aircraft icing”, ICAS, Congress, 20th, Naples, Italy, Proceedings. Vol. 2; UNITED STATES; 8-13 Sept. 1996. pp. 1522-1532. 1996.

9. Myers, T. G. and Hammond, D. W., "Ice and Water Film Growth from Incoming Supercooled Droplets", Intl. J. of Heat and Mass Transfer, vol. 42, pp. 2233-2242, 1999.

6

American Institute of Aeronautics and Astronautics 
10. Myers, T. G., Charpin, J. P. F., and Chapman, S. J., "The Flow and Solidification of a Thin Fluid Film on an Arbitrary Three-dimensional Surface”, Phys. Of Fluids, Vol. 14, No. 8, pp. 2788-2804, Aug. 2002.

11. Bourgault, Y., Boutanios, Z. Habashi, W., "FENSAP-ICE's Three-Dimensional In-Flight Ice Accretion Module, ICE3D”, Journal of Aircraft, vol.37 no.1 (95-103) 2000.

12. Beaugendre, H; Morency, F; Habashi, W G, "FENSAP-ICE's three-dimensional in-flight ice accretion module: ICE3D", Journal of Aircraft. Vol. 40, no. 2, pp. 239-247. Mar.-Apr. 2003

13. Emmanuel, M., et al., "ECLIPPS: 1. Three-Dimensional CFD Prediction of the Ice Accretion". 1st AIAA Atmospheric and Space Environments Conference, American Institute of Aeronautics and Astronautics (2009).

14. Petrosino, F., et al., "Ice Accretion Model on Multi-Element Airfoil." Journal of Aircraft 48(6): 1913-1920 (2009).

15. Shen, X., et al., "Three-Dimensional Numerical Simulation of Ice Accretion at the Engine Inlet." Journal of Aircraft 50(2): 635-642 (2009).

16. Guy, F., et al. CIRAAMIL, "Ice Accretion Code Improvements", 1st AIAA Atmospheric and Space Environments Conference, American Institute of Aeronautics and Astronautics (2009).

17. Zhihong, Z., et al., "Icing Numerical Simulation for Single and Multi-Element Airfoils", 28th AIAA Applied Aerodynamics Conference, American Institute of Aeronautics and Astronautics (2010).

18. Michael, K., et al., “A Finite-Volume Approach to Modeling Ice Accretion,” 28th AIAA Applied Aerodynamics Conference, American Institute of Aeronautics and Astronautics (2010).

19. Nakakita, K., et al., "Toward Real-Time Aero-Icing Simulation of Complete Aircraft via FENSAP-ICE." Journal of Aircraft 47(1): 96-109 (2012).

20. Hasanzadeh, K., et al.. "Quasi-Steady Convergence of Multistep Navier-Stokes Icing Simulations." Journal of Aircraft 50(4): 1261-1274, (2012).

21. Kazem Hasanzadeh, L., et al., "Validation and Verification of Multi-Steps Icing Calculation Using CANICE2D-NS Code", 31st AIAA Applied Aerodynamics Conference, American Institute of Aeronautics and Astronautics (2013).

22. Jason, G., "Computational 3-D Icing Results for Scaled DLR-F6 Geometry", AIAA Atmospheric Flight Mechanics Conference, American Institute of Aeronautics and Astronautics (2012).

23. Weiliang, K. and L. Hong, "An Ice Accretion Model for Aircraft Icing Based on Supercooled Icing: Theory and Application", 50th AIAA Aerospace Sciences Meeting including the New Horizons Forum and Aerospace Exposition, American Institute of Aeronautics and Astronautics (2012).

24. Thomas, R., et al., "FENSAP-ICE Simulation of Icing on Wind Turbine Blades, Part 1: Performance Degradation", 51st AIAA Aerospace Sciences Meeting including the New Horizons Forum and Aerospace Exposition, American Institute of Aeronautics and Astronautics (2013).

25. Andrew, P., et al., "A 3D Mesh Deformation Technique for Irregular In-flight Ice Accretion Shapes", 44th AIAA Fluid Dynamics Conference, American Institute of Aeronautics and Astronautics (2014).

26. Cao, Y. and J. Huang, "New Method for Direct Numerical Simulation of Three-Dimensional Ice Accretion", Journal of Aircraft 52(2): 650-659 (2014).

27. Carlos Gallego, C. and P. R.-C. Luis, "Prediction of ice accretion on the nacelle of a turboprop aircraft", 52nd Aerospace Sciences Meeting, American Institute of Aeronautics and Astronautics (2014). 
28. Daniel, M. K., et al., "Numerical investigation of ice particle accretion on heated surfaces with application to aircraft engines," 11th AIAA/ASME Joint Thermophysics and Heat Transfer Conference, American Institute of Aeronautics and Astronautics (2014).

29. David, S., et al., "FENSAP-ICE Simulation of Complex Wind Turbine Icing Events, and Comparison to Observed Performance Data", 32nd ASME Wind Energy Symposium, American Institute of Aeronautics and Astronautics (2014).

30. Pierre, T. and V. Philippe, "Heat and mass transfer analogies for evaporation models at high evaporation rate", 6th AIAA Atmospheric and Space Environments Conference, American Institute of Aeronautics and Astronautics (2014).

31. Xiaoling, T., et al., "Robust Surface Evolution and Mesh Deformation for Three Dimensional Aircraft Icing Applications on a Swept GLC-305 Airfoil", 6th AIAA Atmospheric and Space Environments Conference, American Institute of Aeronautics and Astronautics (2014).

32. Giulio, G., et al., "A model for in-flight ice accretion based on the exact solution of the unsteady Stefan problem", 7th AIAA Atmospheric and Space Environments Conference, American Institute of Aeronautics and Astronautics (2015).

33. Lakshmi, N. S. and A. Muhammad, "In-Cloud Ice Accretion Modeling on Wind Turbine Blades Using an Extended Messinger Model", 13th International Energy Conversion Engineering Conference, American Institute of Aeronautics and Astronautics (2015).

34. Marie, C. P., et al., "Development of CFD-based icing model for wind turbines: A case study of ice sensor," 33rd Wind Energy Symposium, American Institute of Aeronautics and Astronautics (2015).

35. Simon, B.-C. and L. Eric, "Two-Dimensional/Infinite Swept Wing Ice Accretion Model”, 53rd AIAA Aerospace Sciences Meeting, American Institute of Aeronautics and Astronautics (2015).

36. Wright, W. B. and Chung, J., "Correlation Between Geometric Similarity of Ice Shapes and the Resulting Aerodynamic Performance Degradation - A Preliminary Investigation Using WIND”, AIAA-2000-0097.

37. Thompson, D. S. and Soni, B. K., "ICEG2D: A Software Package for Ice Accretion Prediction," AIAA 2003-1070, Jan. 2003.

38. Kreeger, R. and Wright, W. B., "The Influence of Viscous Effects on Ice Accretion Prediction and Airfoil Performance Predictions", AIAA-2005-1373, Jan. 2005.

39. "Guide for the Verification and Validation of Computational Fluid Dynamics Simulation", AIAA G-077-1998, 2002.

40. R. T. Biedron et. al., "FUN3D Manual: 13.0”, NASA TM 2016-219330, Aug. 2016.

41. Steinbrenner, J. P., Michal, T., Abelanet, J.P., "An Industry Specification for Mesh Generation Software”, AIAA-20055239, June 2005.

42. http://www.pointwise.com/glyph2/files/Glyph/cxx/GgGlyph-cxx.html

43. Bidwell, C. S., "Icing Analysis of a Swept NACA0012 Wing Using LEWICE3D Version 3.48", AIAA-2014-2200, June 2014.

44. Wilcox, D. C. "Formulation of the k-w Turbulence Model Revisited", AIAA Journal, vol. 46, no. 11, Nov. 2008, pp. 2823-2838.

45. Steinbrenner, J. P., "Construction of Prism and Hex Layers from Anisotropic Tetrahedra”, AIAA-2015-2296, June 2015.

46. Addy, H. E., Broeren, A. P., Zoeckler, J. G., and S. Lee, "Wind Tunnel Study of the Icing Effects on a Business Jet Airfoil, AIAA-2003-727, Jan. 2003. 
American Institute of Aeronautics and Astronautics 
Figure 1: Ice Shape Comparison on Calibration Condition

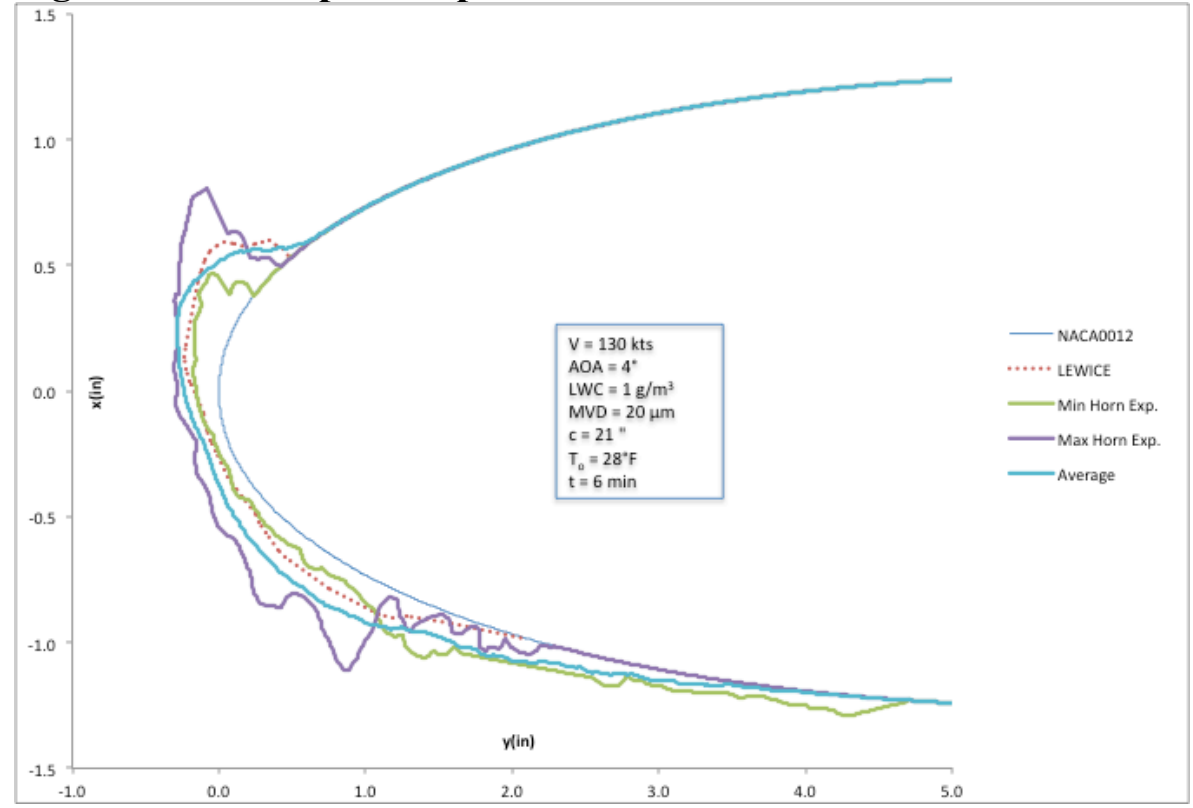

10

American Institute of Aeronautics and Astronautics 


\section{Figure 2: Airfoils Used in Validation Study}

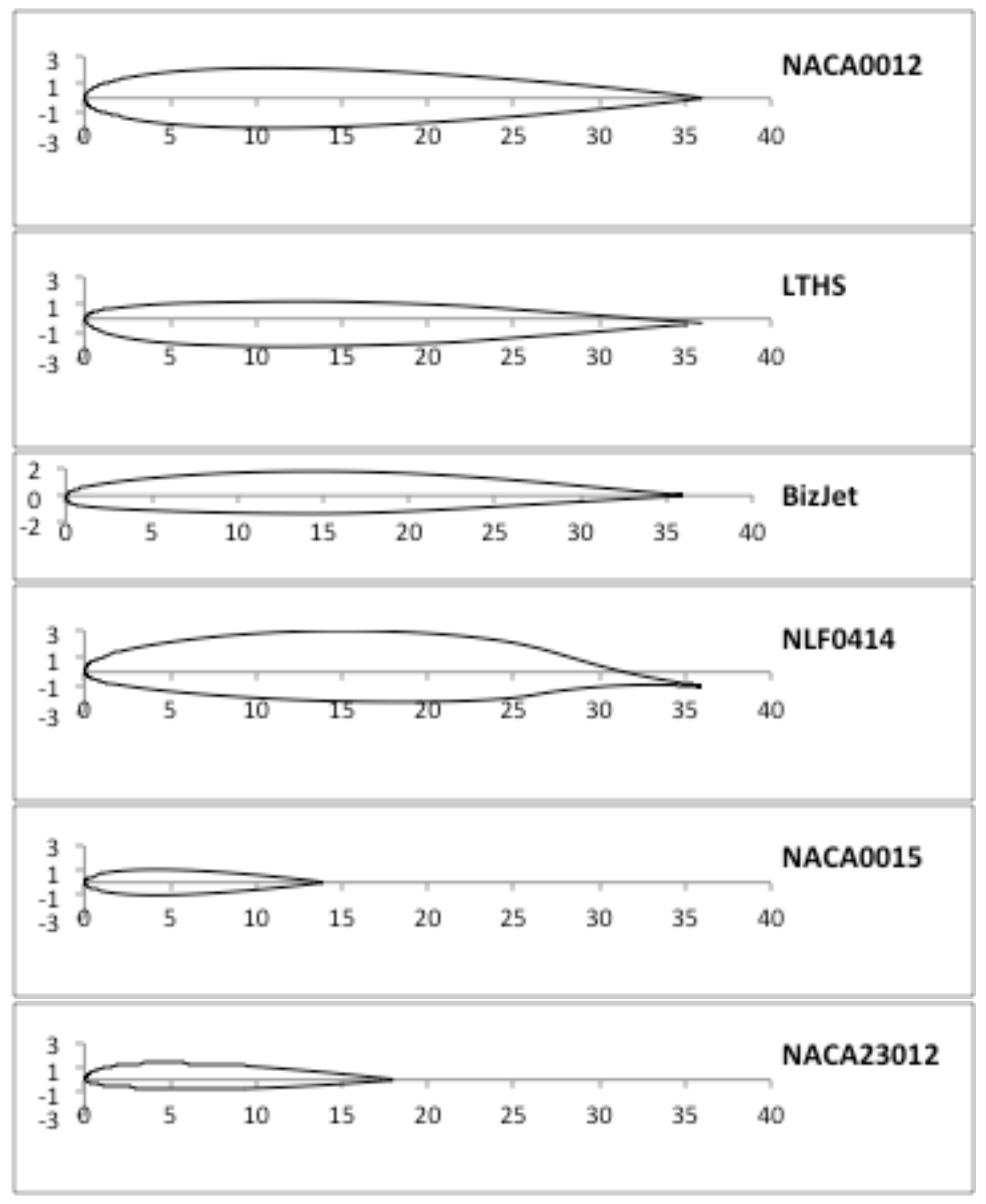

11

American Institute of Aeronautics and Astronautics 


\section{Table 1: List of Icing Conditions}

\begin{tabular}{|c|c|c|c|c|c|c|c|c|c|c|}
\hline Case & Airfoil & $\begin{array}{l}\text { Chord } \\
\text { (m) }\end{array}$ & $\begin{array}{l}\text { Air Speed } \\
(\mathrm{m} / \mathrm{s})\end{array}$ & AOA (deg) & $\begin{array}{l}\text { Total Temp } \\
\left({ }^{\circ} \mathrm{C}\right)\end{array}$ & $\begin{array}{l}\mathbf{L W C} \\
\left(\mathrm{g} / \mathbf{m}^{3}\right)\end{array}$ & $\begin{array}{l}\text { MVD } \\
(\mu \mathrm{m})\end{array}$ & $\begin{array}{l}\text { Time } \\
\text { (s) }\end{array}$ & Mach & $\mathrm{Re}^{*} 10^{-6}$ \\
\hline 1 & NACA0012 & 0.53 & 102.9 & 4 & -5.6 & 1.8 & 30 & 360 & 0.32 & 4.40 \\
\hline 2 & NACA0012 & 0.91 & 77.1 & 0 & -8.3 & 1 & 15 & 1224 & 0.24 & 5.67 \\
\hline 3 & NACA23012 & 0.46 & 102.9 & 2 & -2.2 & 0.75 & 15.4 & 300 & 0.31 & 3.68 \\
\hline 4 & NACA23012 & 1.83 & 90.0 & 2 & -5.0 & 0.94 & 15 & 600 & 0.28 & 13.03 \\
\hline 5 & BizJet & 0.30 & 139.4 & 0 & -7.9 & 1.12 & 19 & 138 & 0.44 & 3.58 \\
\hline 6 & BizJet & 0.46 & 88.4 & 0 & -6.1 & 1.47 & 29 & 240 & 0.27 & 3.22 \\
\hline 7 & BizJet & 0.61 & 89.4 & 0 & -6.0 & 1.3 & 35 & 360 & 0.27 & 4.34 \\
\hline 8 & BizJet & 0.61 & 89.4 & 0 & -13.0 & 1.27 & 43 & 360 & 0.28 & 4.57 \\
\hline 9 & BizJet & 0.91 & 90.0 & 6 & -0.8 & 0.54 & 20 & 1350 & 0.27 & 6.32 \\
\hline 10 & NLF0414 & 0.91 & 66.9 & 2 & -3.1 & 0.54 & 20 & 1350 & 0.20 & 4.71 \\
\hline 11 & LTHS & 0.91 & 130.2 & 0 & -1.4 & 0.563 & 21 & 1476 & 0.40 & 9.47 \\
\hline 12 & NACA0015 & 0.35 & 95.2 & 0 & -5.5 & 0.75 & 19 & 600 & 0.29 & 2.68 \\
\hline
\end{tabular}

12

American Institute of Aeronautics and Astronautics 
Figure 3: Ice Shape for Condition 9

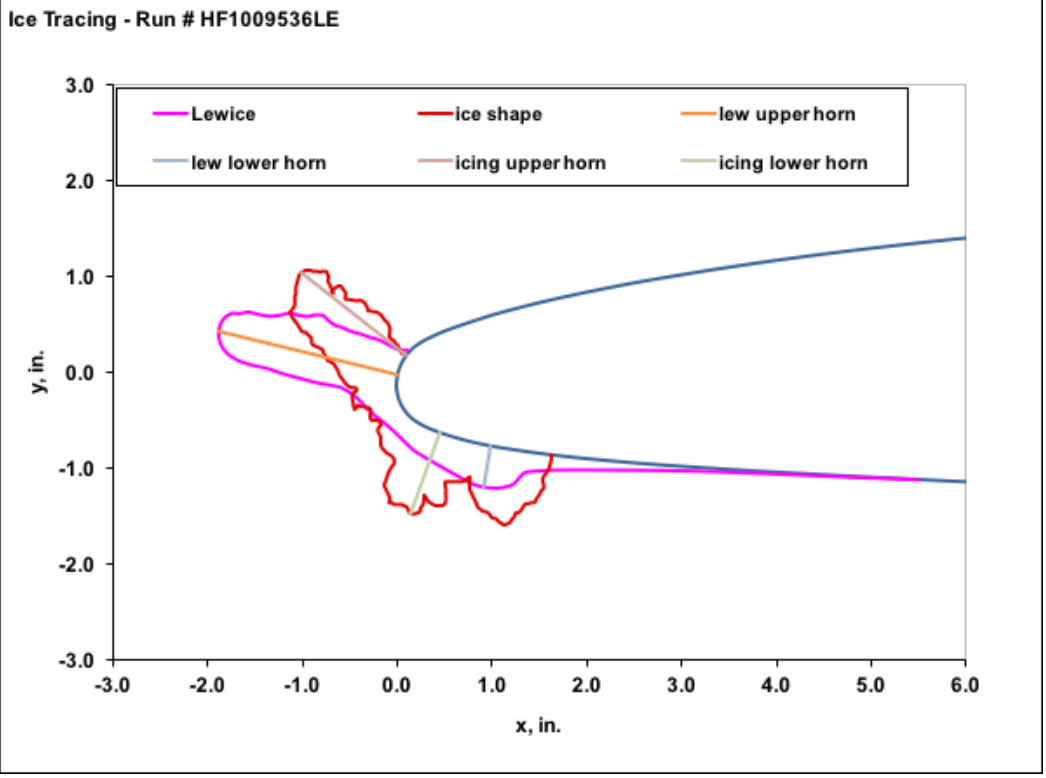

Figure 4: Comparison of Computed Lift to Experiment for Condition 9

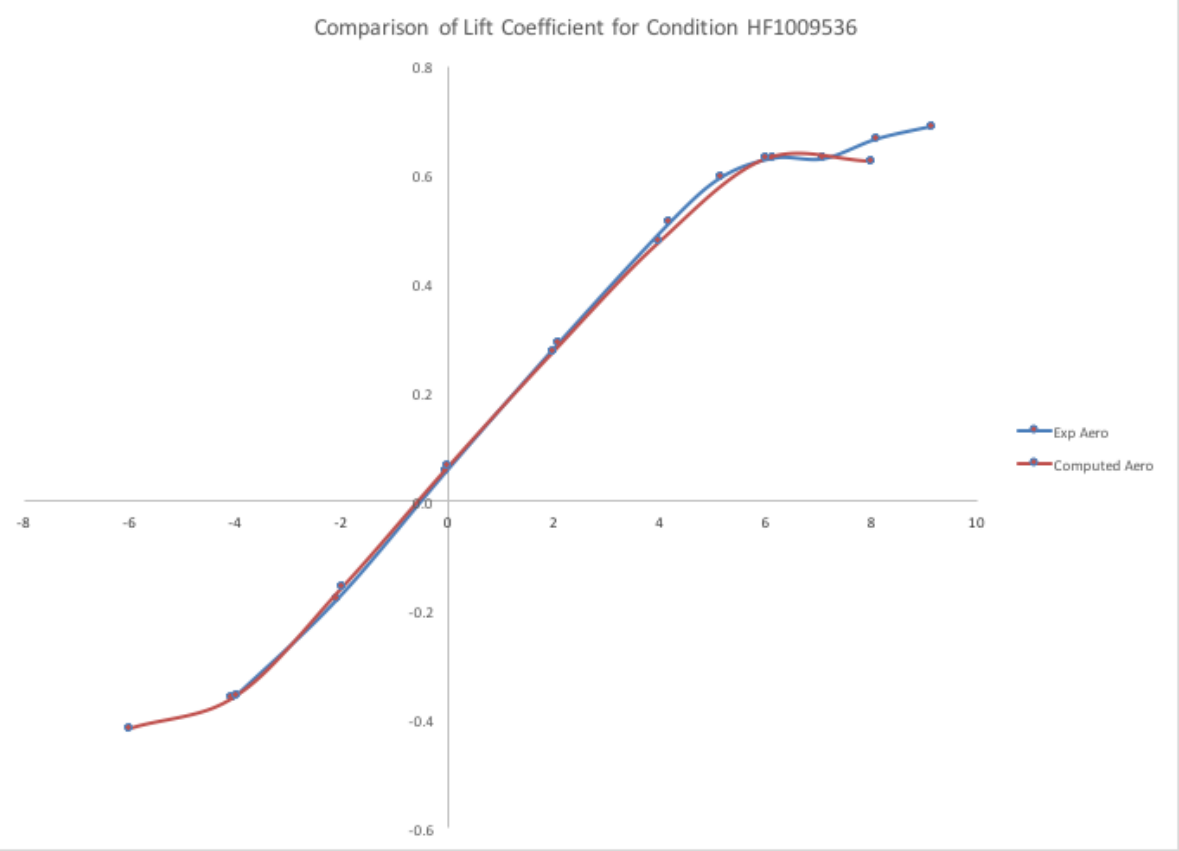

13

American Institute of Aeronautics and Astronautics 
Figure 5: Comparison of Computed Drag to Experiment for Condition 9

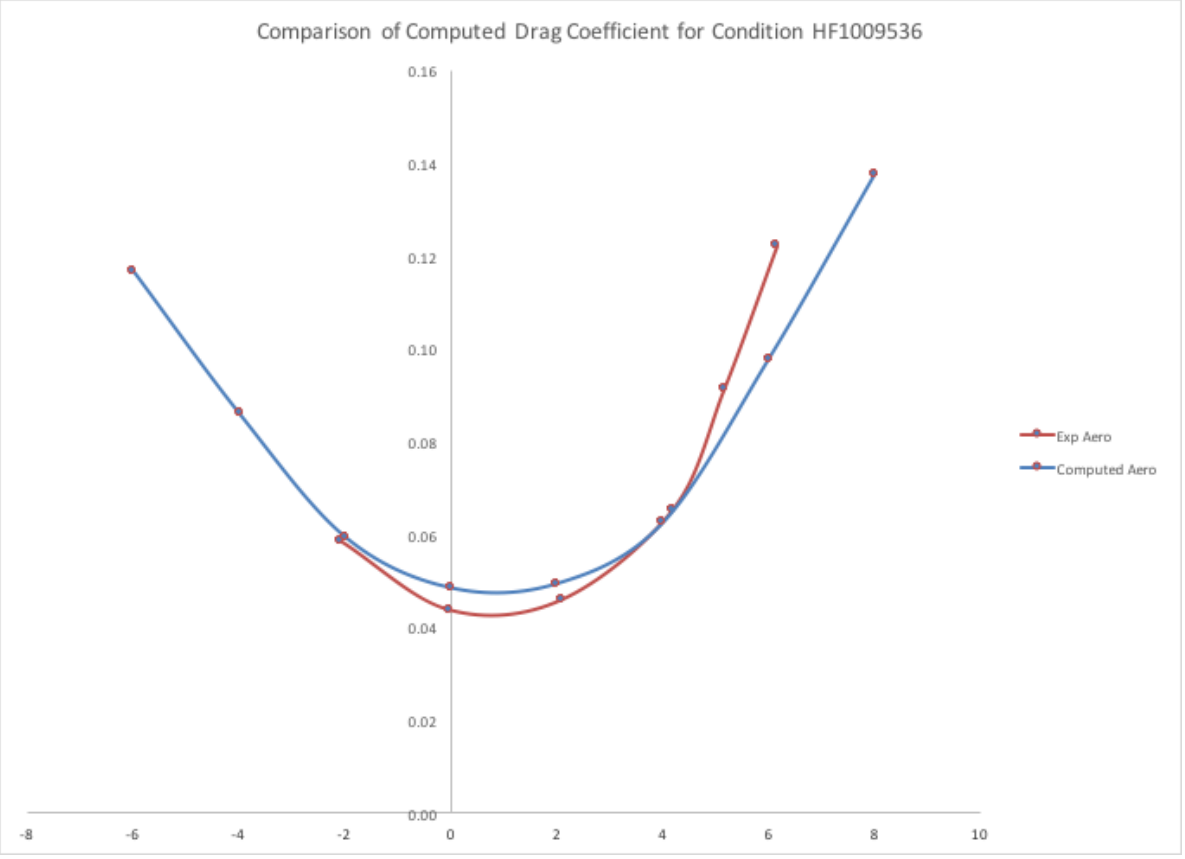

Figure 6: Comparison of Computed Lift for Condition 9

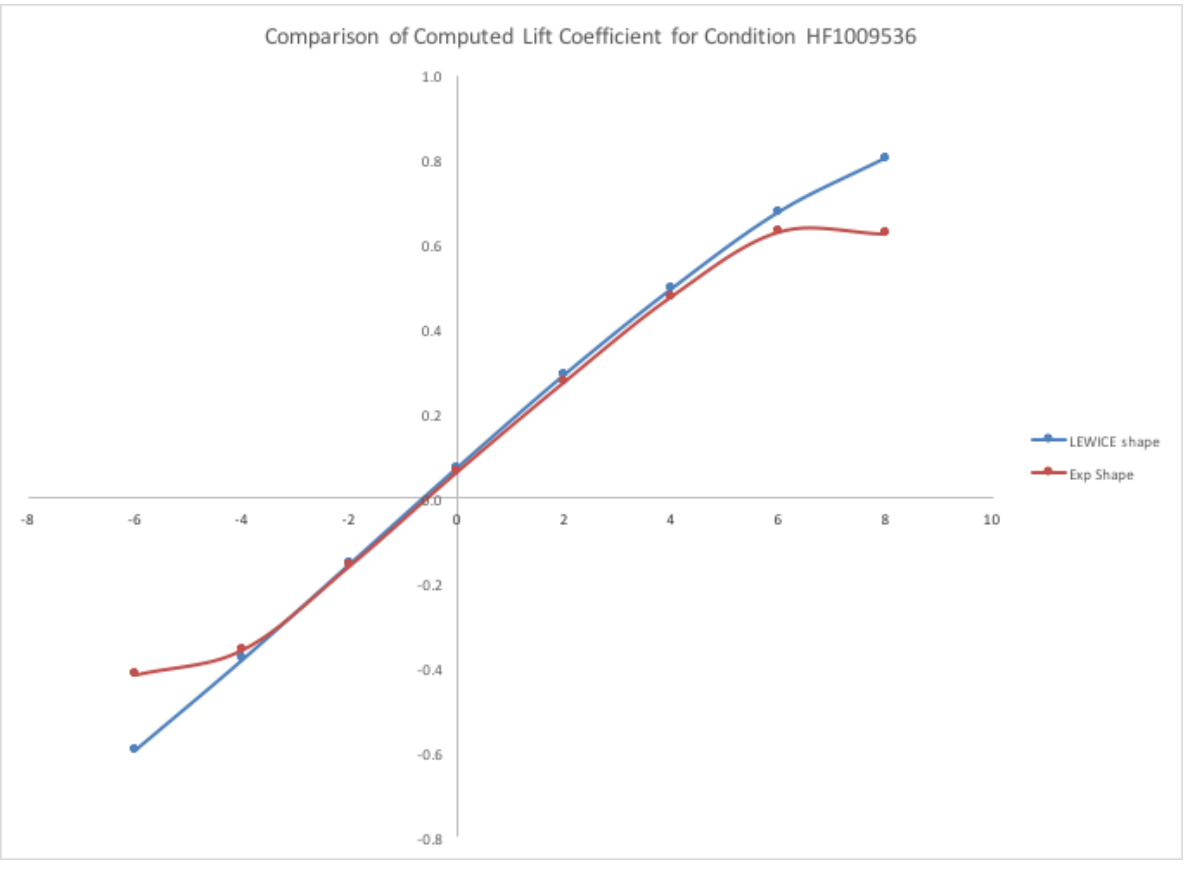

14

American Institute of Aeronautics and Astronautics 


\section{Figure 7: Comparison of Computed Drag for Condition 9}

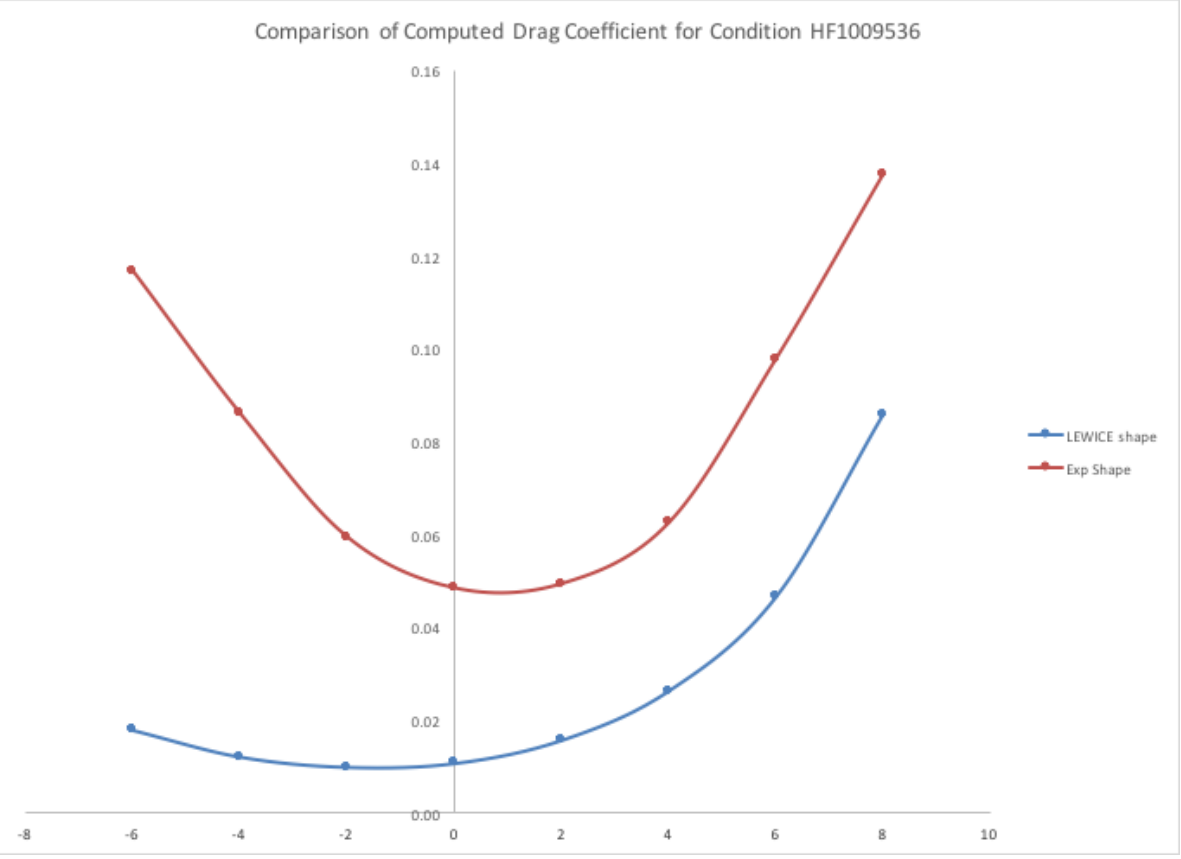

Figure 8: Repeatability Comparison for Condition 9

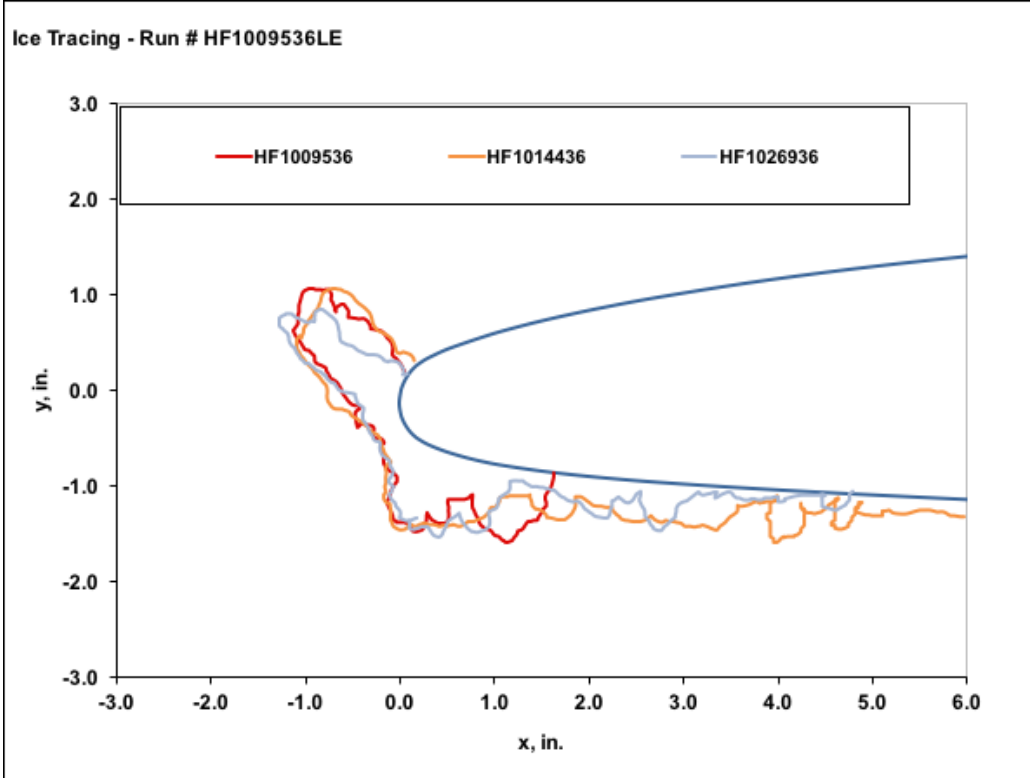


Figure 9: Variation in Computed Lift for Repeats of Condition 9

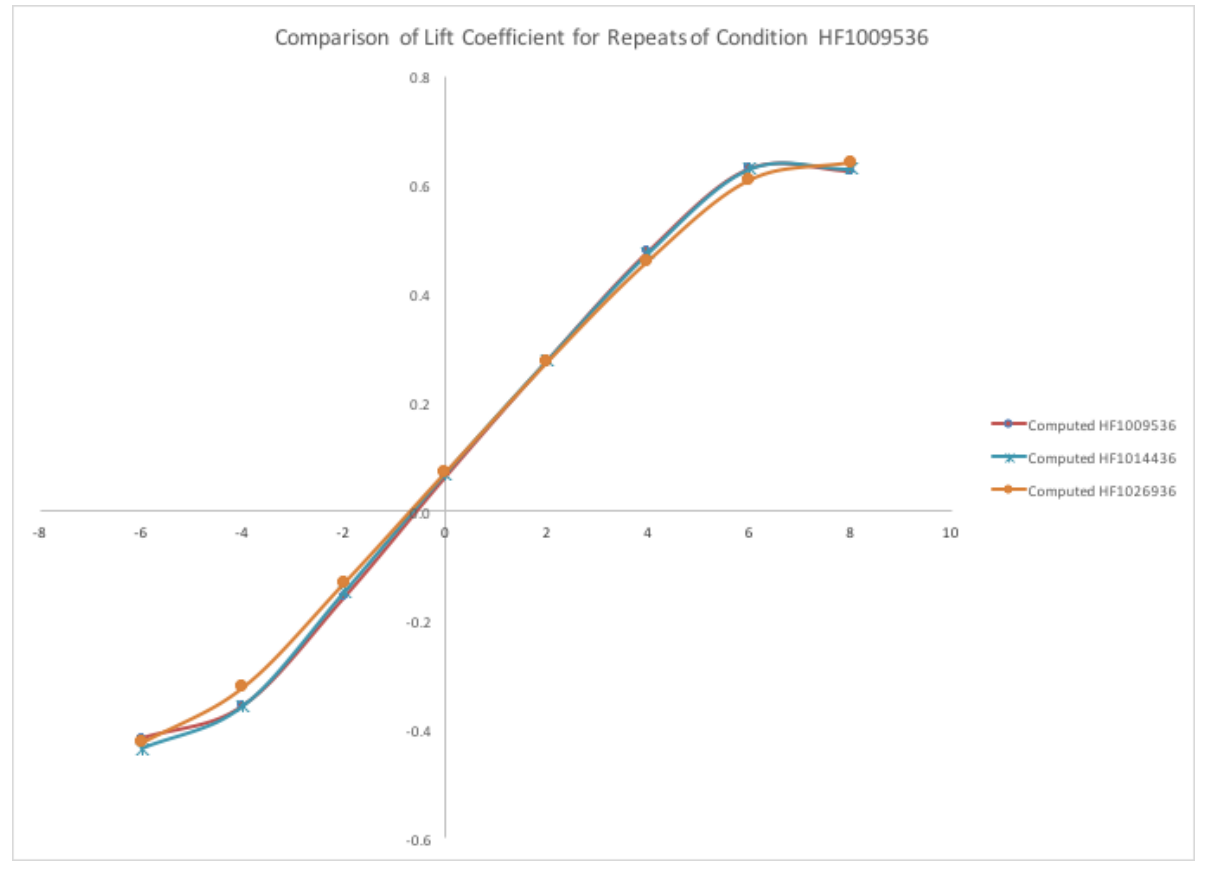

Figure 10: Variation in Computed Drag for Repeats of Condition 9

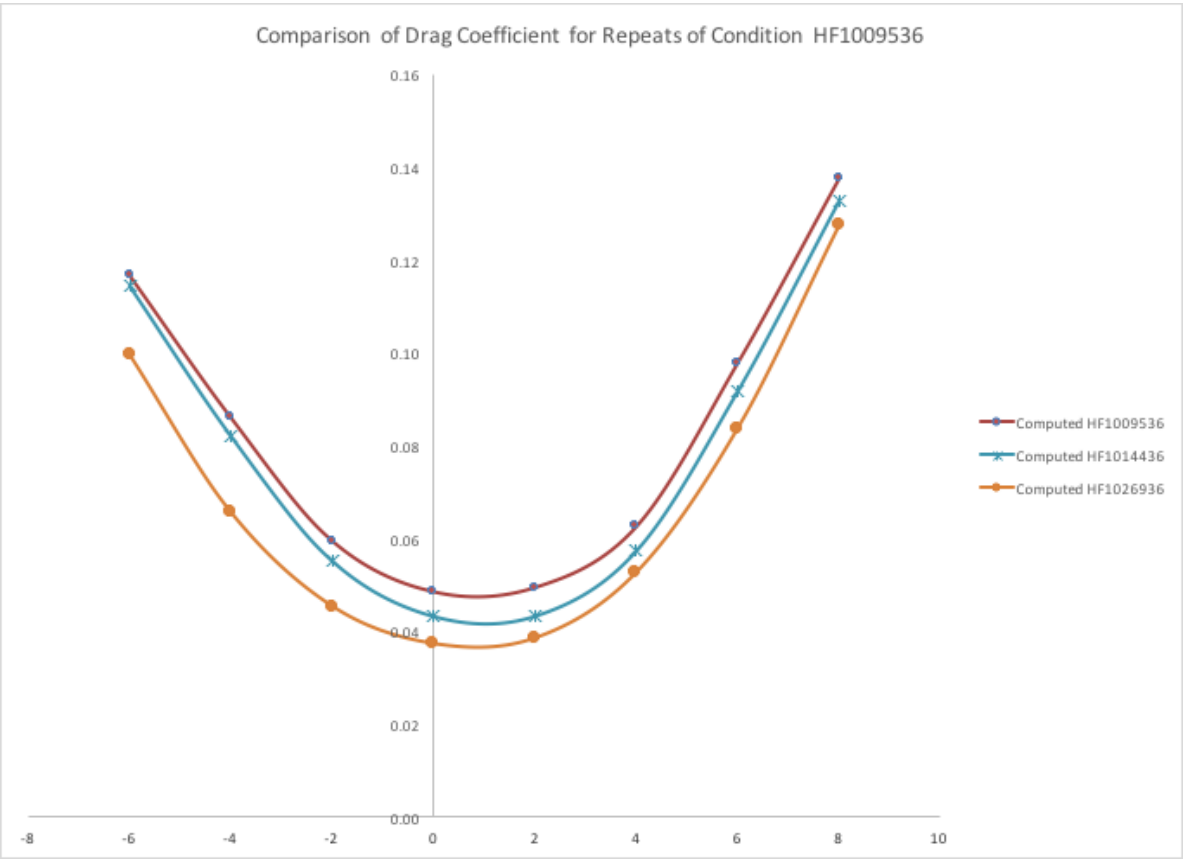


Figure 11: Variation along Span for Condition 9

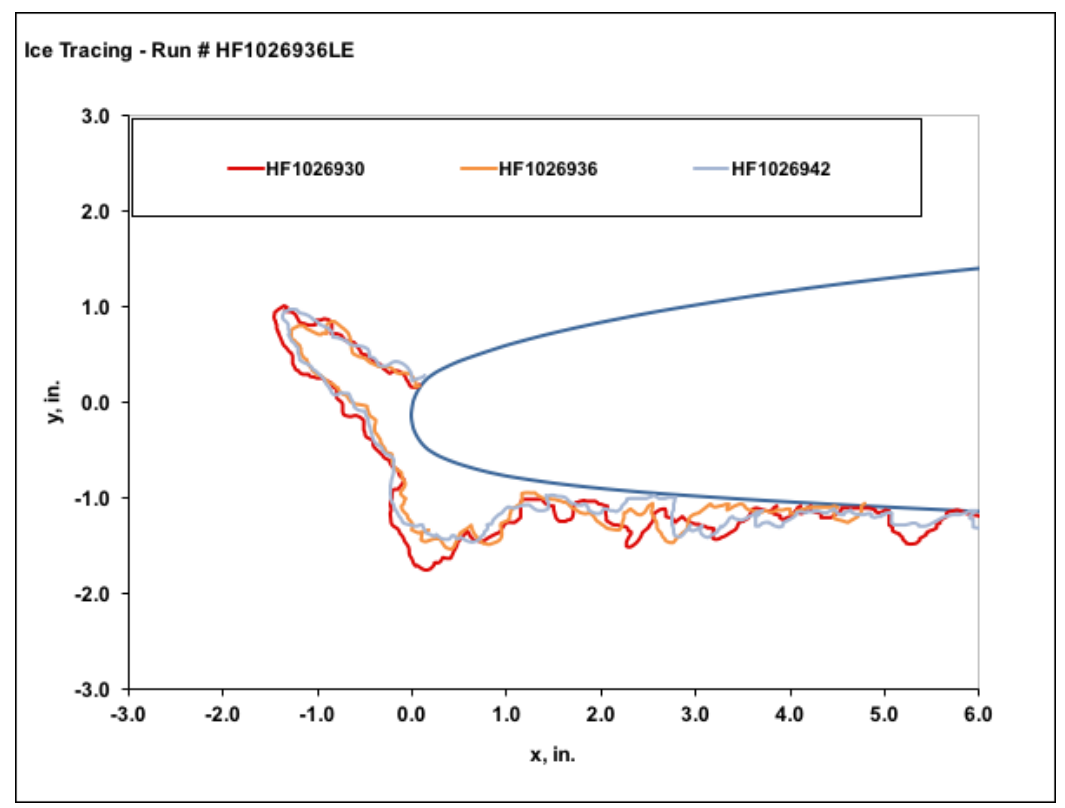

Figure 12: Variation in Computed Lift for Different Span Locations of Condition 9

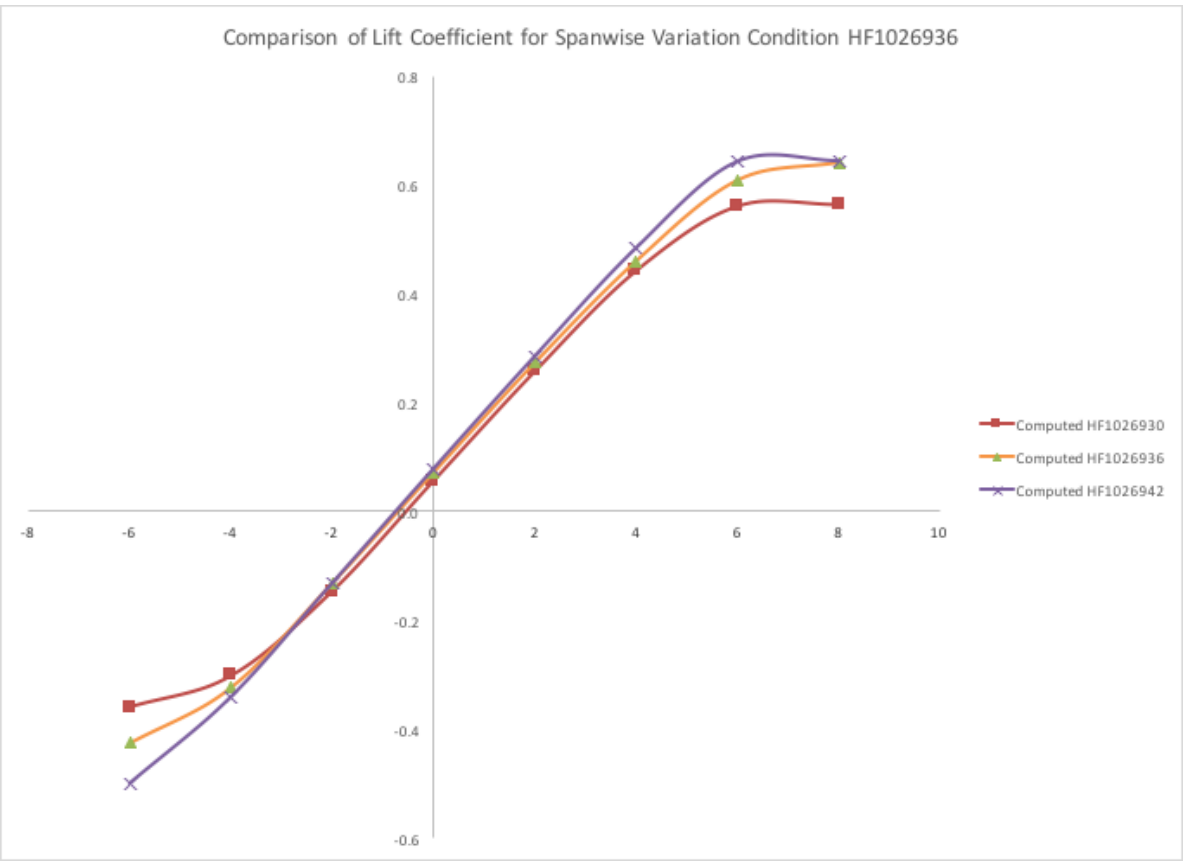


Figure 13: Variation in Computed Drag for Different Span Locations of Condition 9

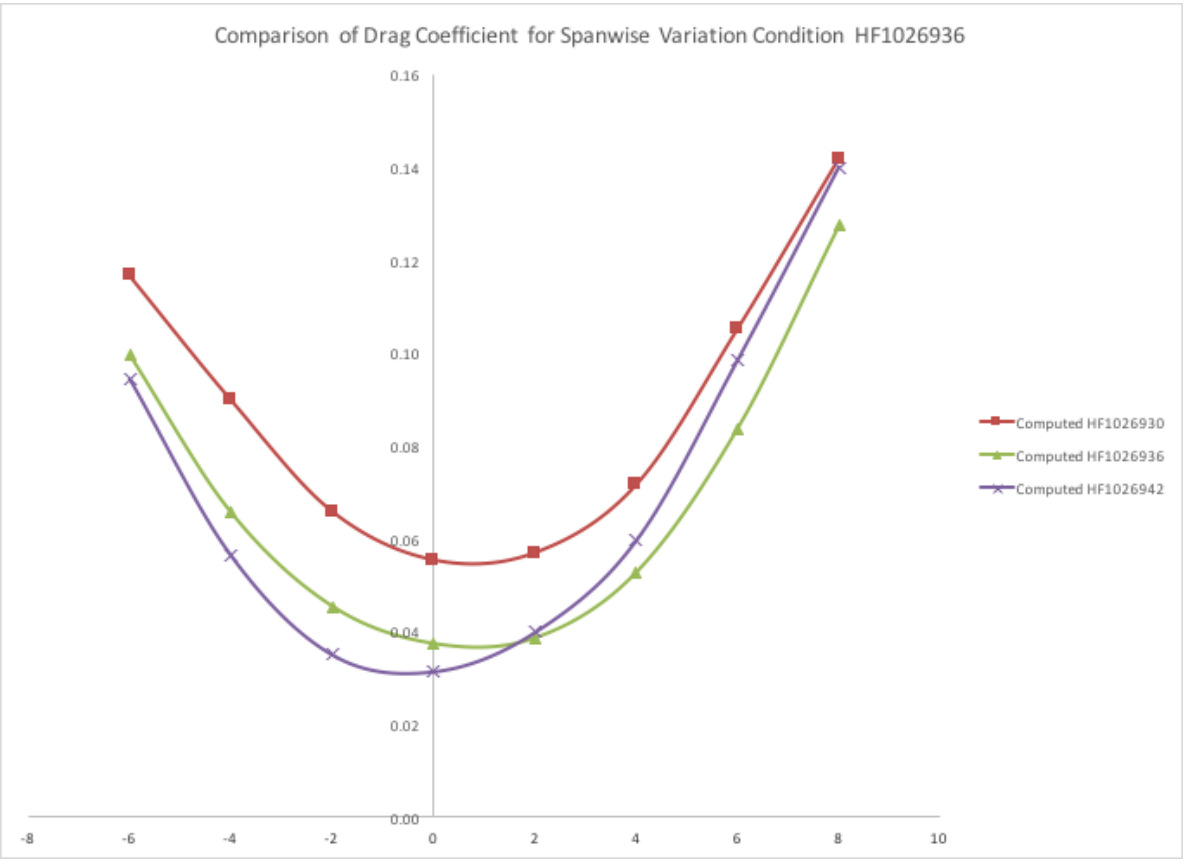

Figure 14: Ice Shape Comparison for Condition 3

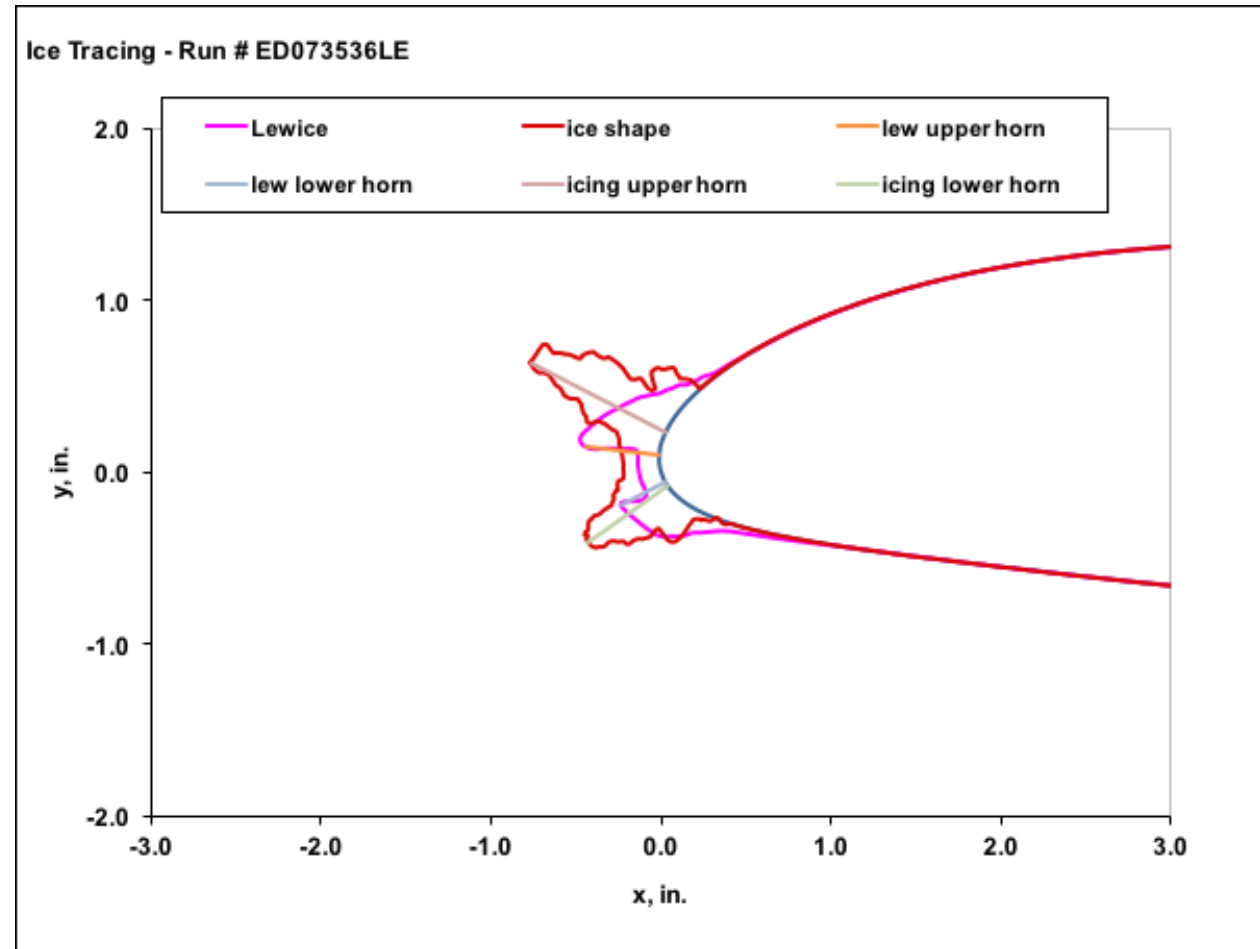


Figure 15: Comparison of Computed Lift to Experiment for Condition 3

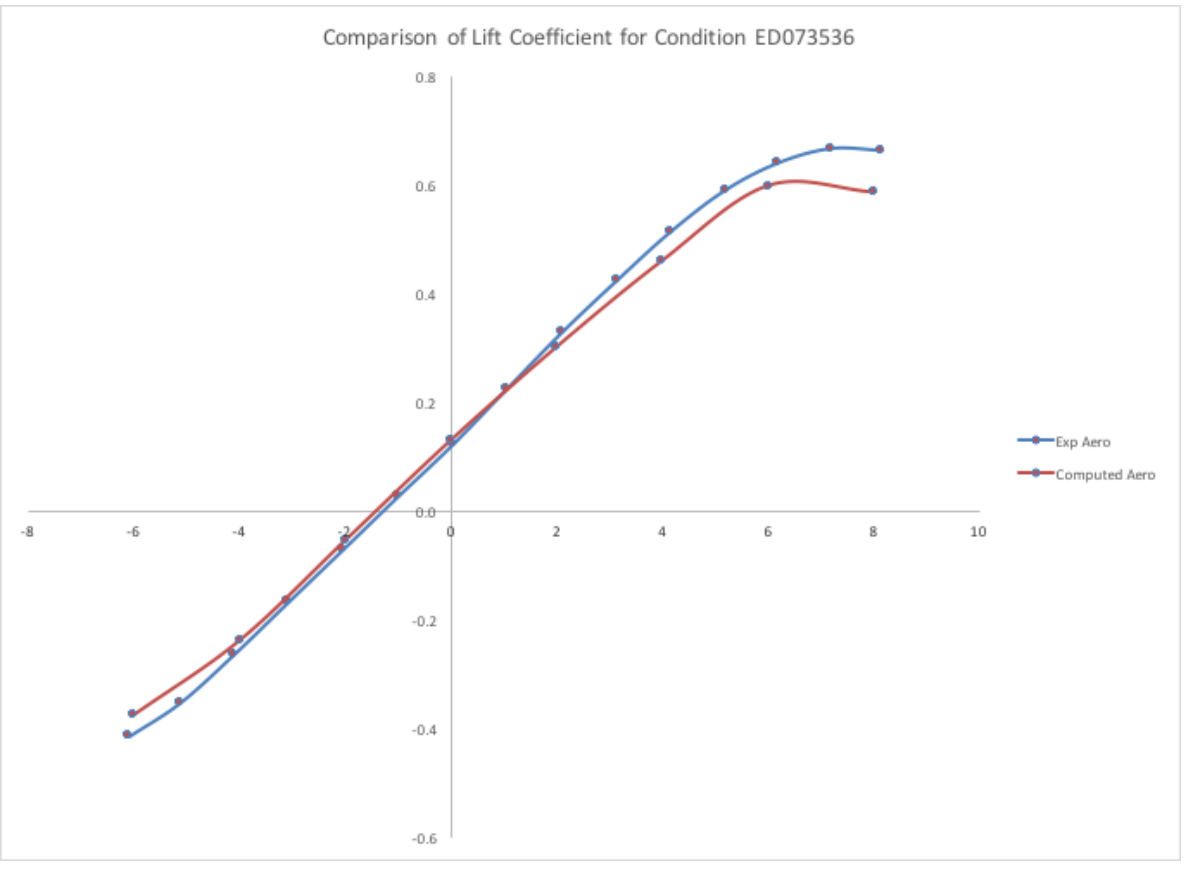

Figure 16: Comparison of Computed Drag to Experiment for Condition 3

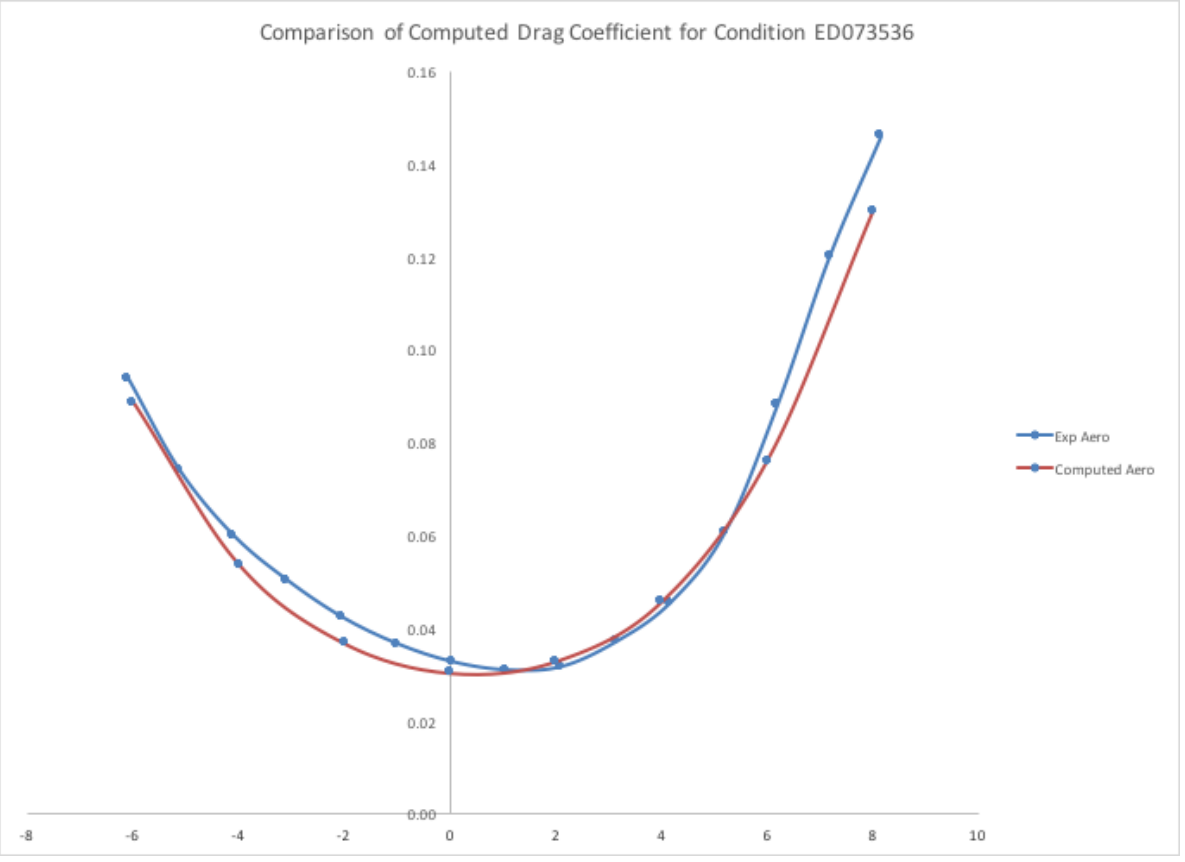

19

American Institute of Aeronautics and Astronautics 
Figure 17: Comparison of Computed Lift for Condition 3

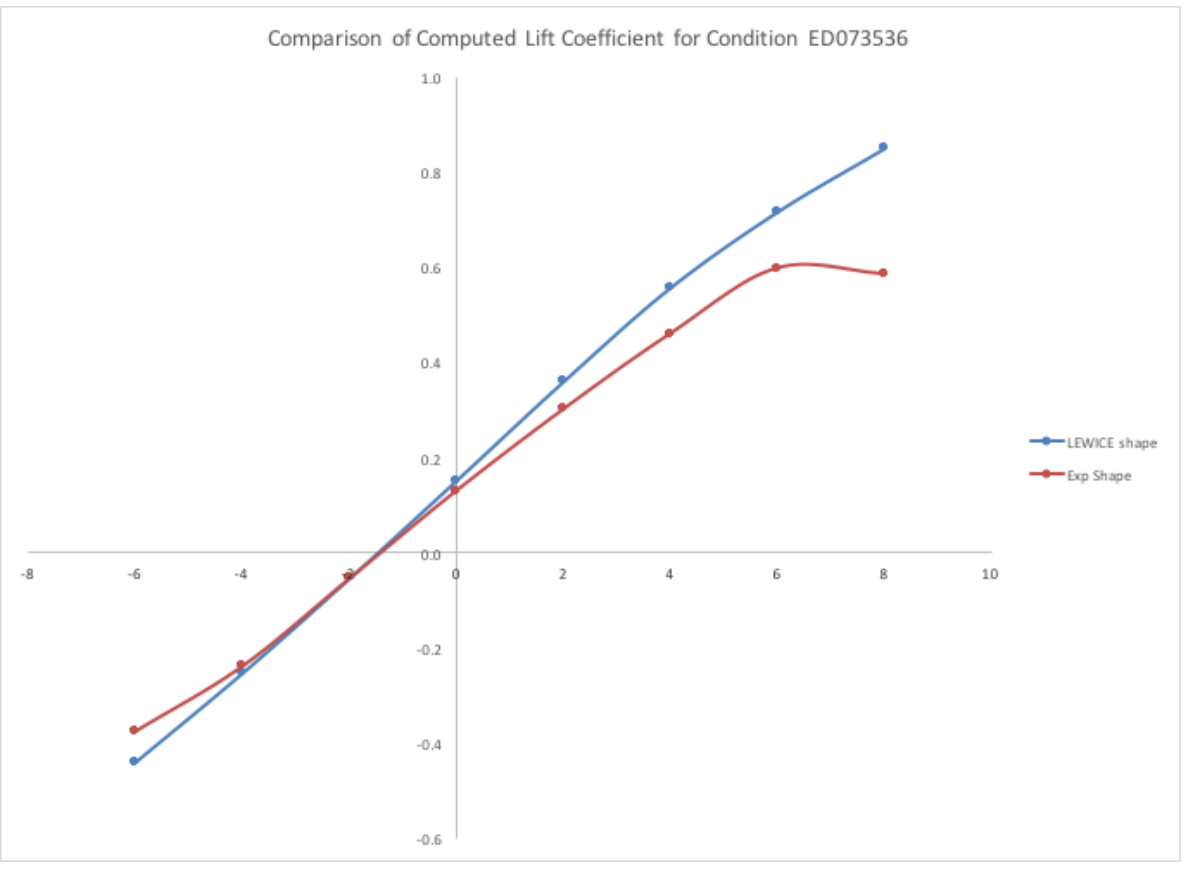

Figure 18: Comparison of Computed Drag for Condition

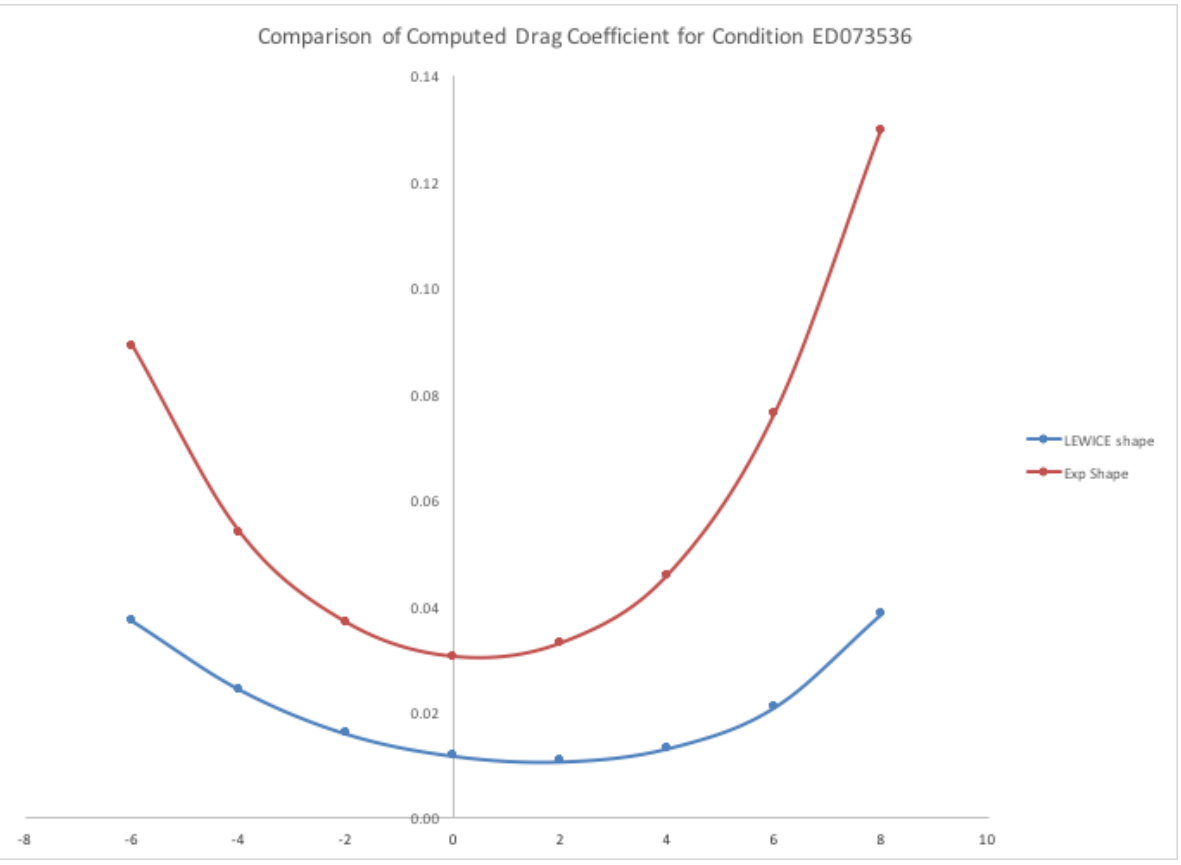


Figure 19: Repeatability Comparison for Condition 3

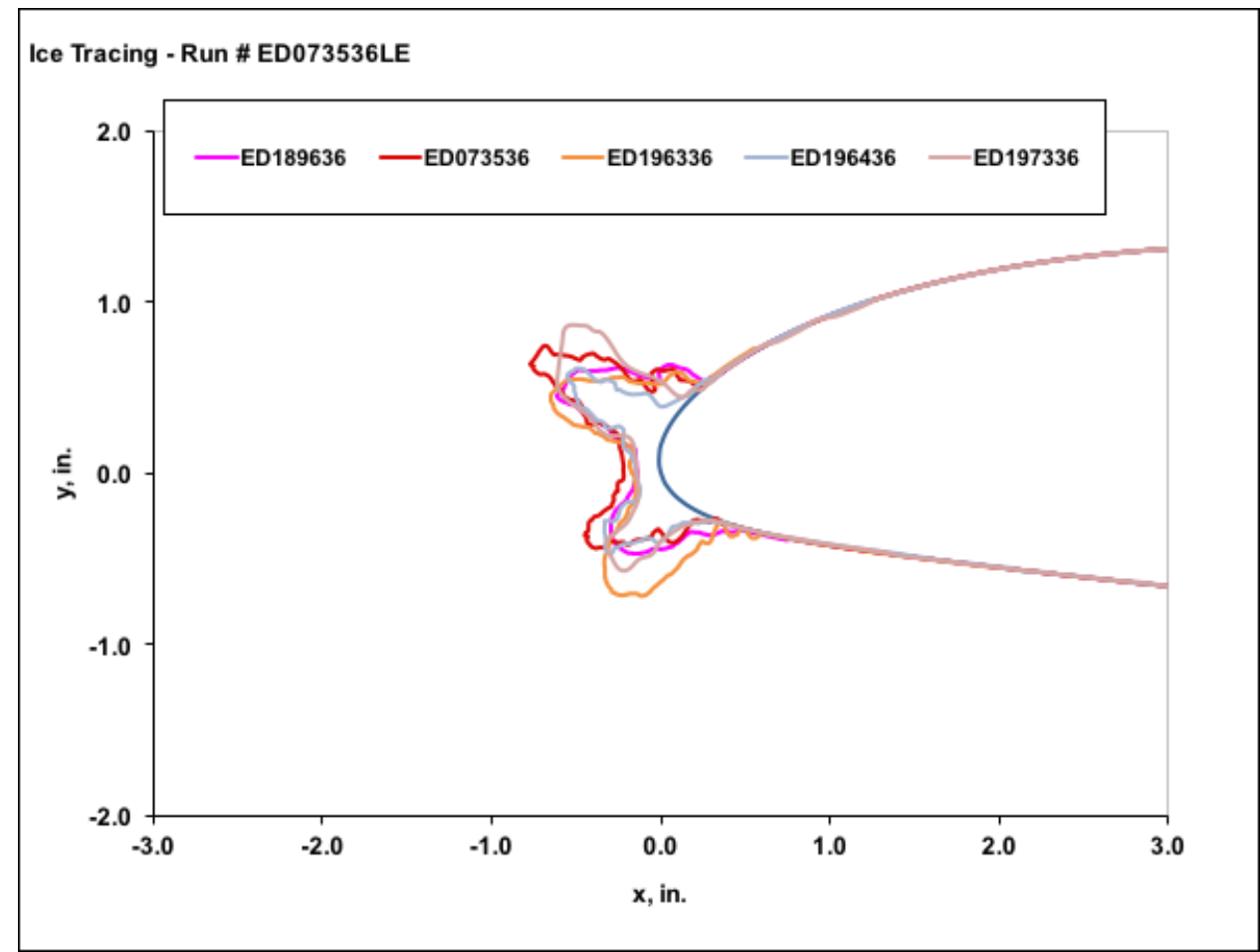

Figure 20: Variation in Computed Lift for Repeats of Condition 3

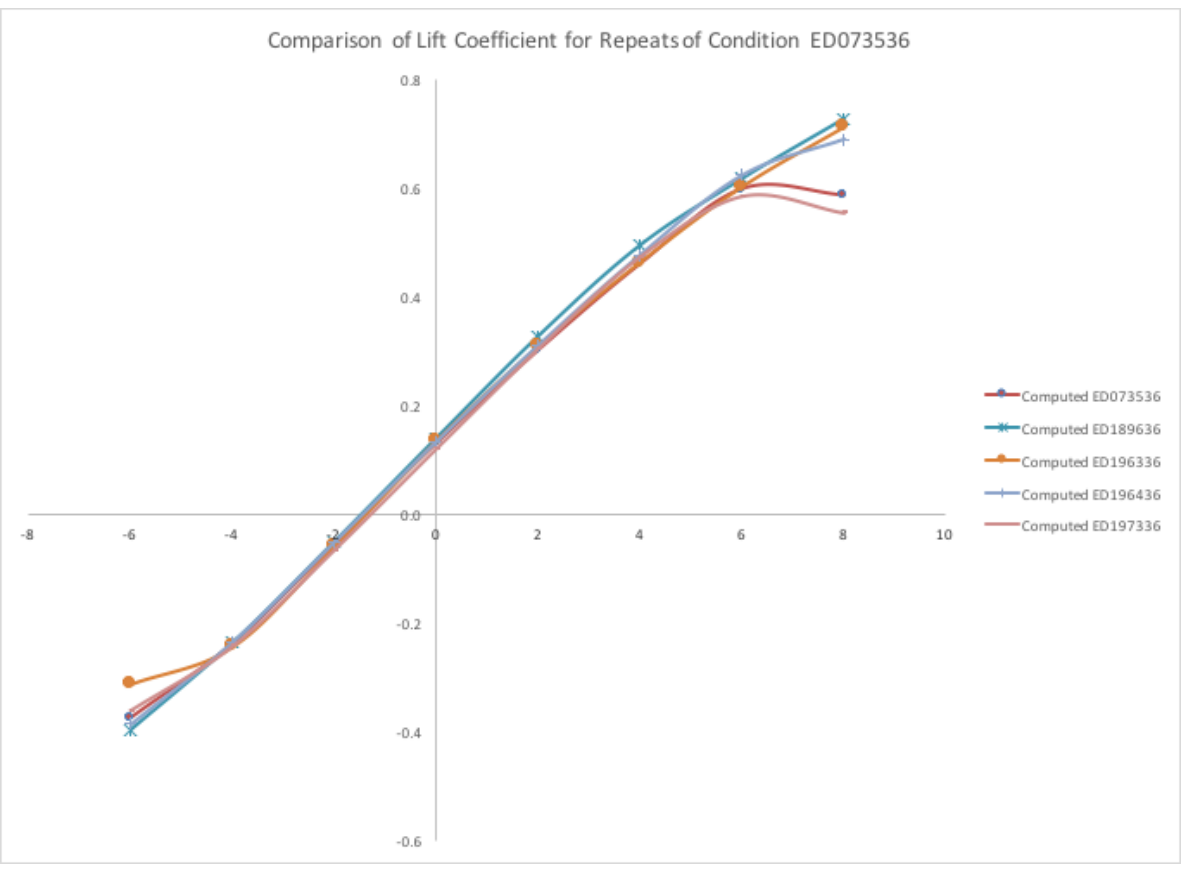


Figure 21: Variation in Computed Drag for Repeats of Condition 3

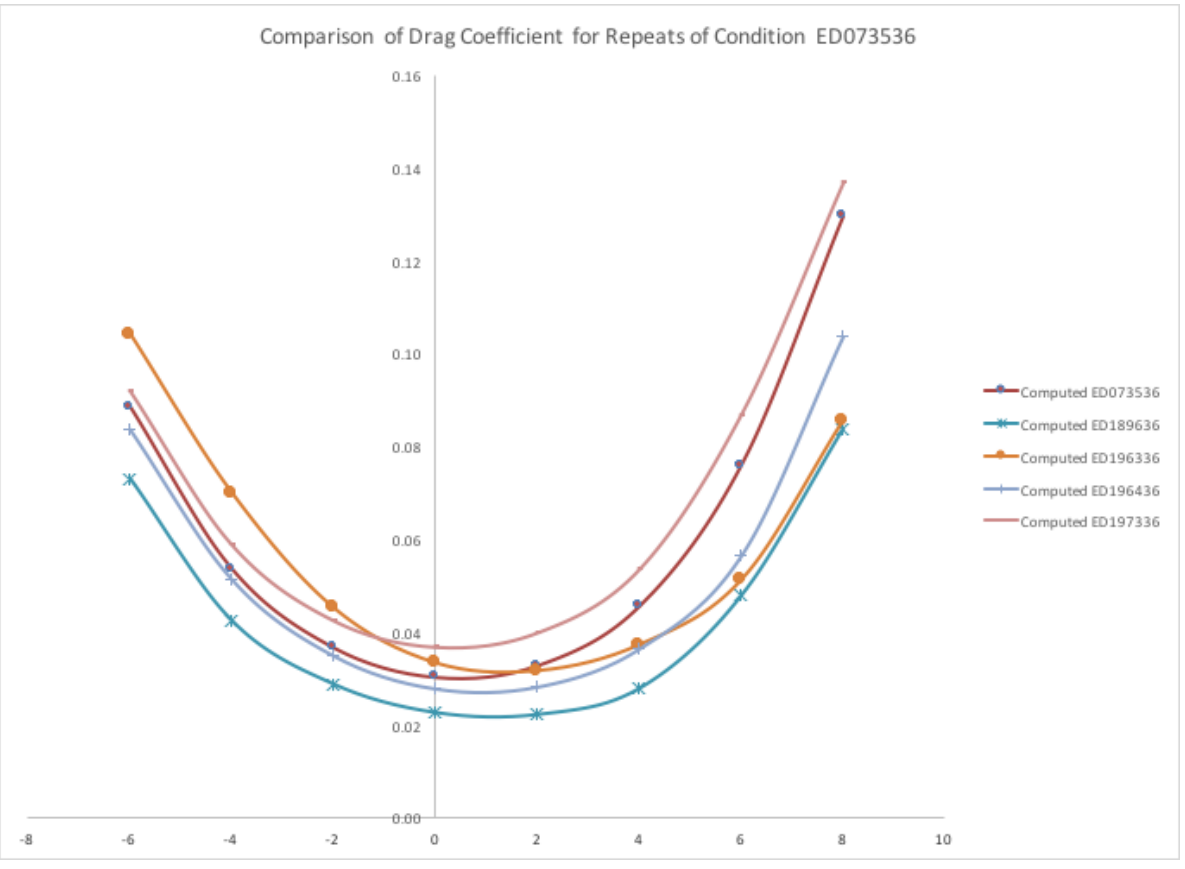

Figure 22: Variation along Span for Condition 3

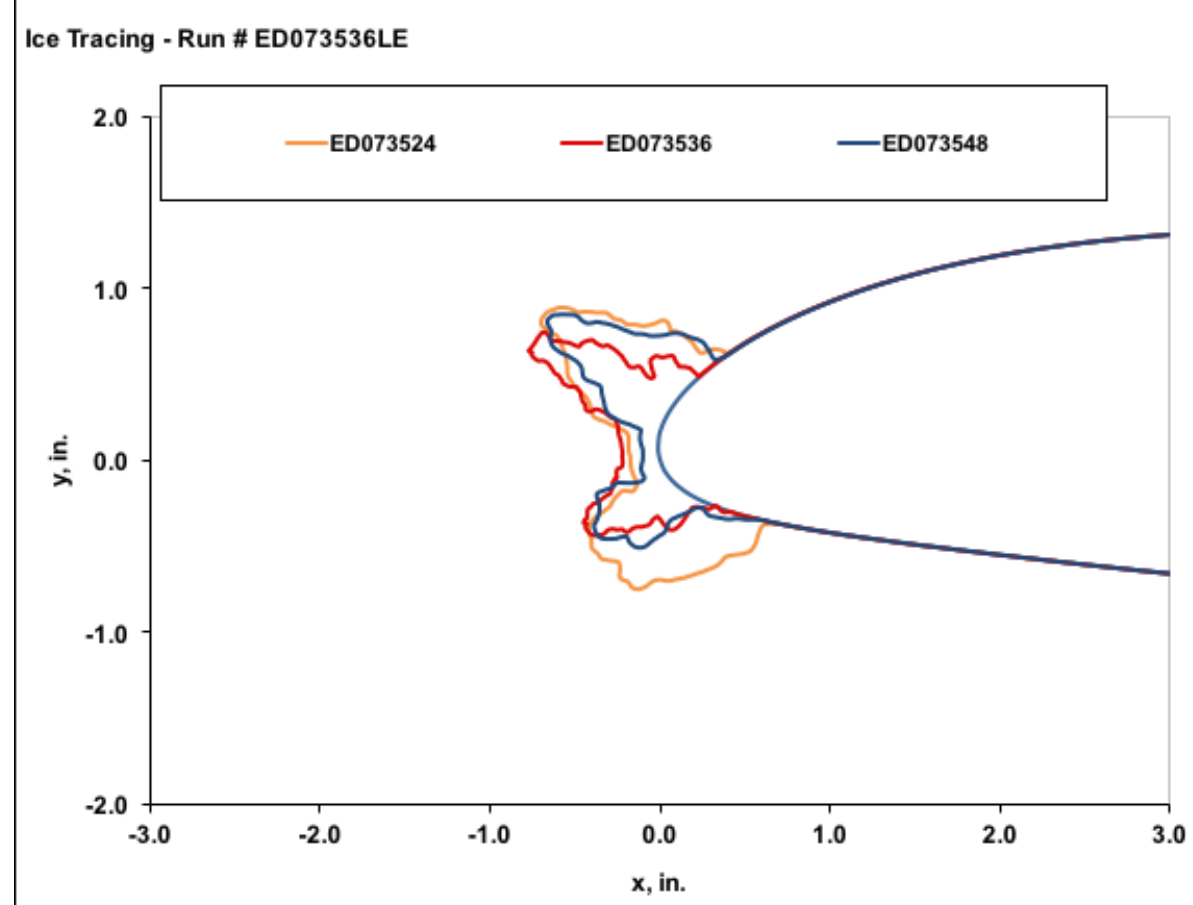


Figure 23: Variation in Computed Lift for Different Span Locations of Condition 3

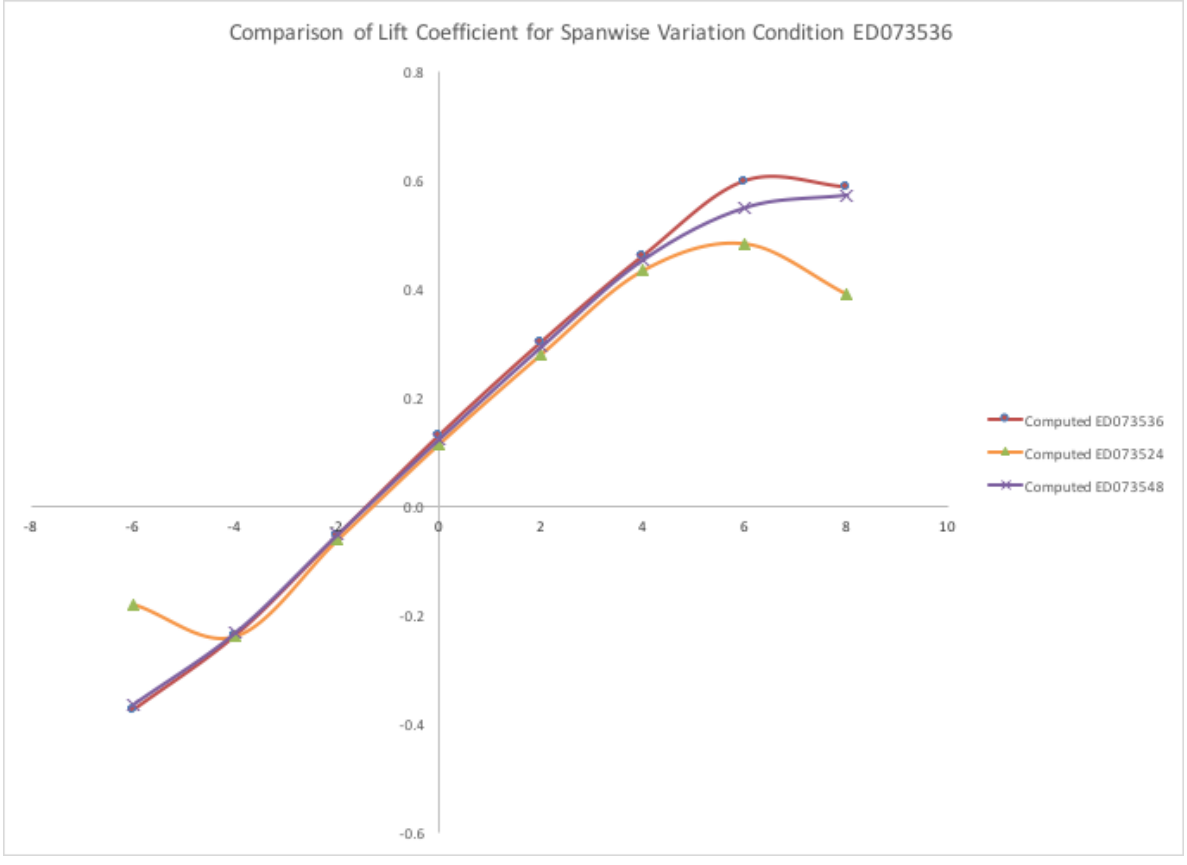

Figure 24: Variation in Computed Drag for Different Span Locations of Condition 3

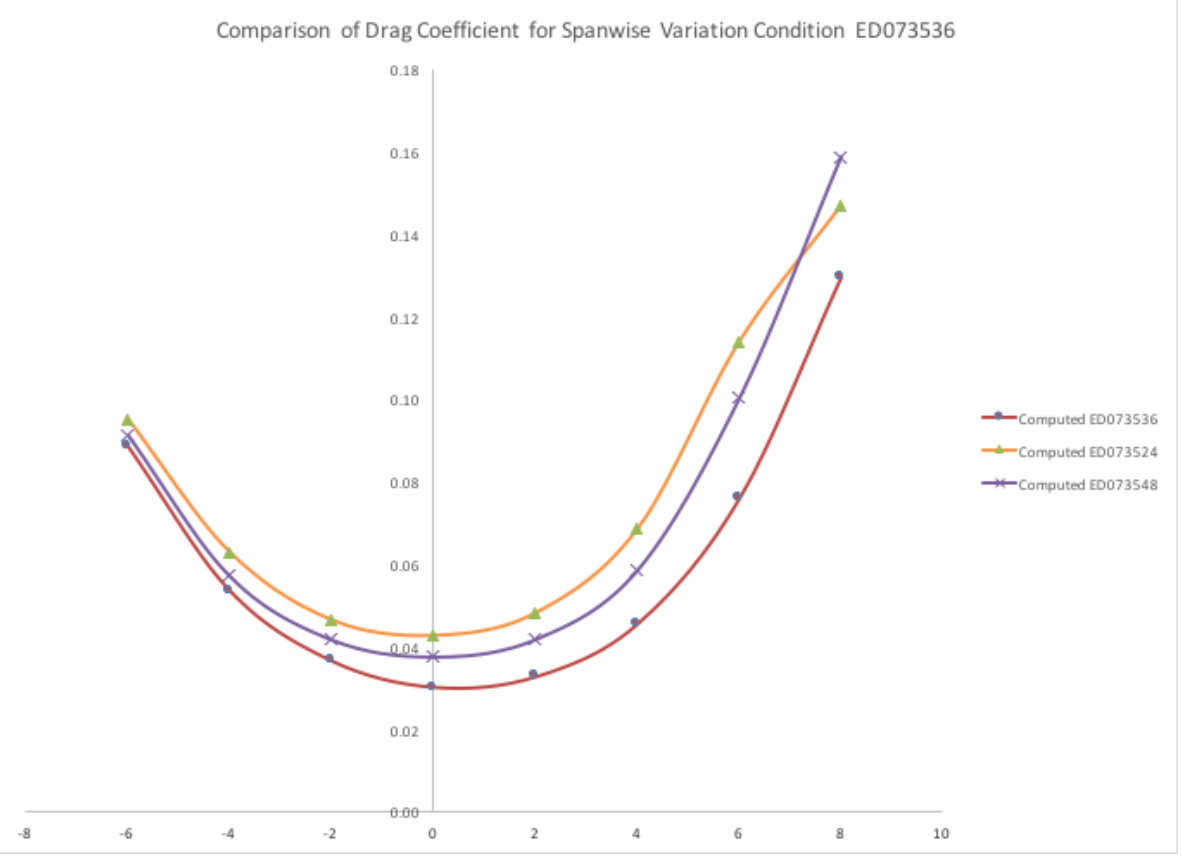


Figure 25: Ice Shape for Condition 10

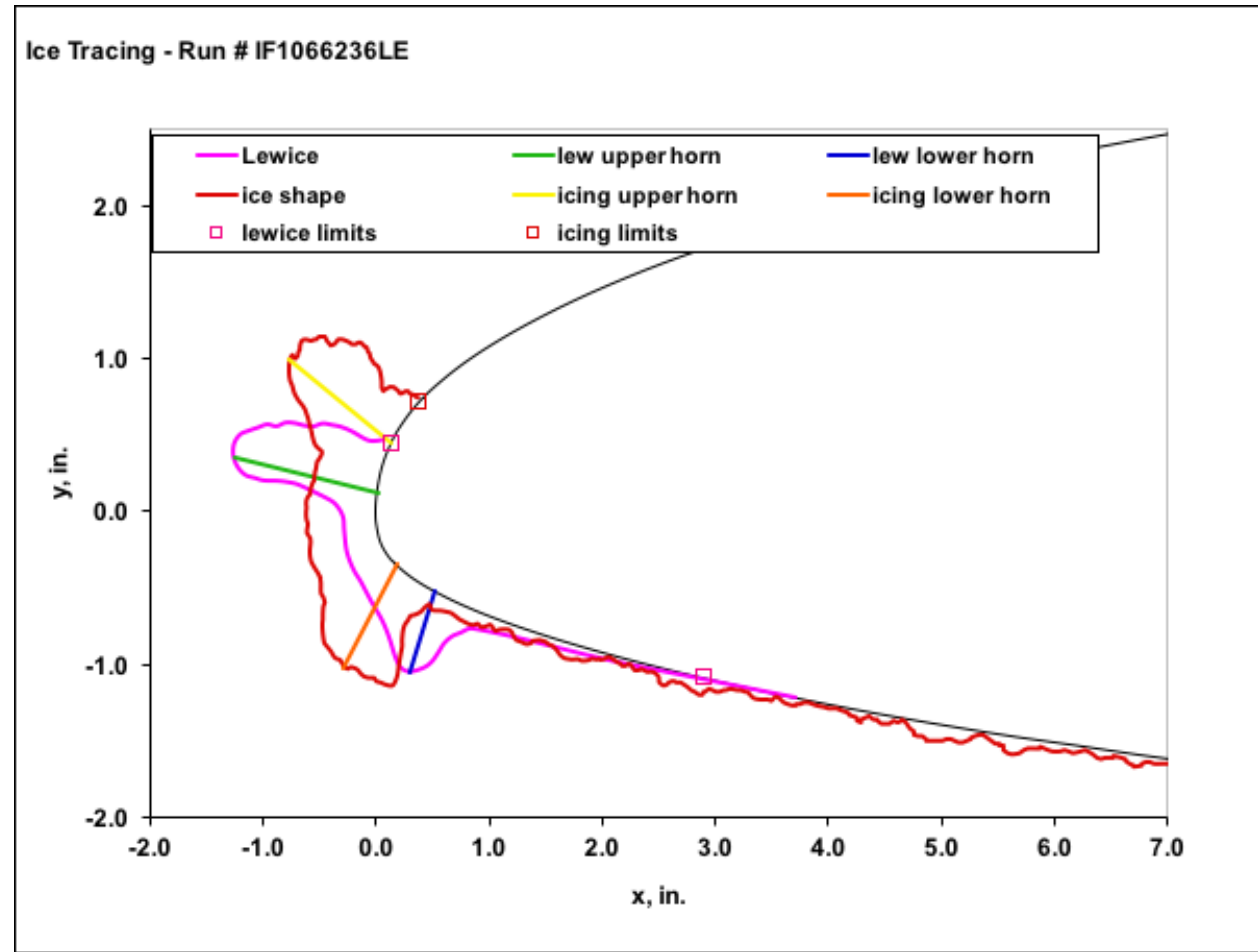

Figure 26: Comparison of Computed Lift to Experiment for Condition 10

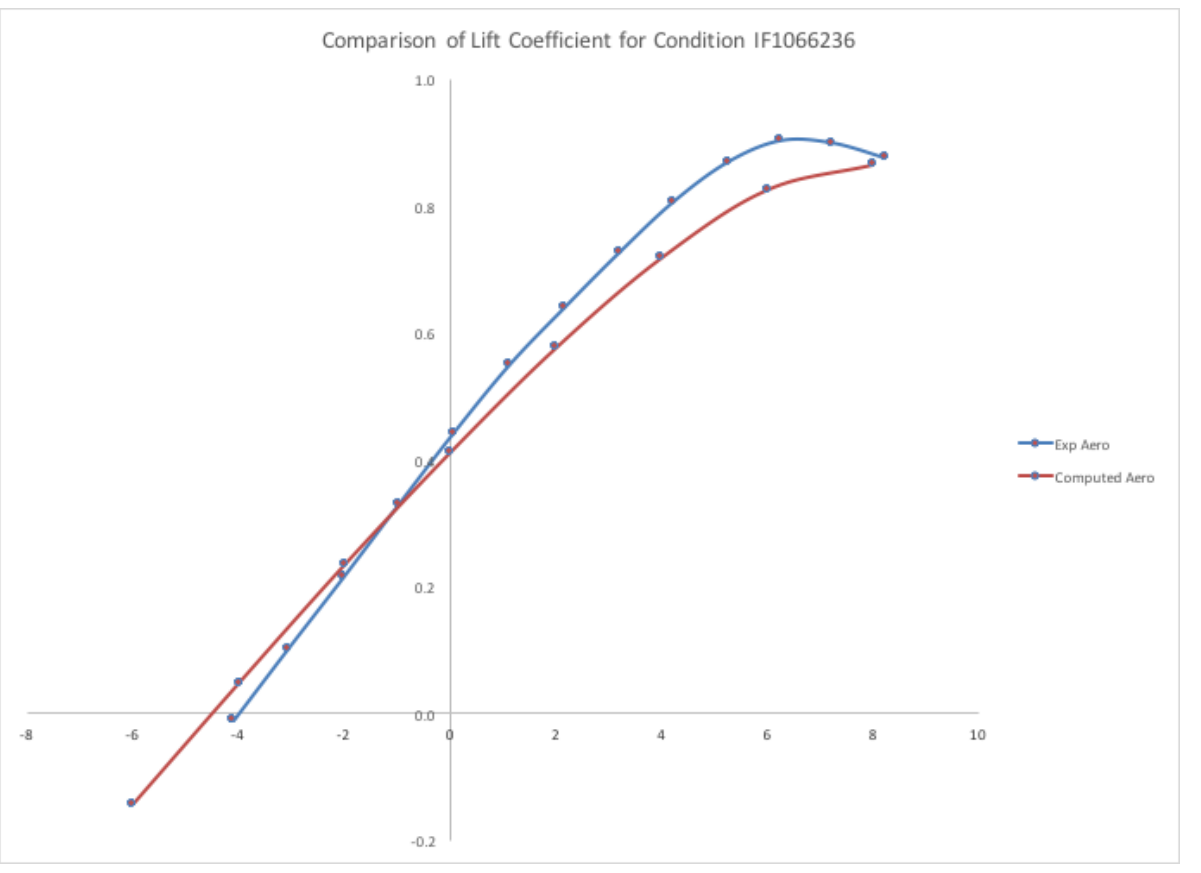


Figure 27: Comparison of Computed Lift for Condition 10

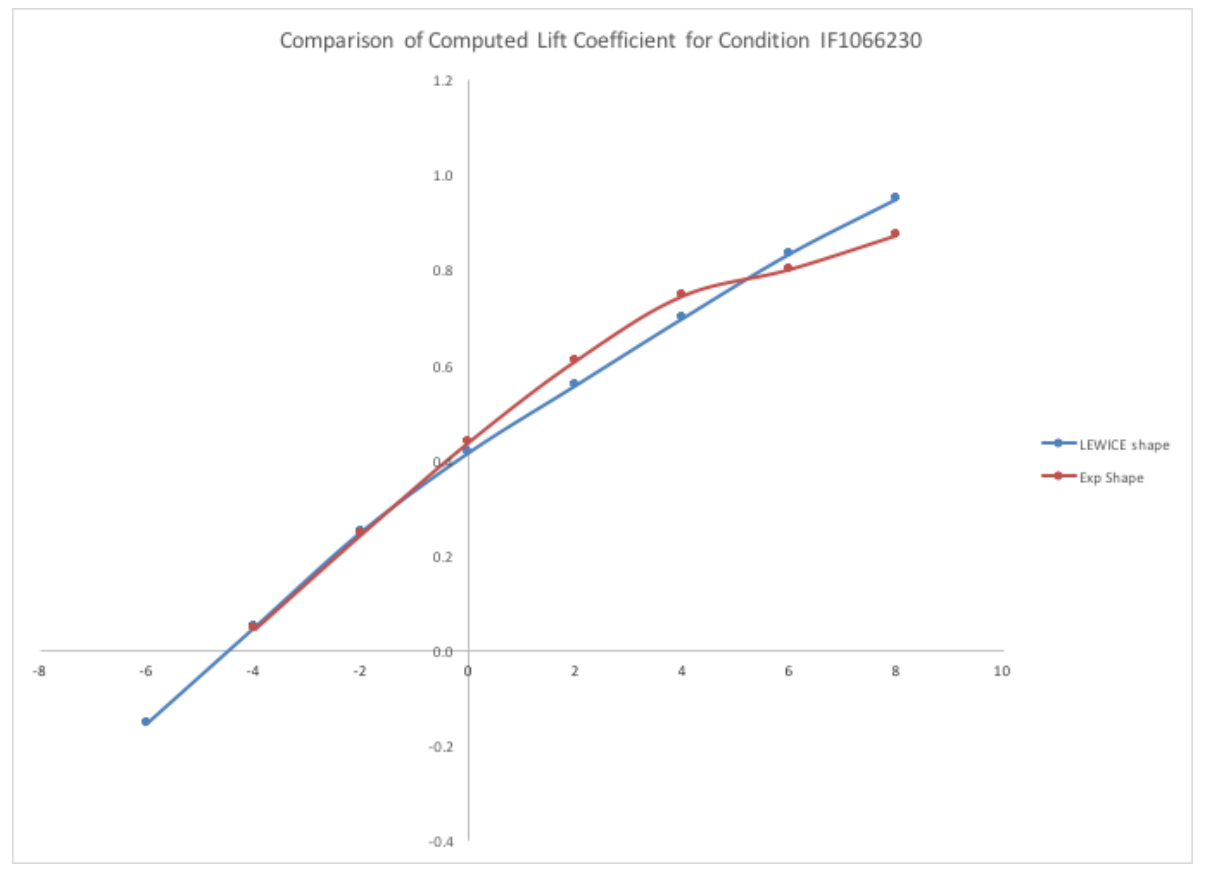

Figure 28: Comparison of Computed Drag for Condition

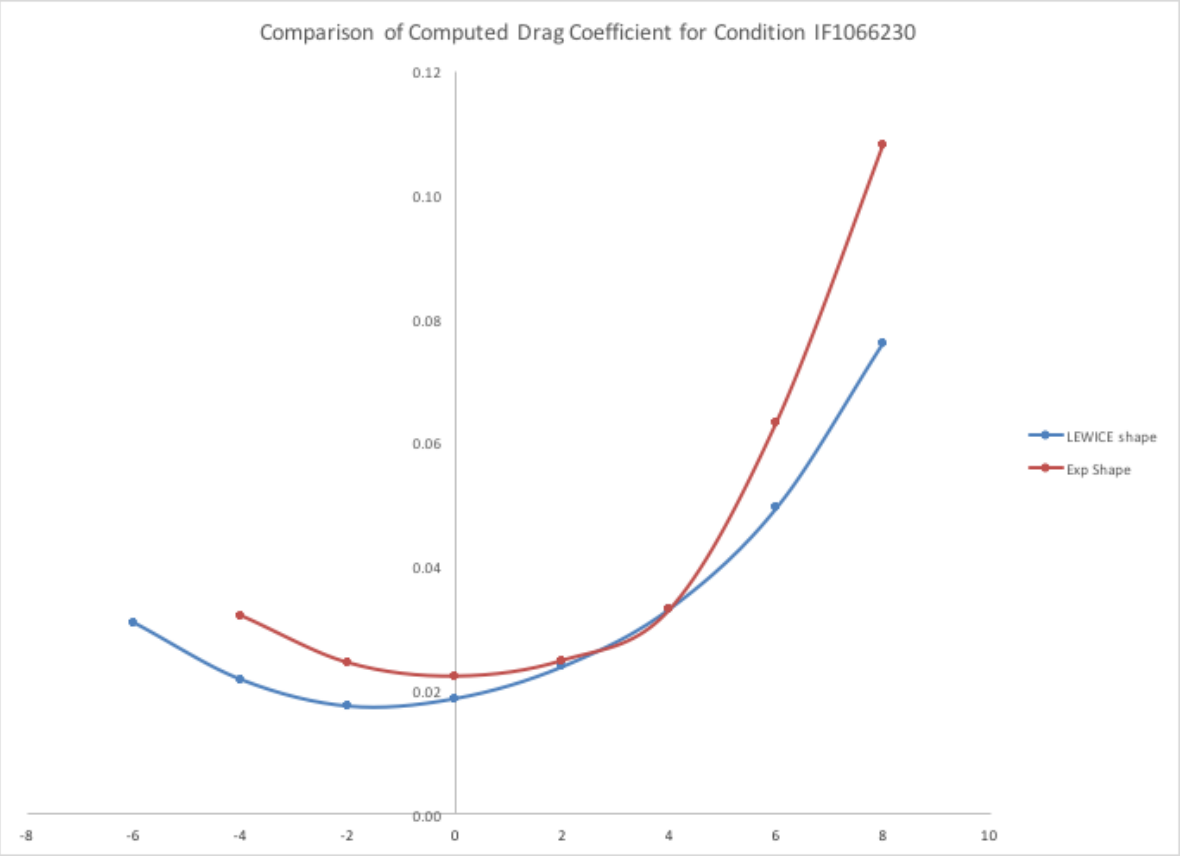


Figure 29: Repeatability Comparison for Condition 10

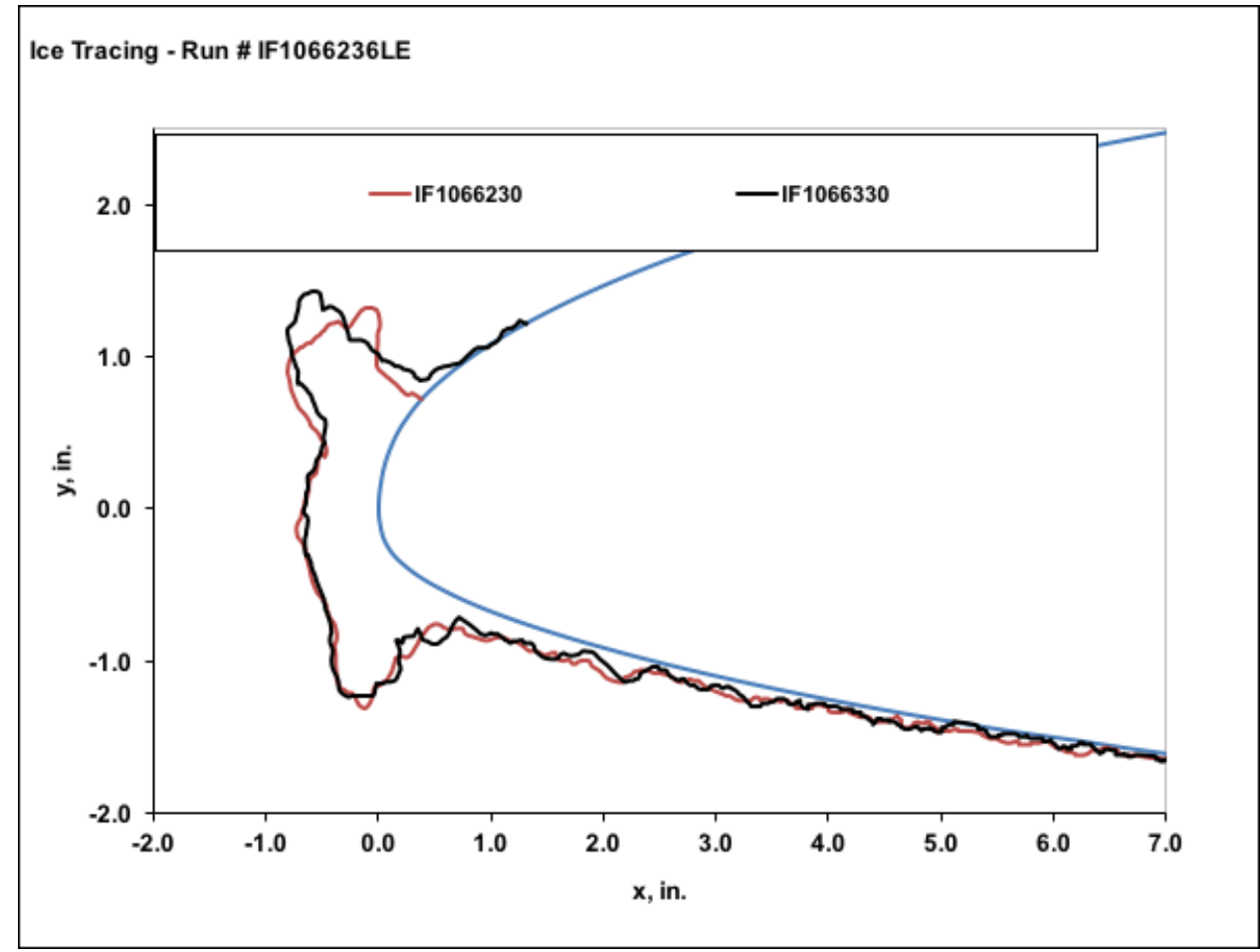

Figure 30: Variation in Computed Lift for Repeats of Condition 10

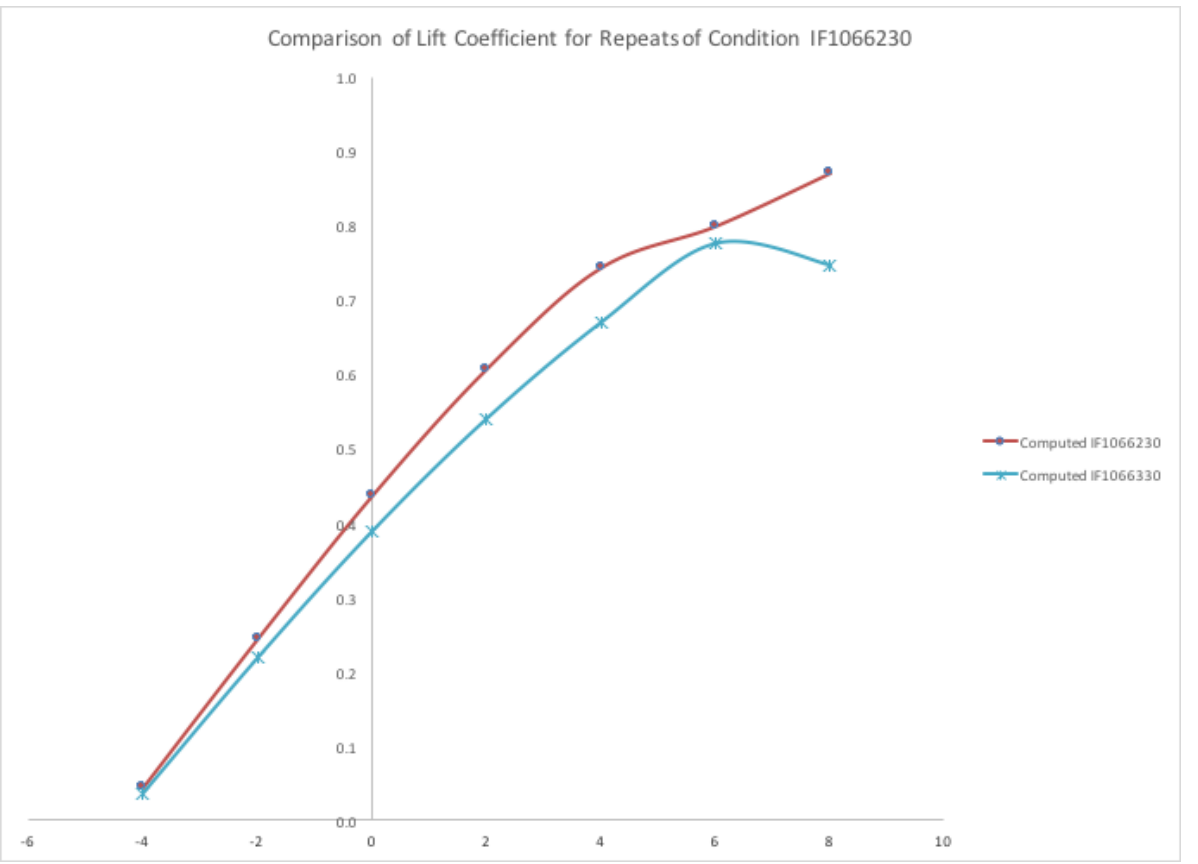


Figure 31: Variation in Computed Drag for Repeats of Condition 10

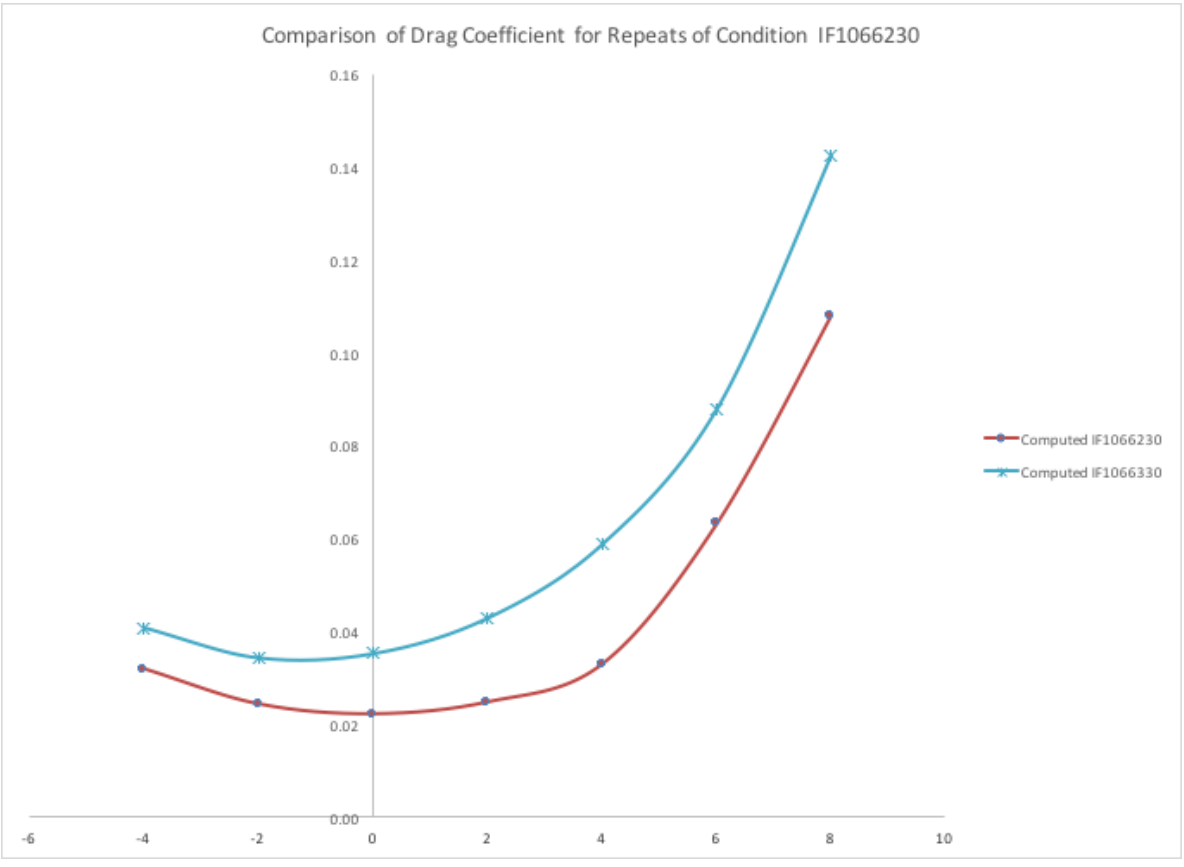

Figure 32: Variation along Span for Condition 10

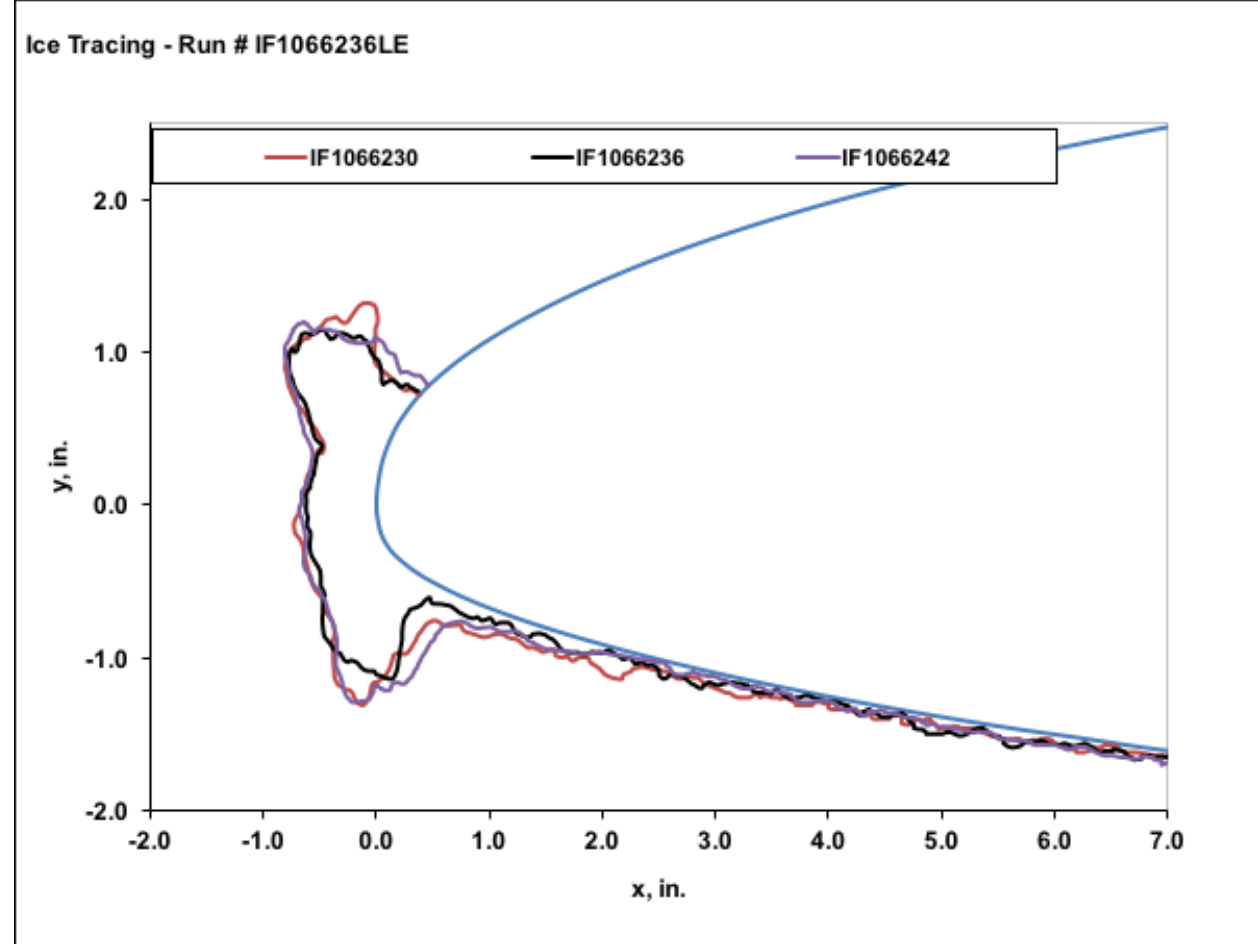


Figure 33: Variation in Computed Lift for Different Span Locations of Condition 10

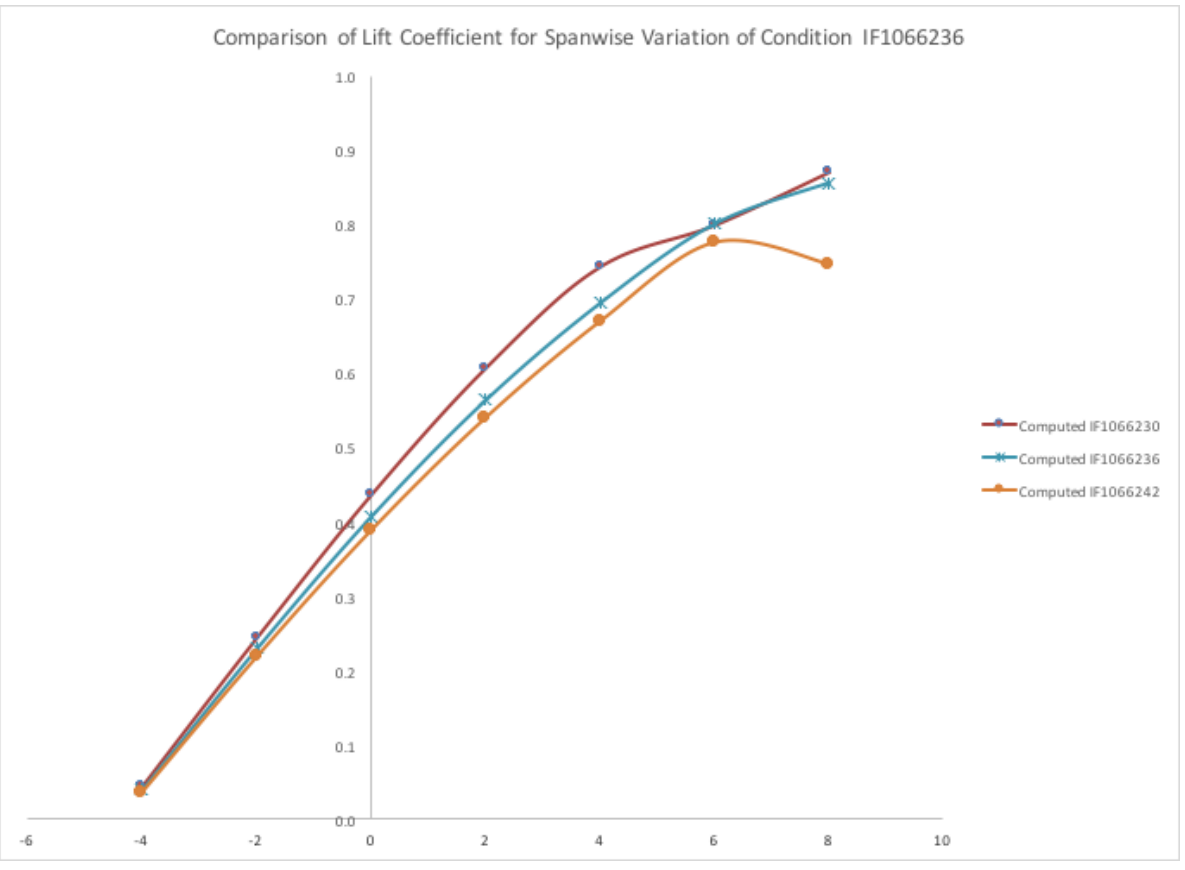

Figure 34: Variation in Computed Drag for Different Span Locations of Condition 10

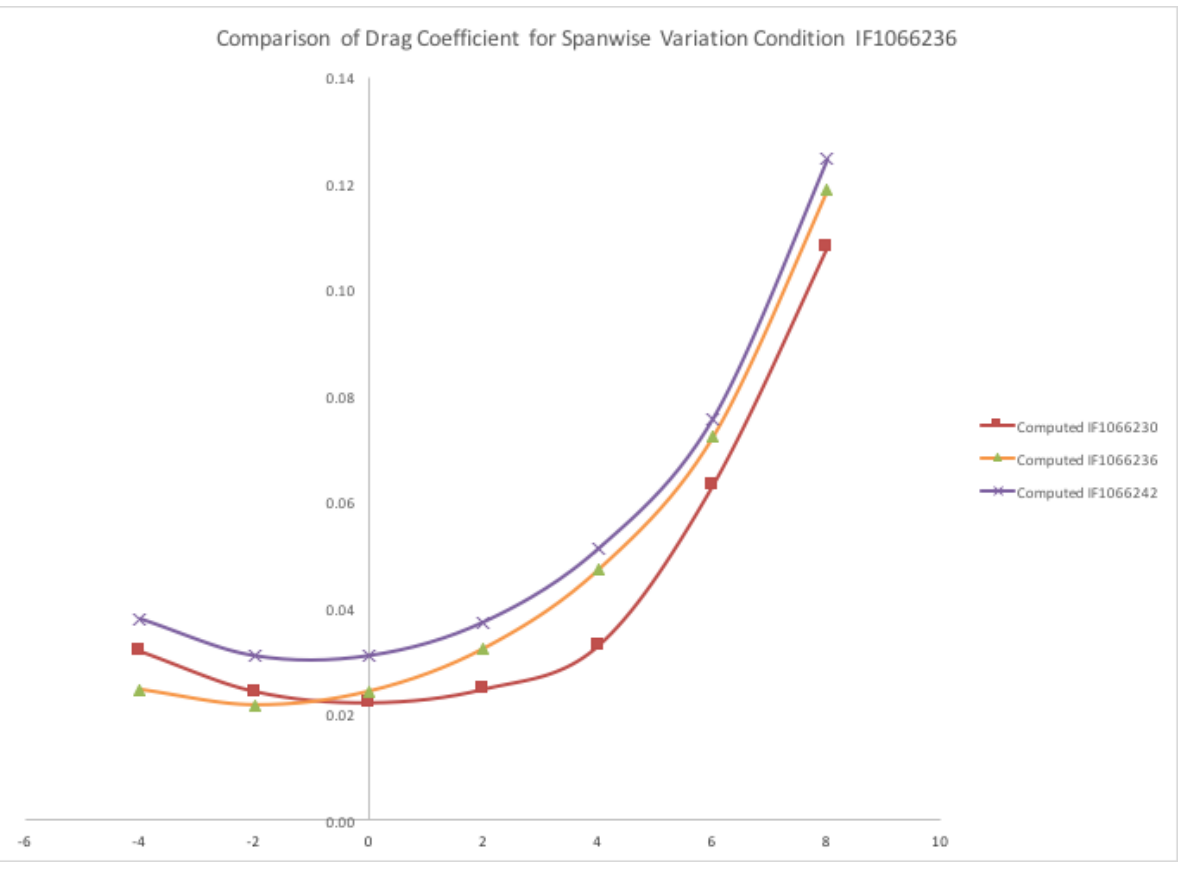


Figure 35: Ice Shape for Condition 1

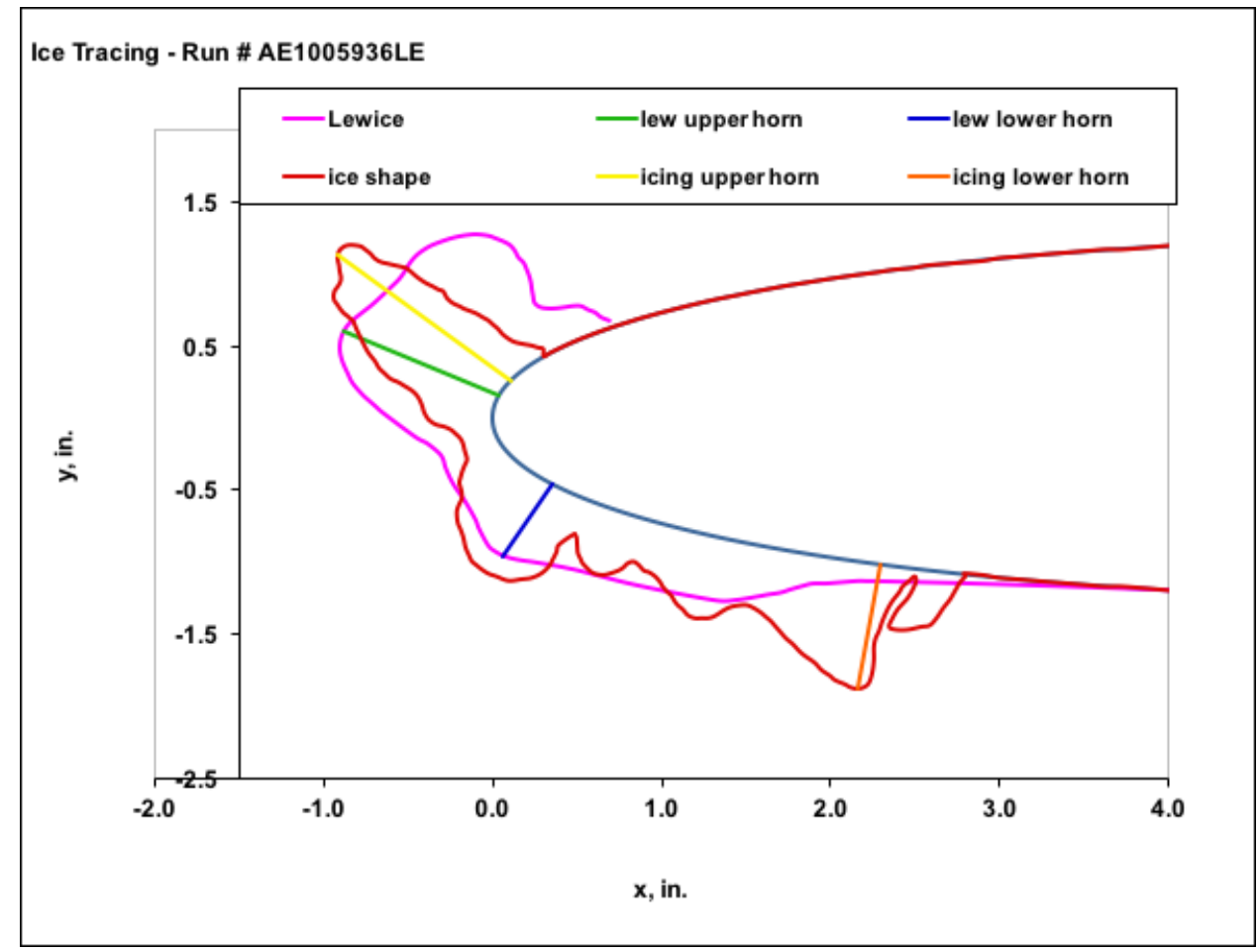

\section{Figure 36: Comparison of Computed Lift for Condition 1}

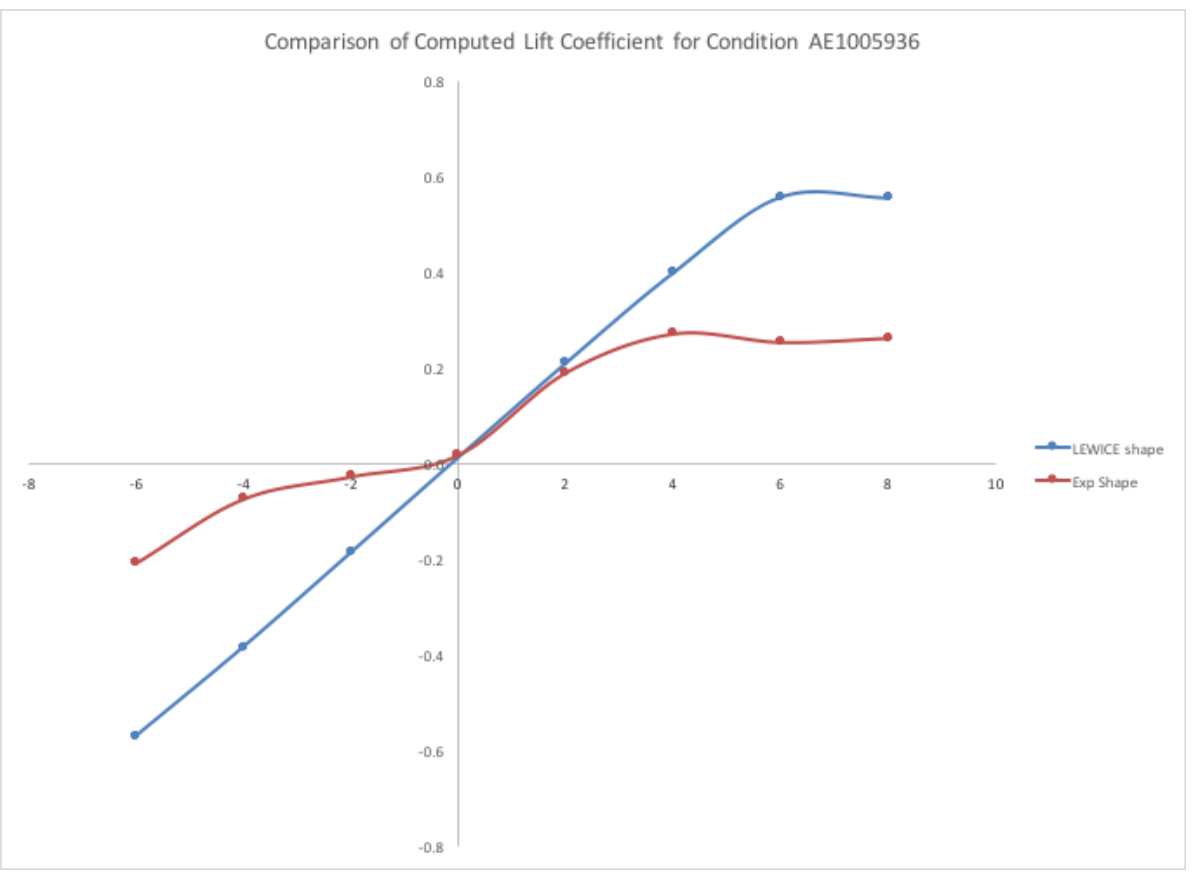


Figure 37: Comparison of Computed Drag for Condition 1

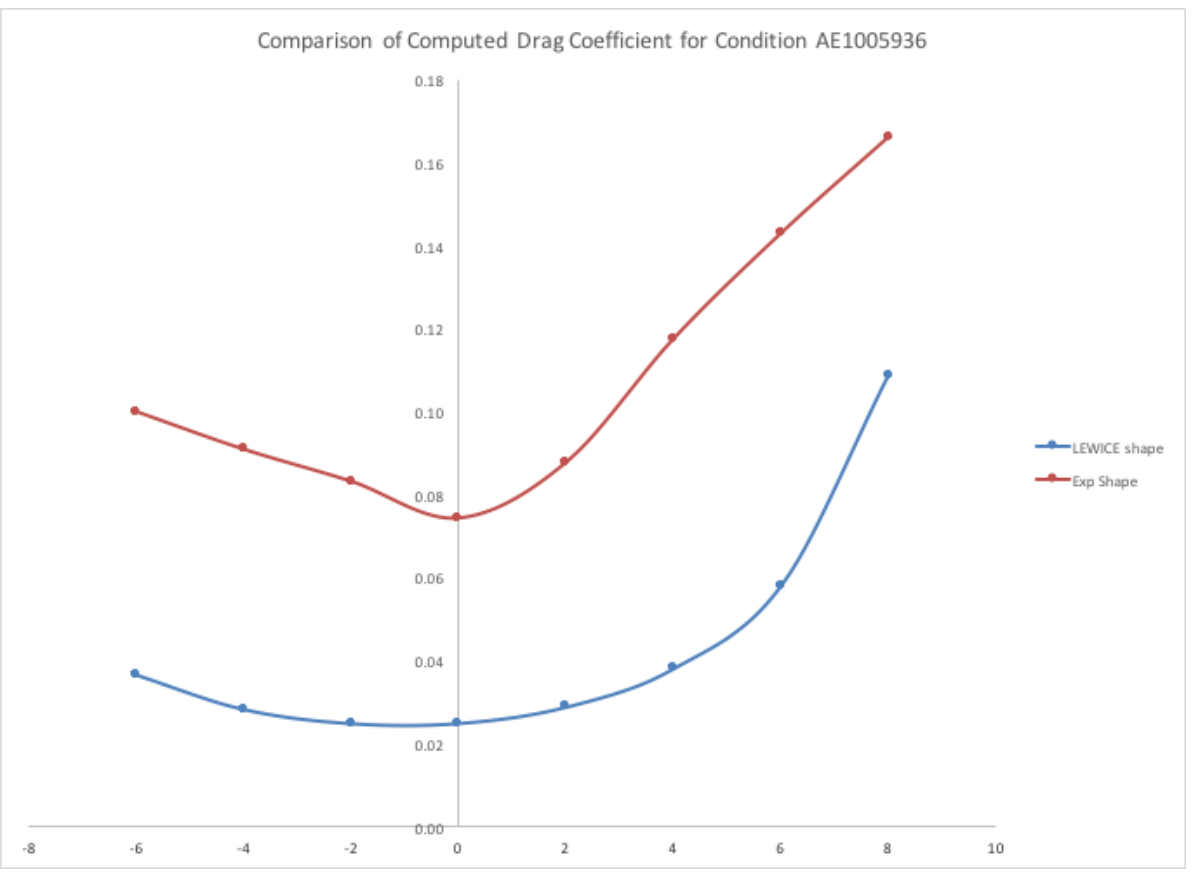

Figure 38: Mach Contours at $\mathrm{AOA}=6^{\circ}$ for IRT Shape

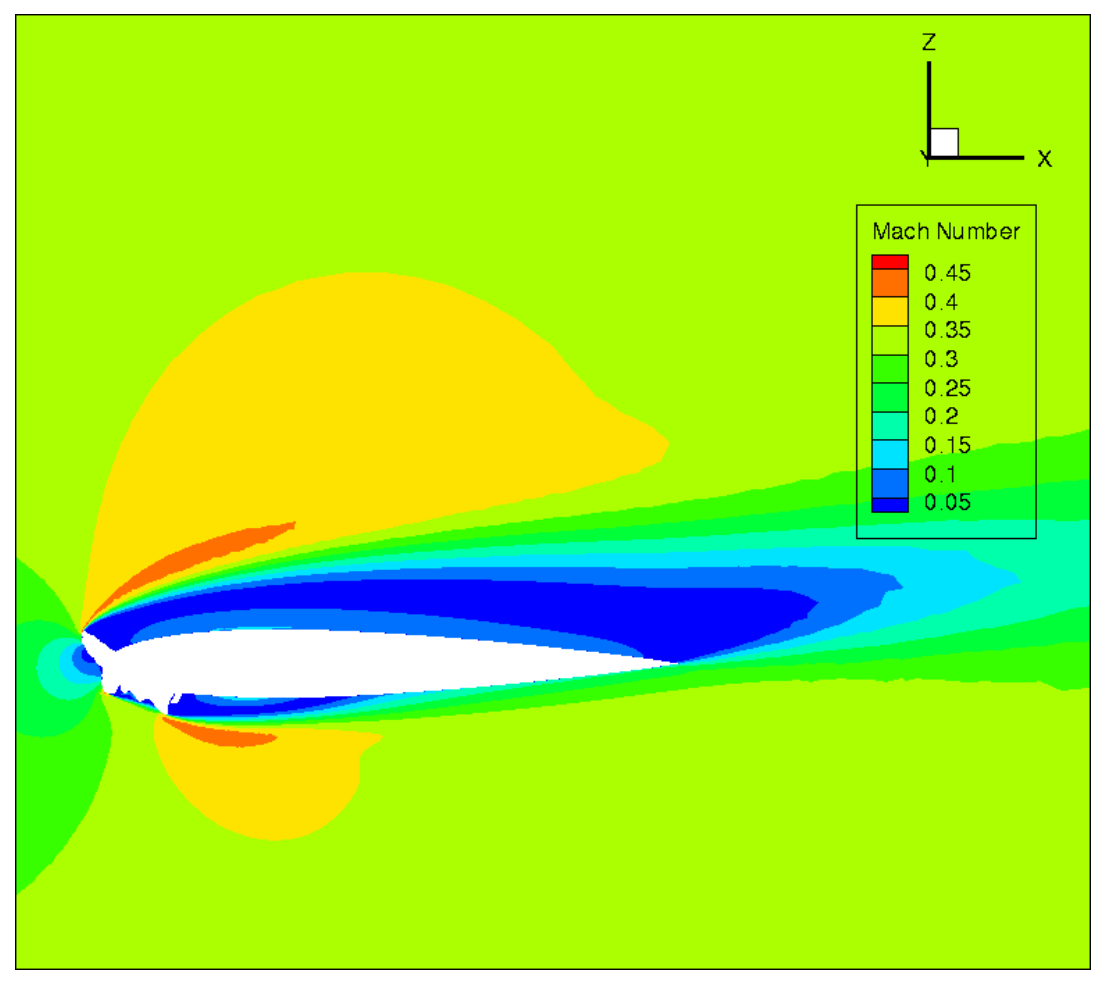


Figure 39: Mach Contours at $\mathrm{AOA}=6^{\circ}$ for $\mathrm{LEWICE}$ Shape

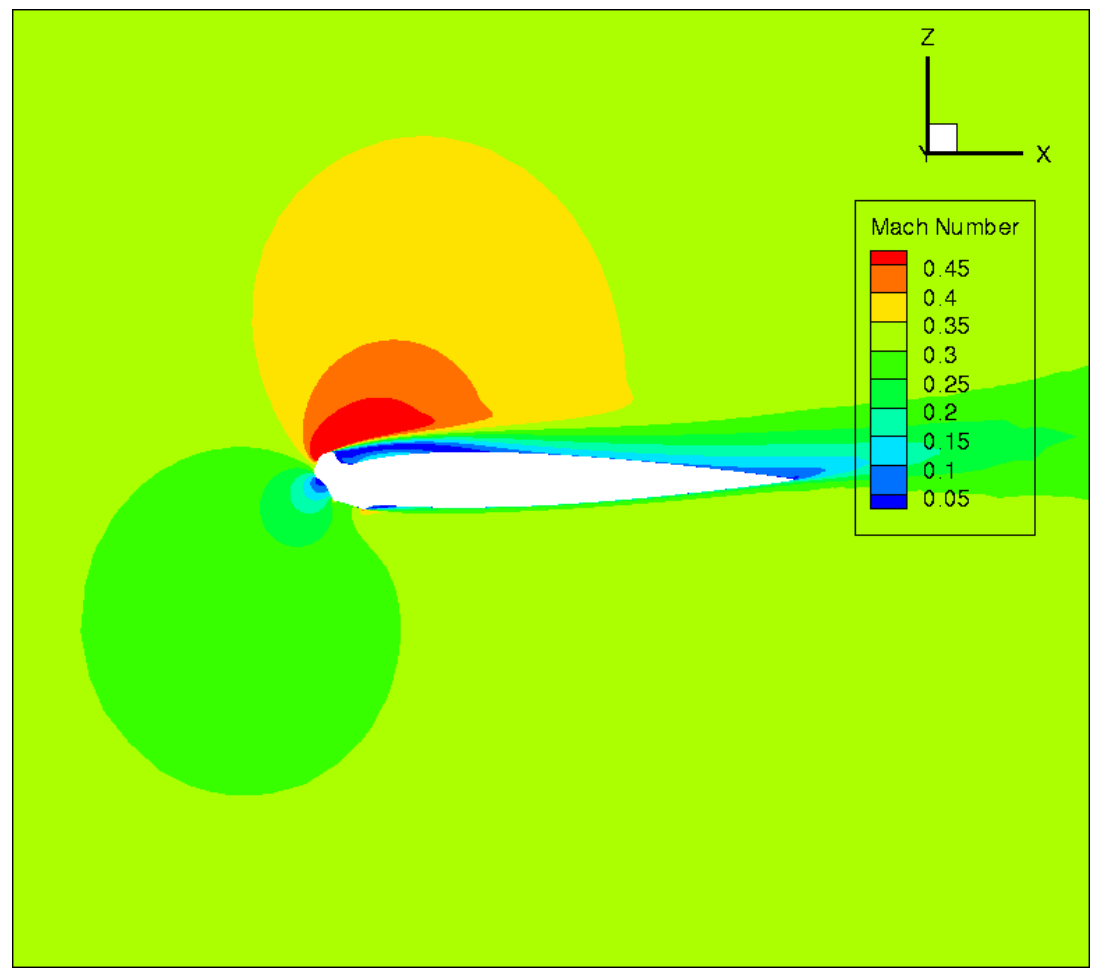

Figure 40: Ice Shape for Condition 2

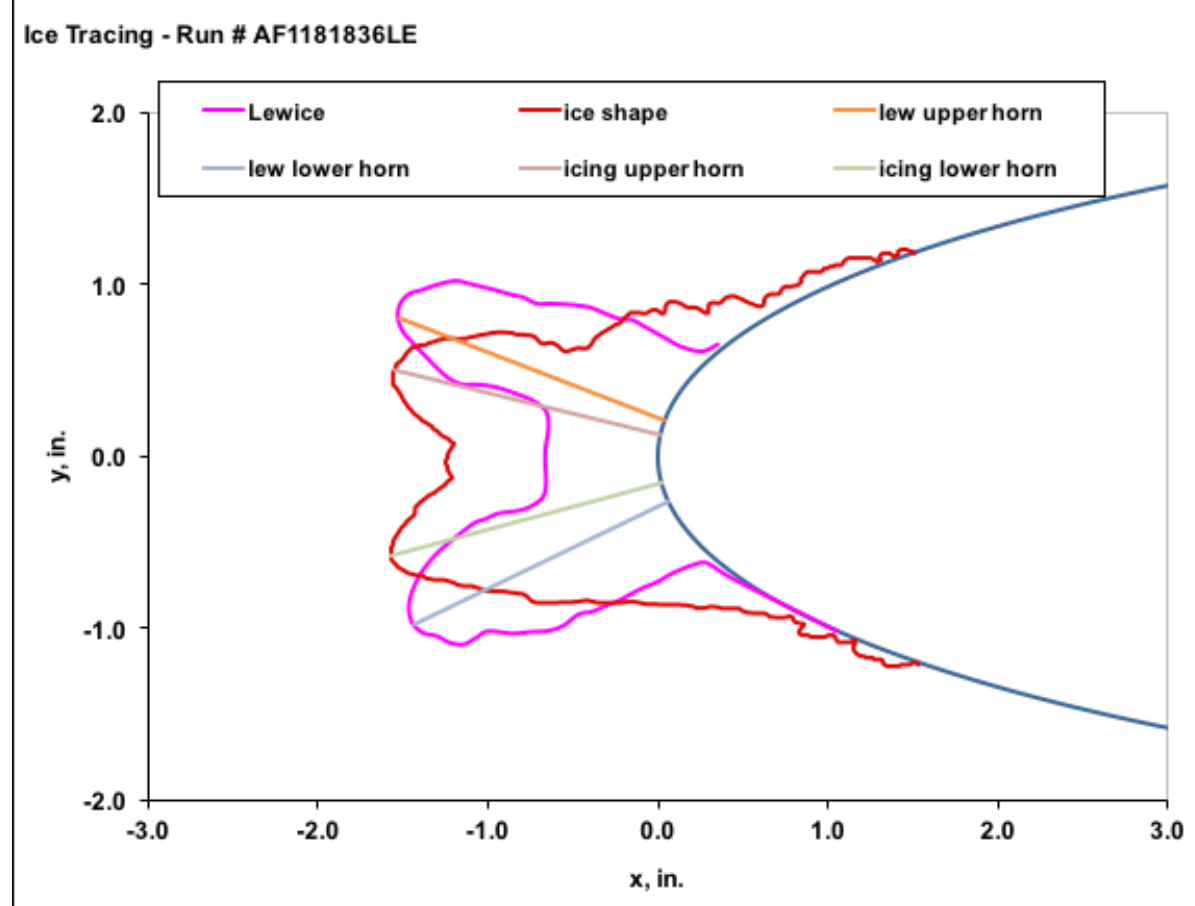


Figure 41: Comparison of Computed Lift for Condition 2

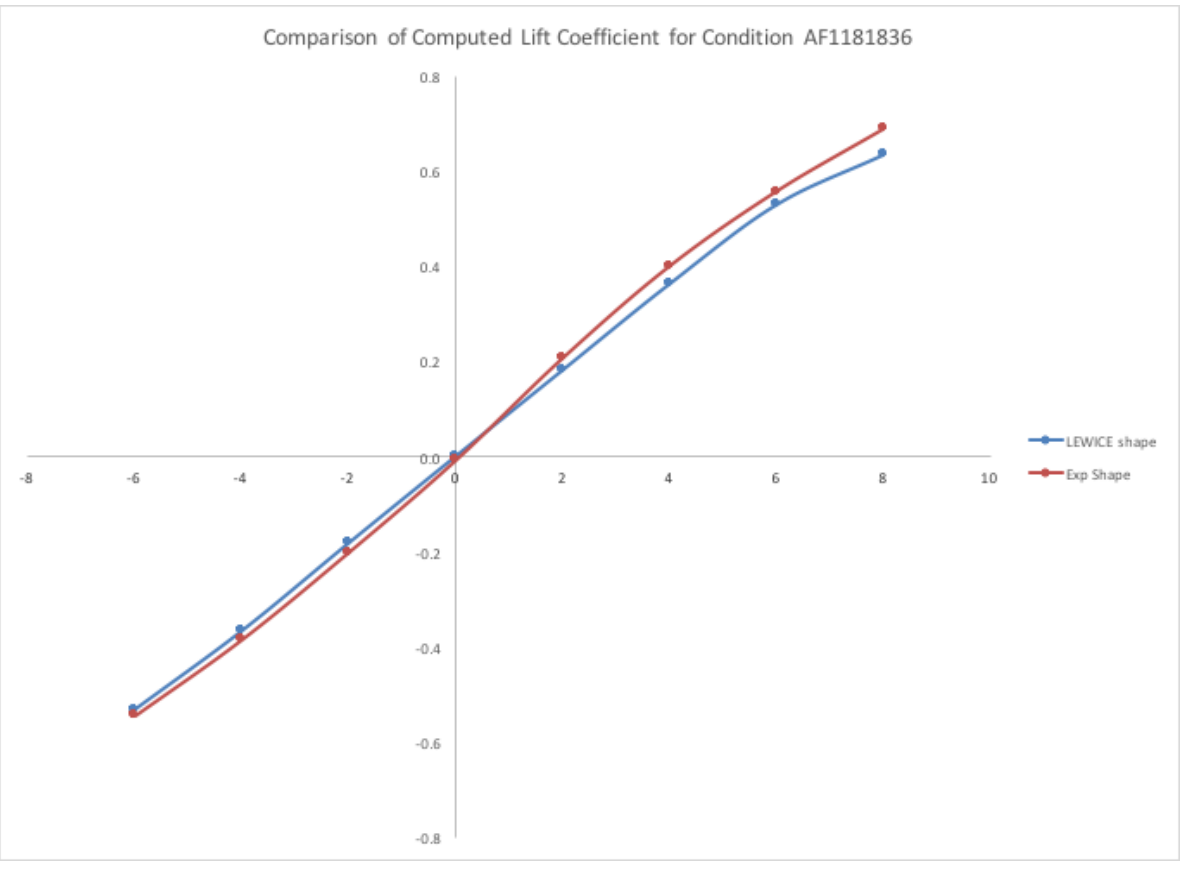

Figure 42: Comparison of Computed Lift for Condition 2

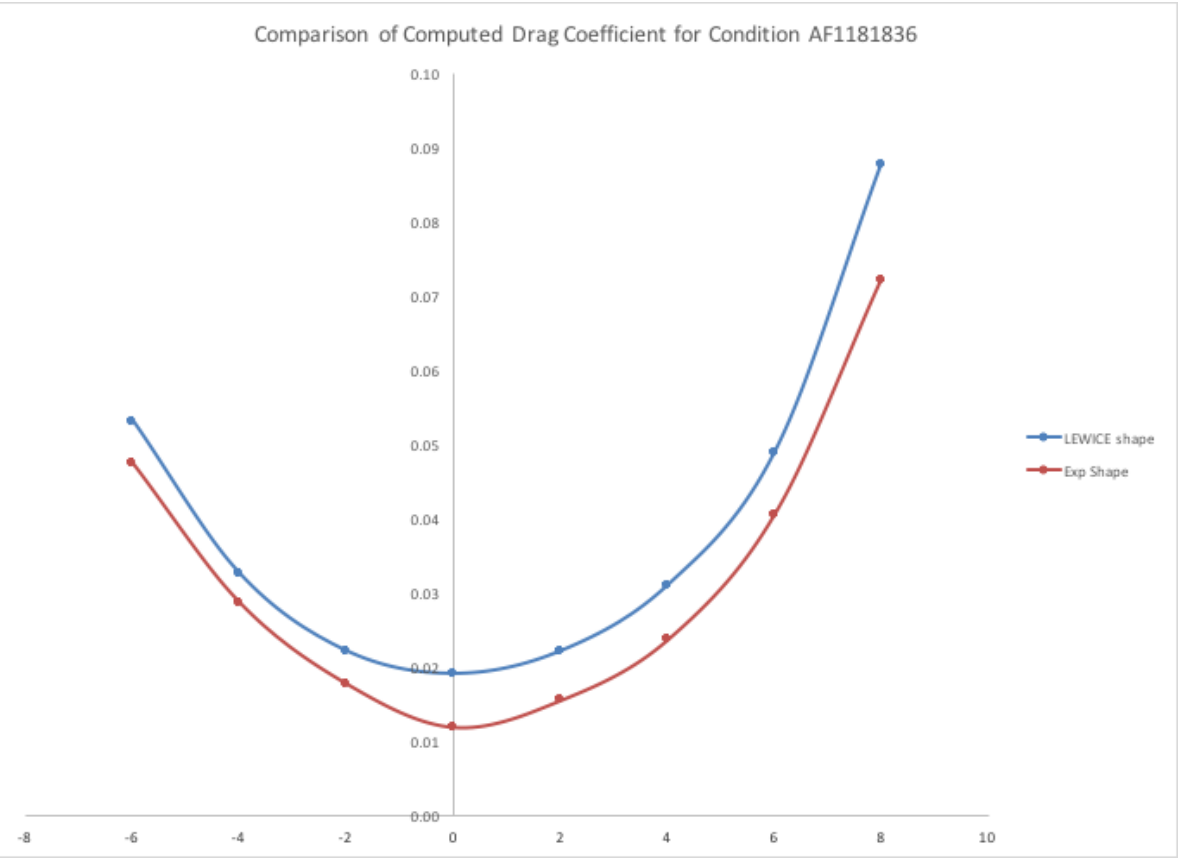


Figure 43: Ice Shape for Condition 4

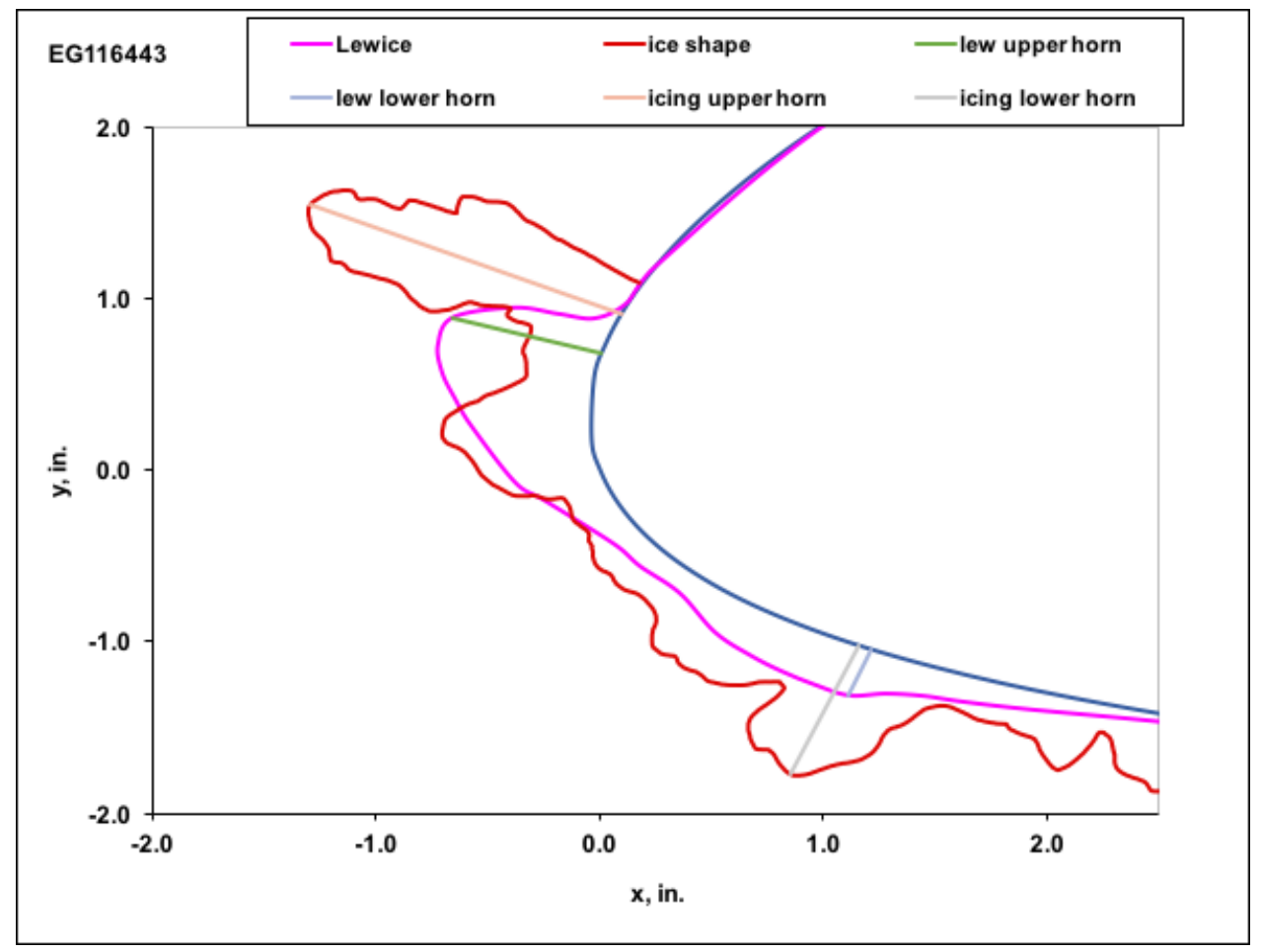

Figure 44: Comparison of Computed Lift for Condition 4

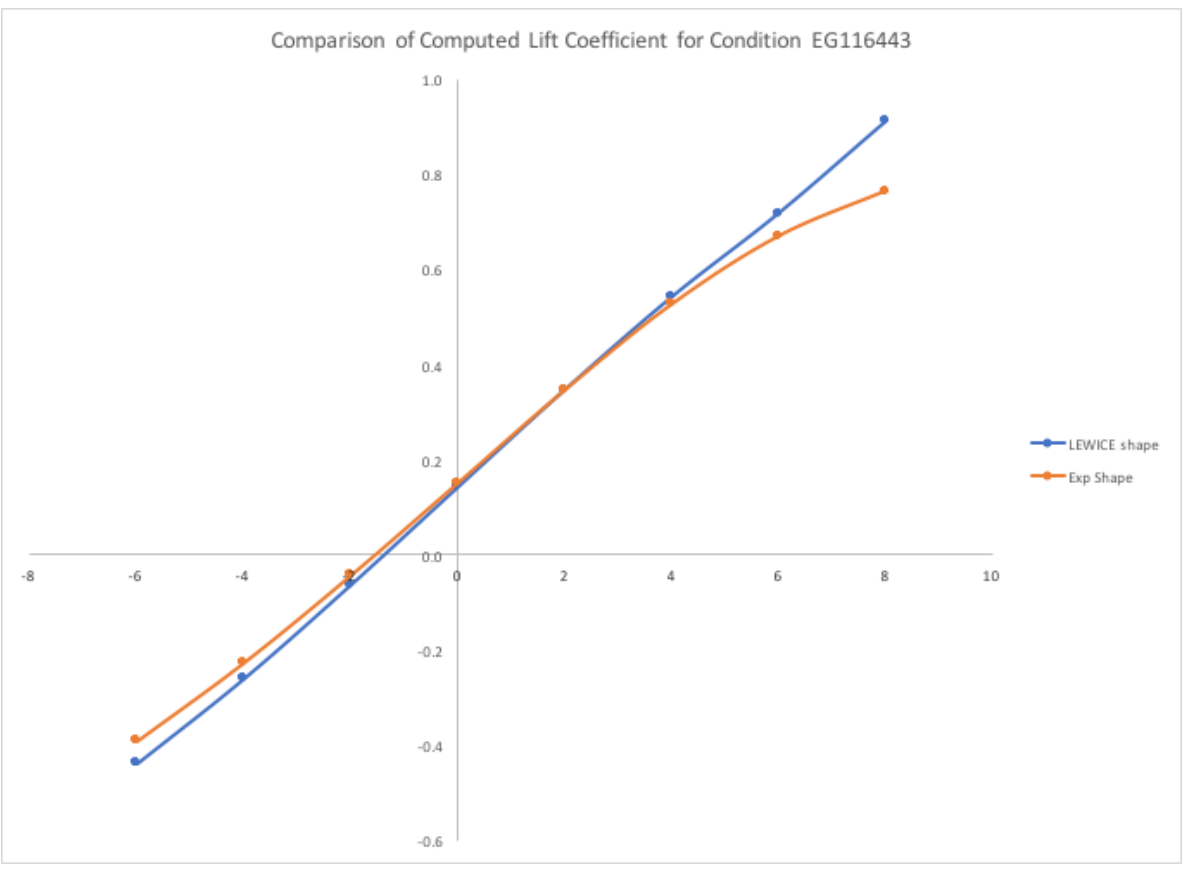




\section{Figure 45: Comparison of Computed Drag for Condition 4}

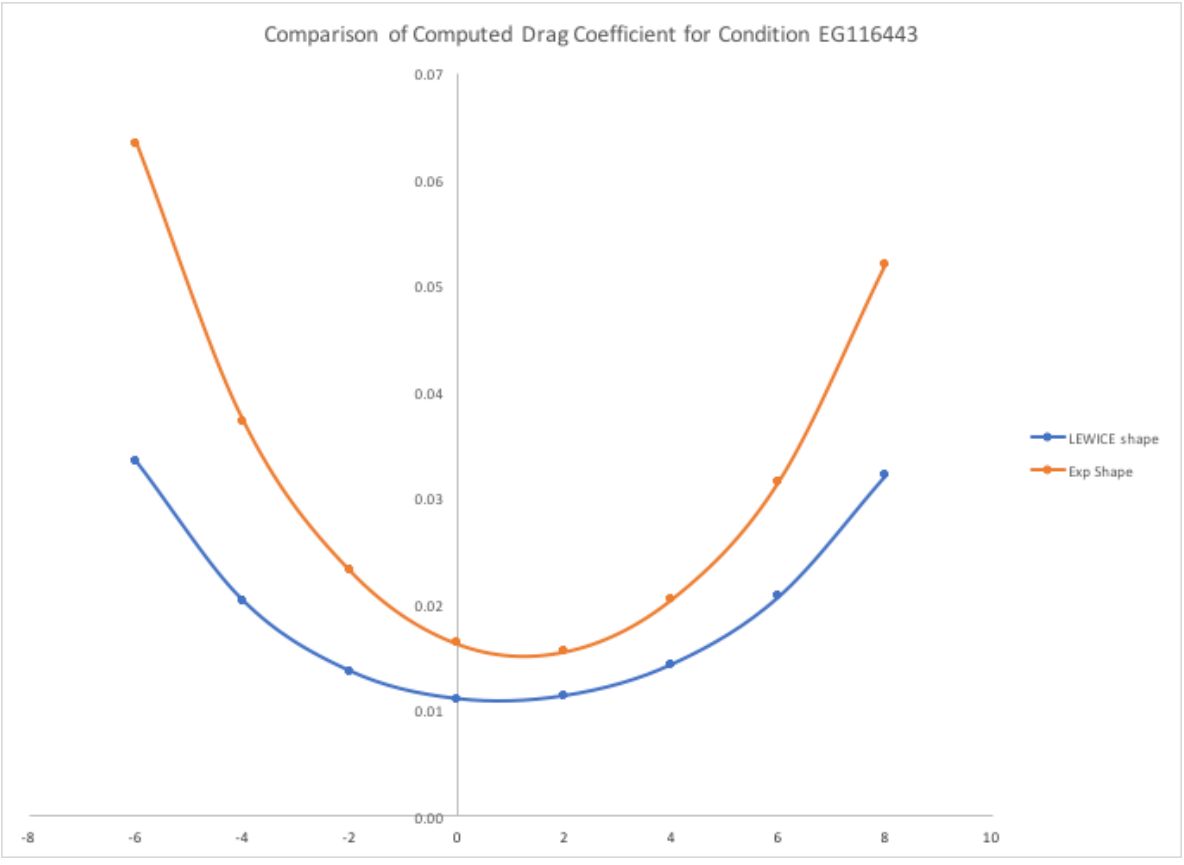

Figure 46: Ice Shape for Condition 5

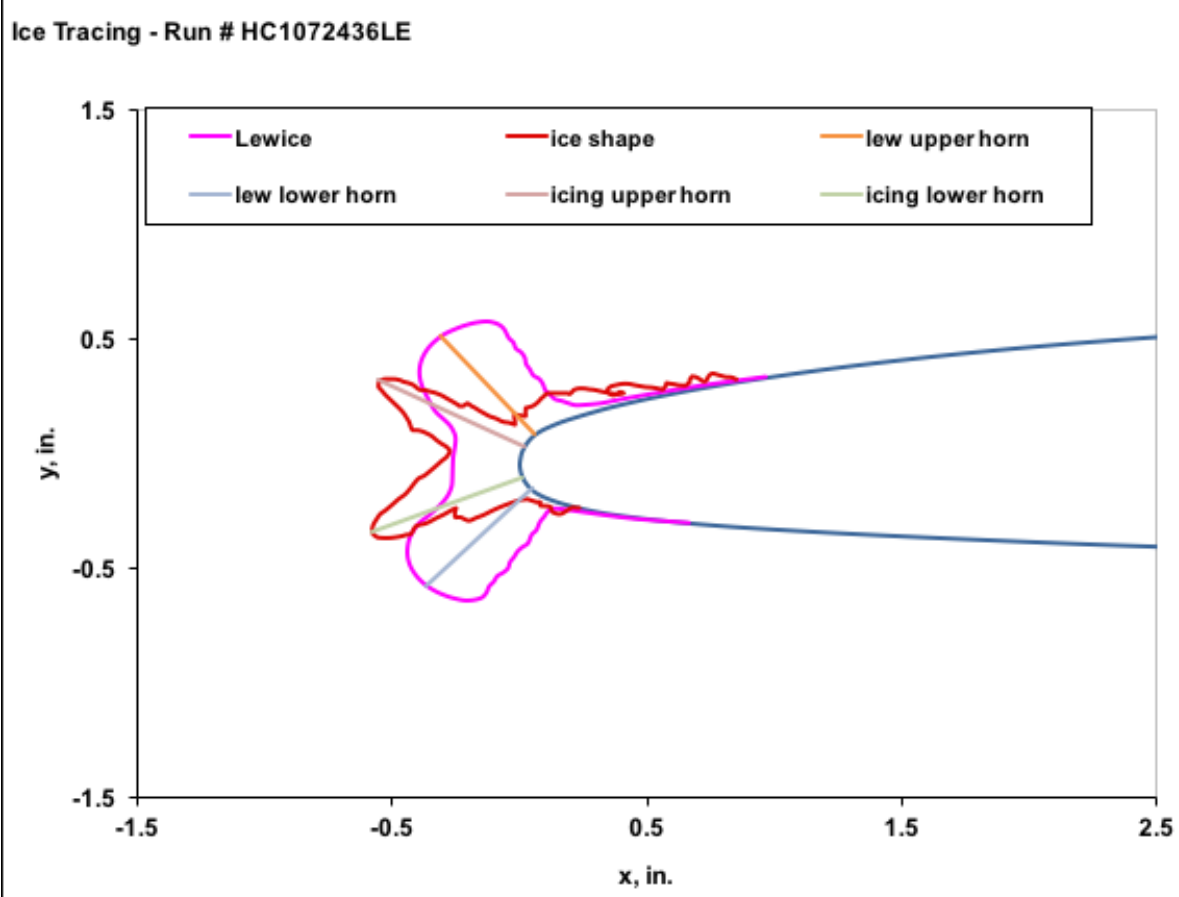


Figure 47: Comparison of Computed Lift for Condition 5

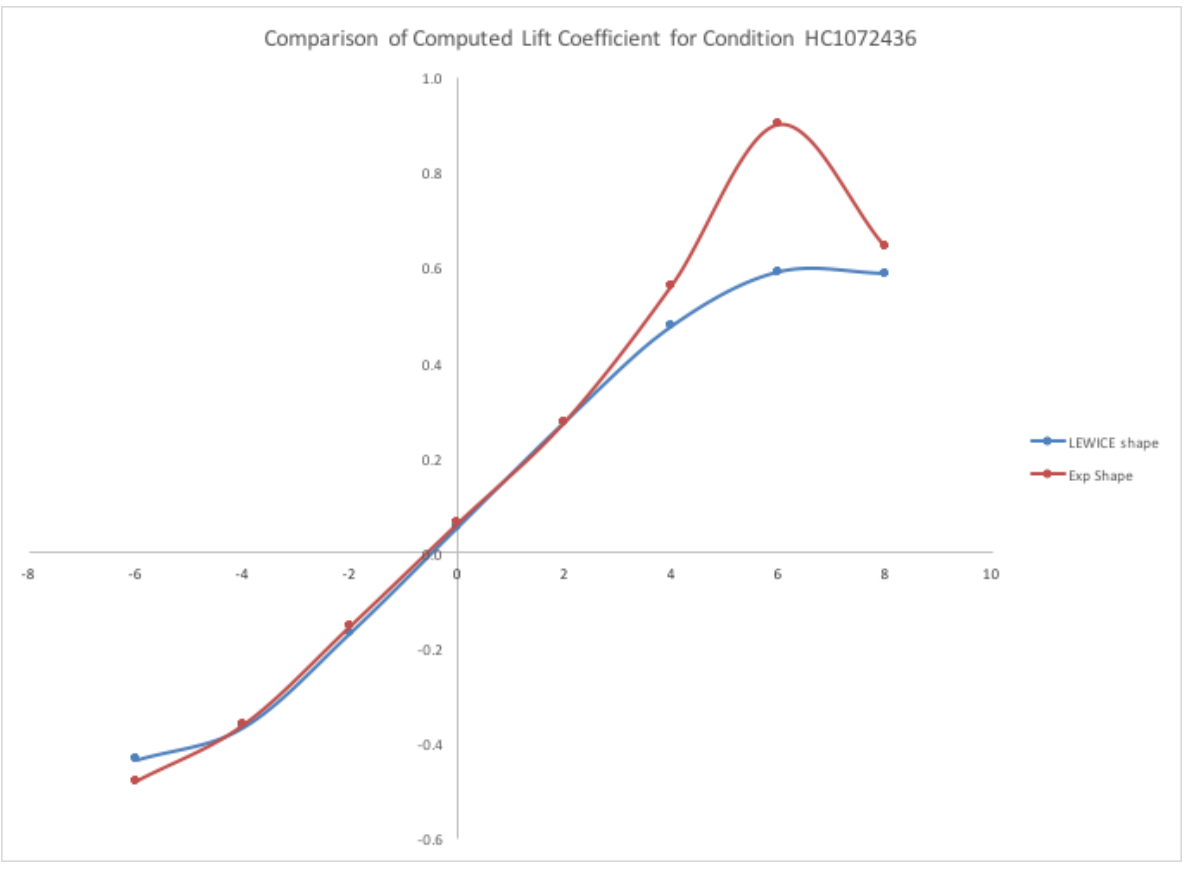

Figure 48: Comparison of Computed Drag for Condition 6

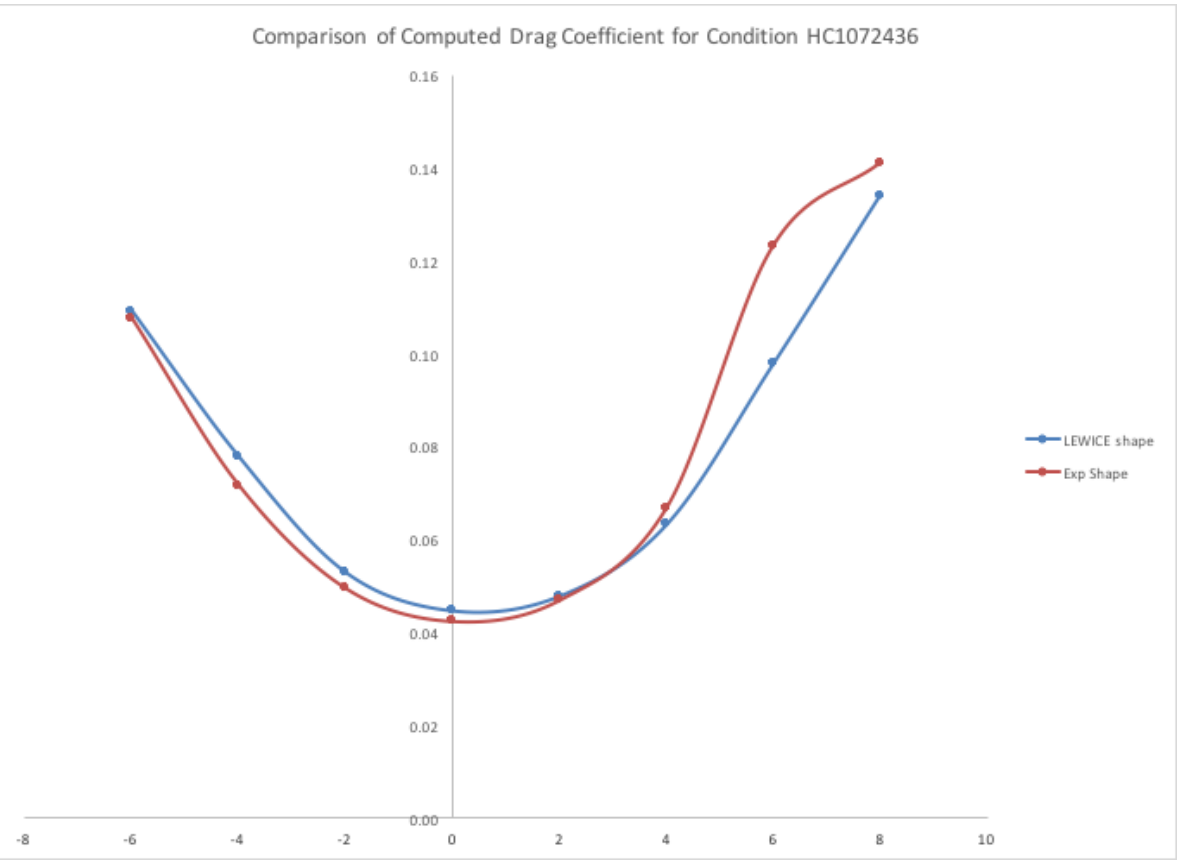


Figure 49: Ice Shape for Condition 6

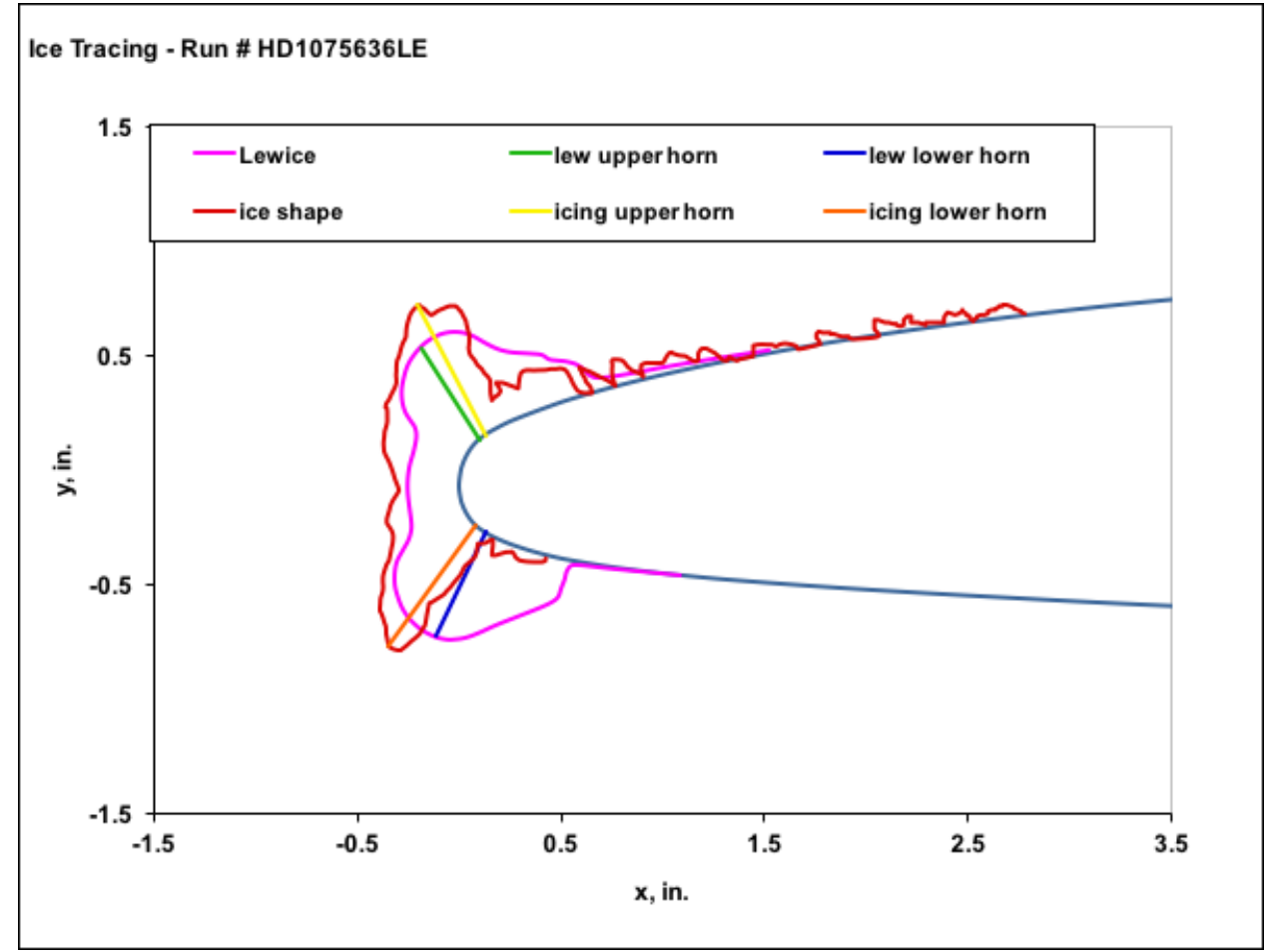

\section{Figure 50: Comparison of Computed Lift for Condition 6}

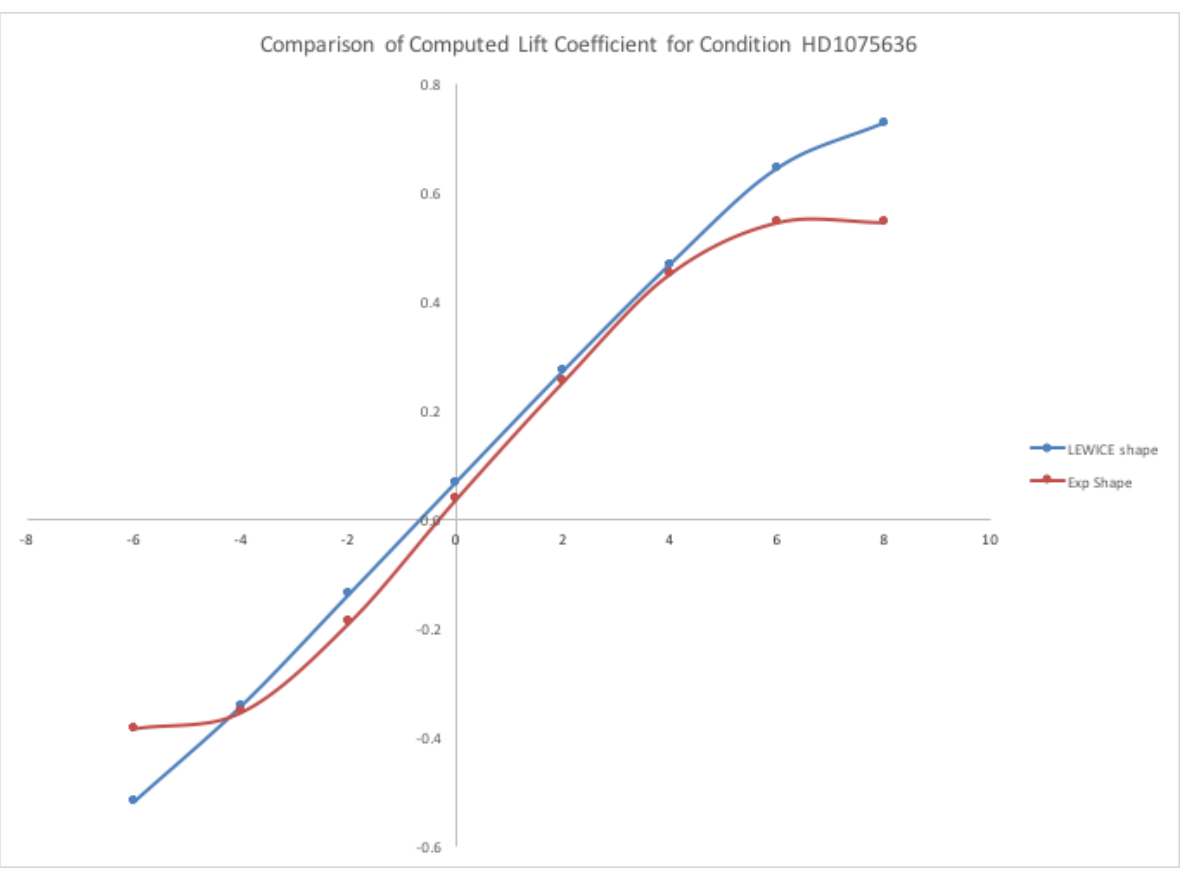




\section{Figure 51: Comparison of Computed Drag for Condition 6}

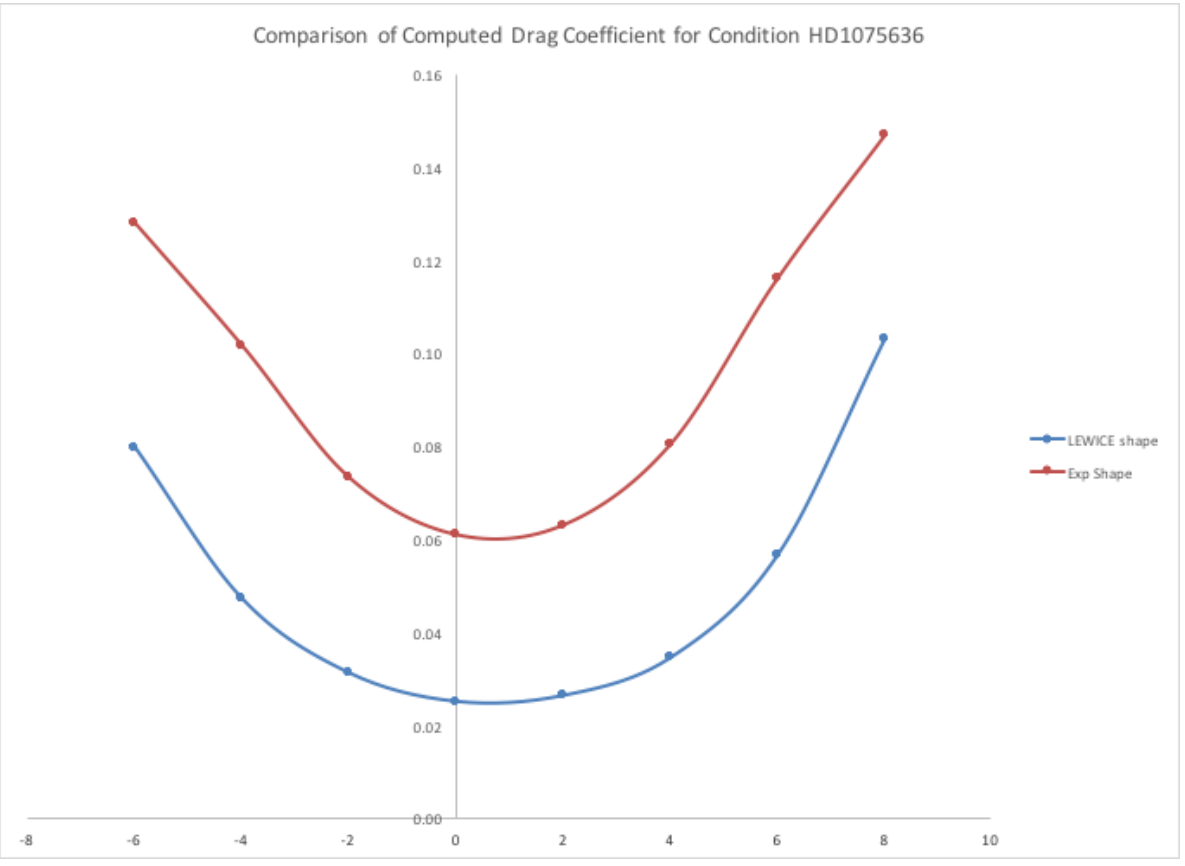

Figure 52: Ice Shape for Condition 7

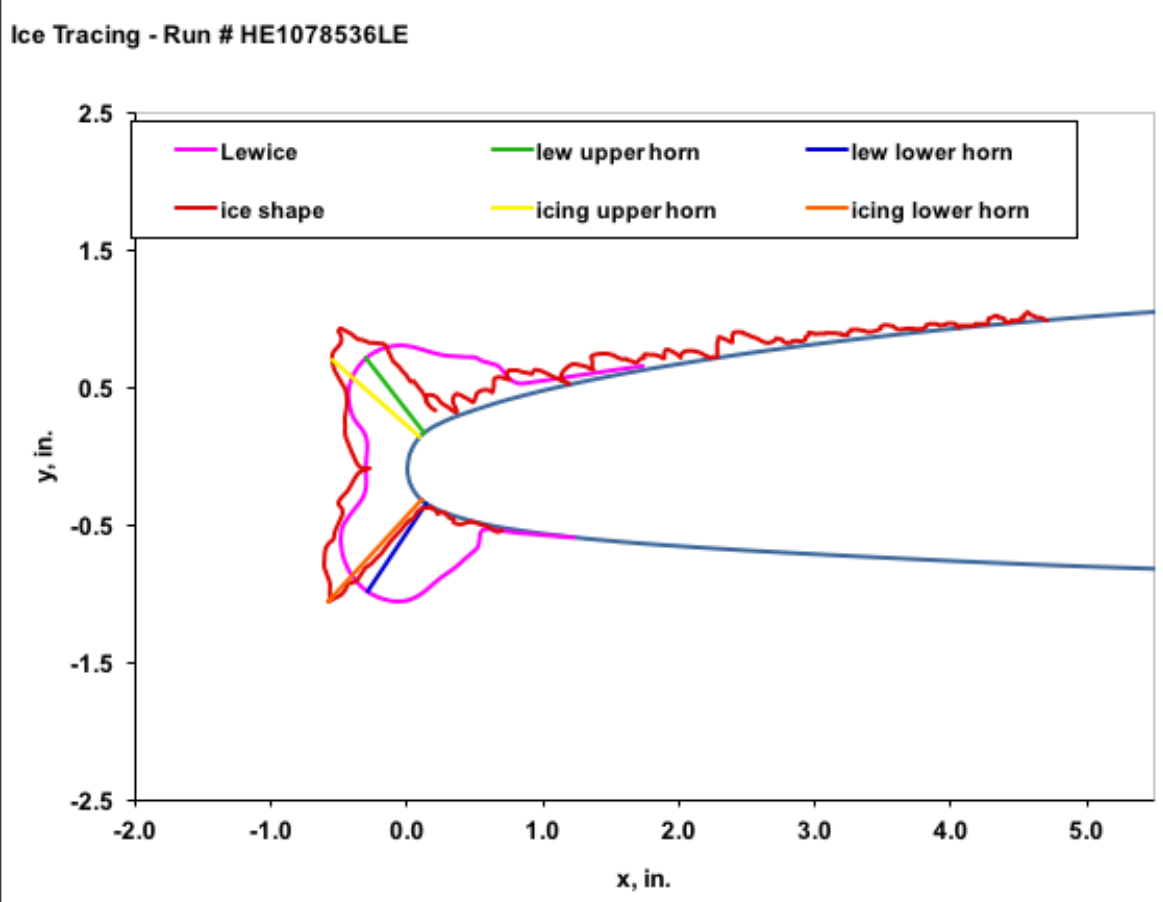


Figure 53: Comparison of Computed Lift for Condition 7

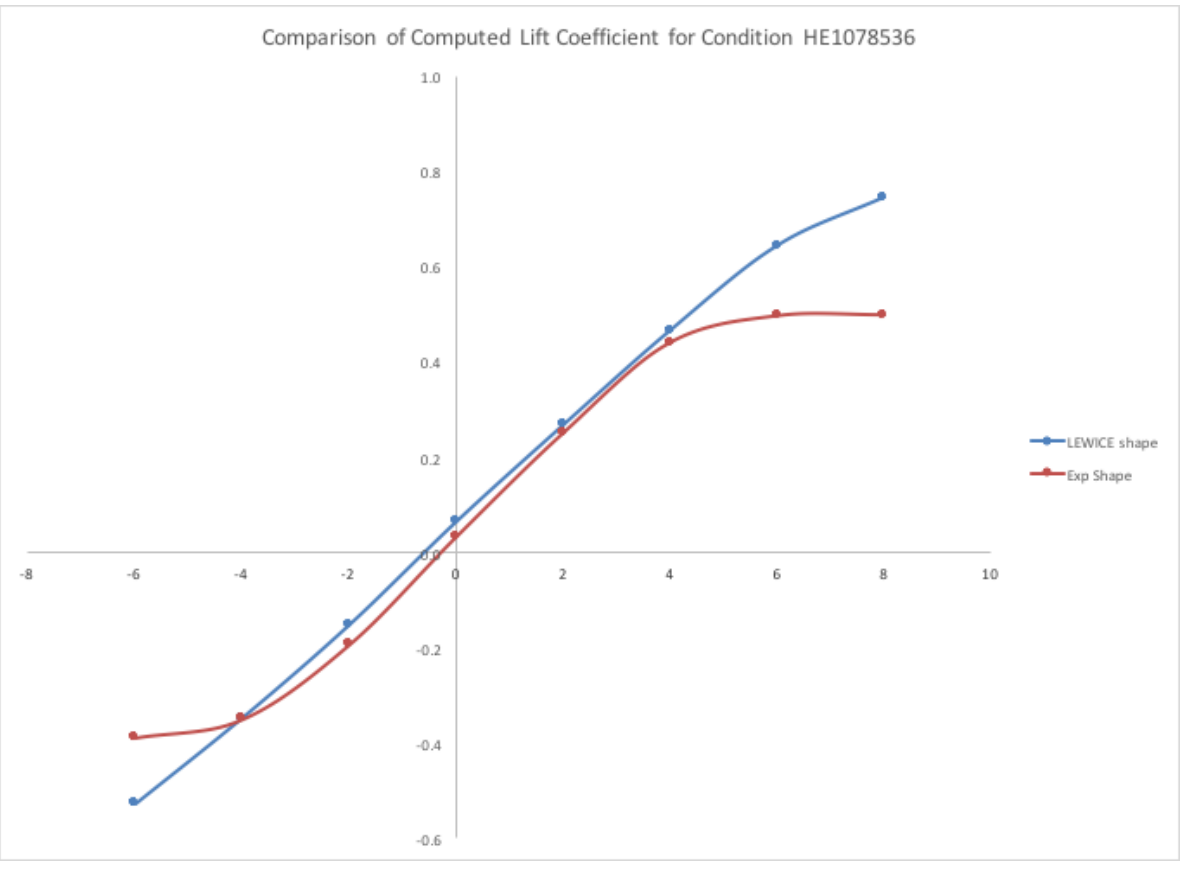

Figure 54: Comparison of Computed Drag for Condition 7

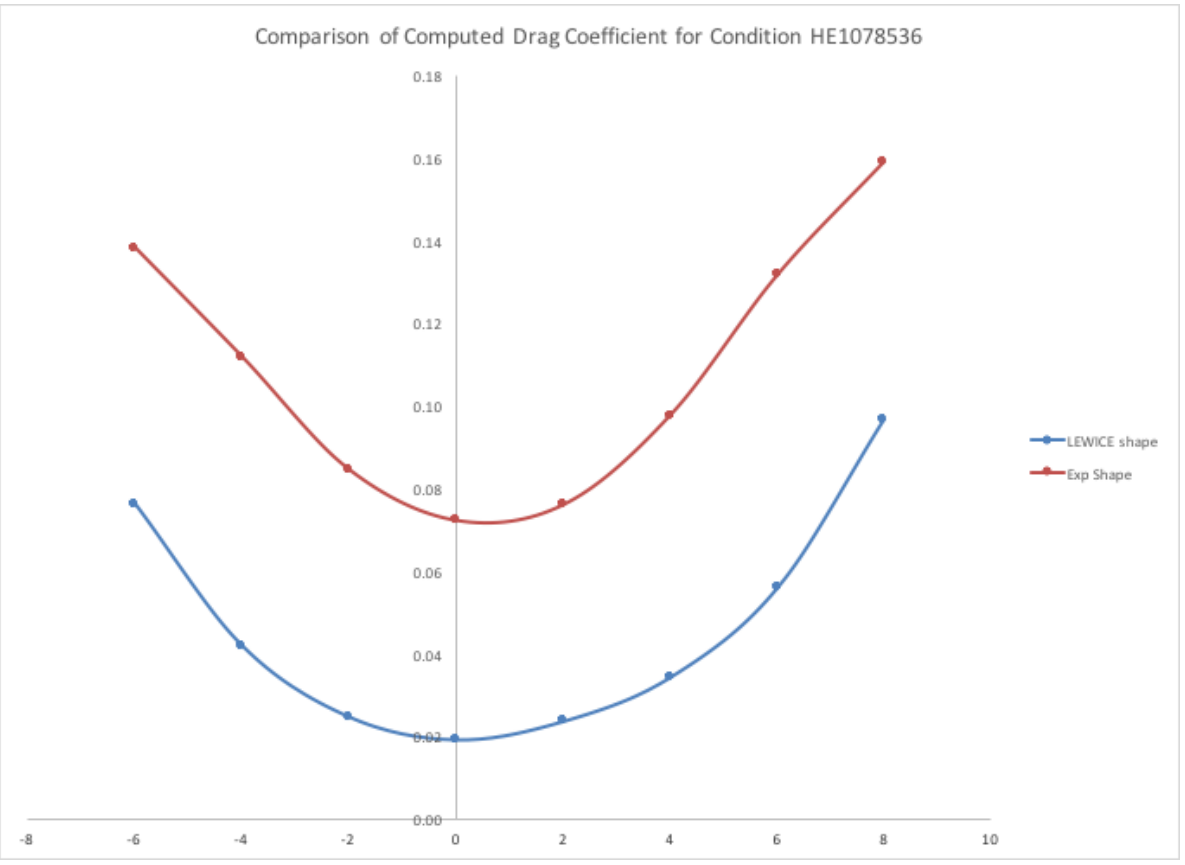


Figure 55: Ice Shape for Condition 8

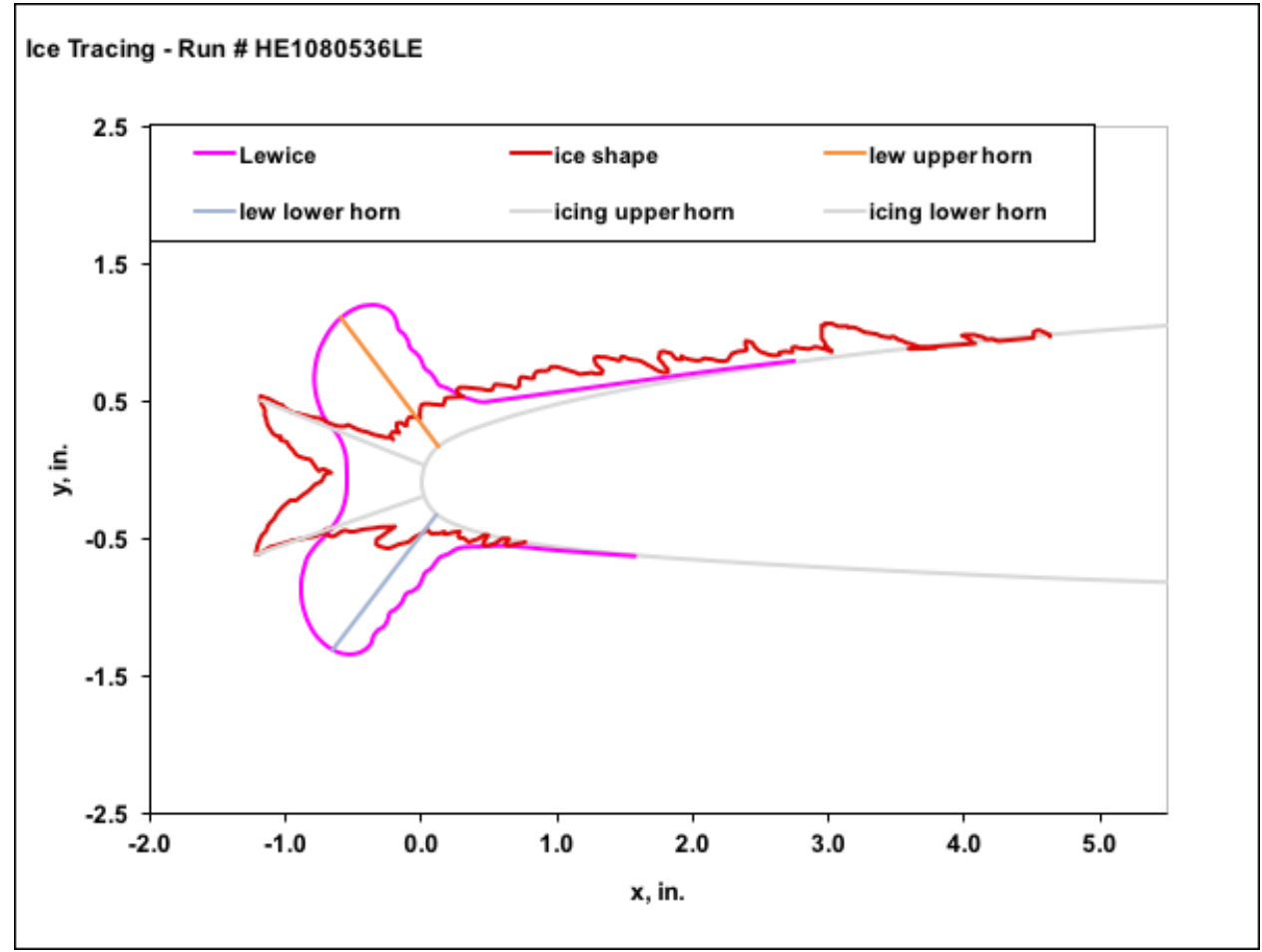

\section{Figure 56: Comparison of Computed Lift for Condition 8}

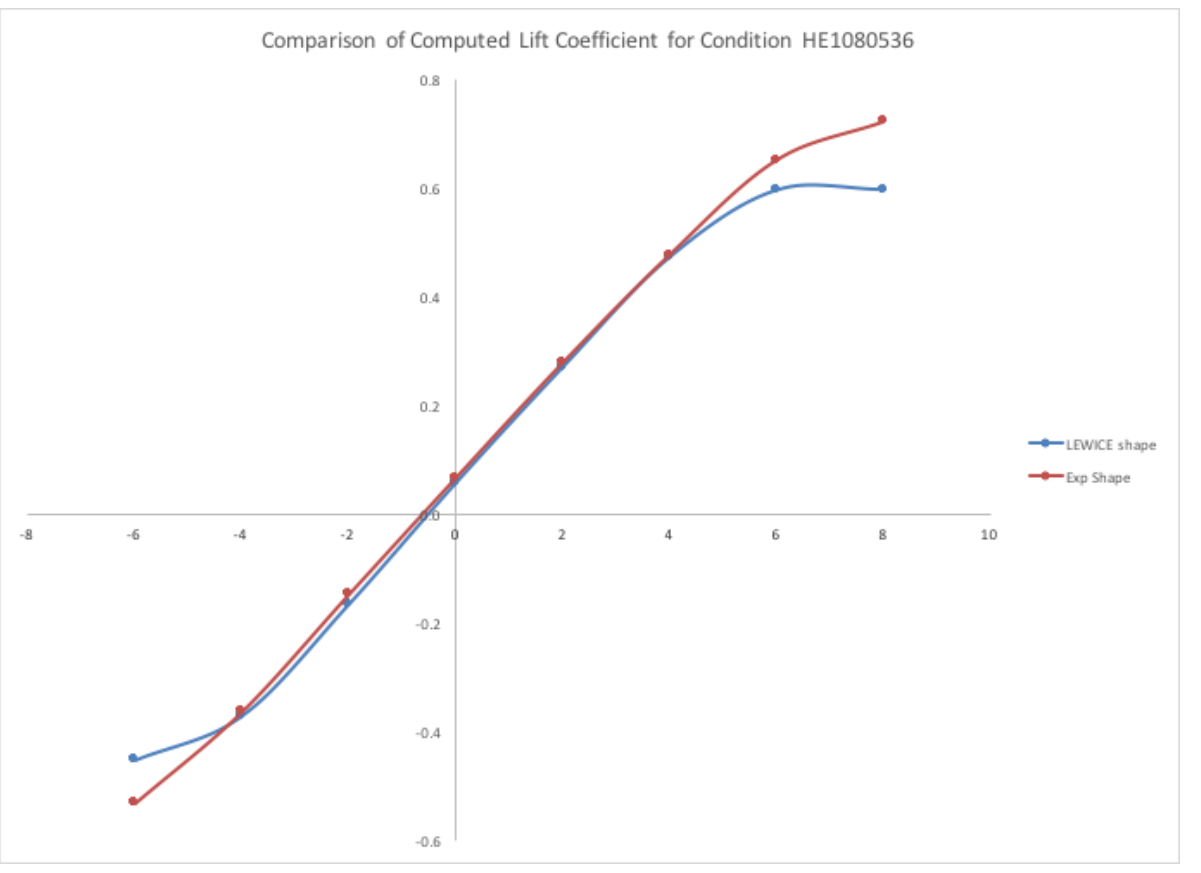




\section{Figure 57: Comparison of Computed Drag for Condition 8}

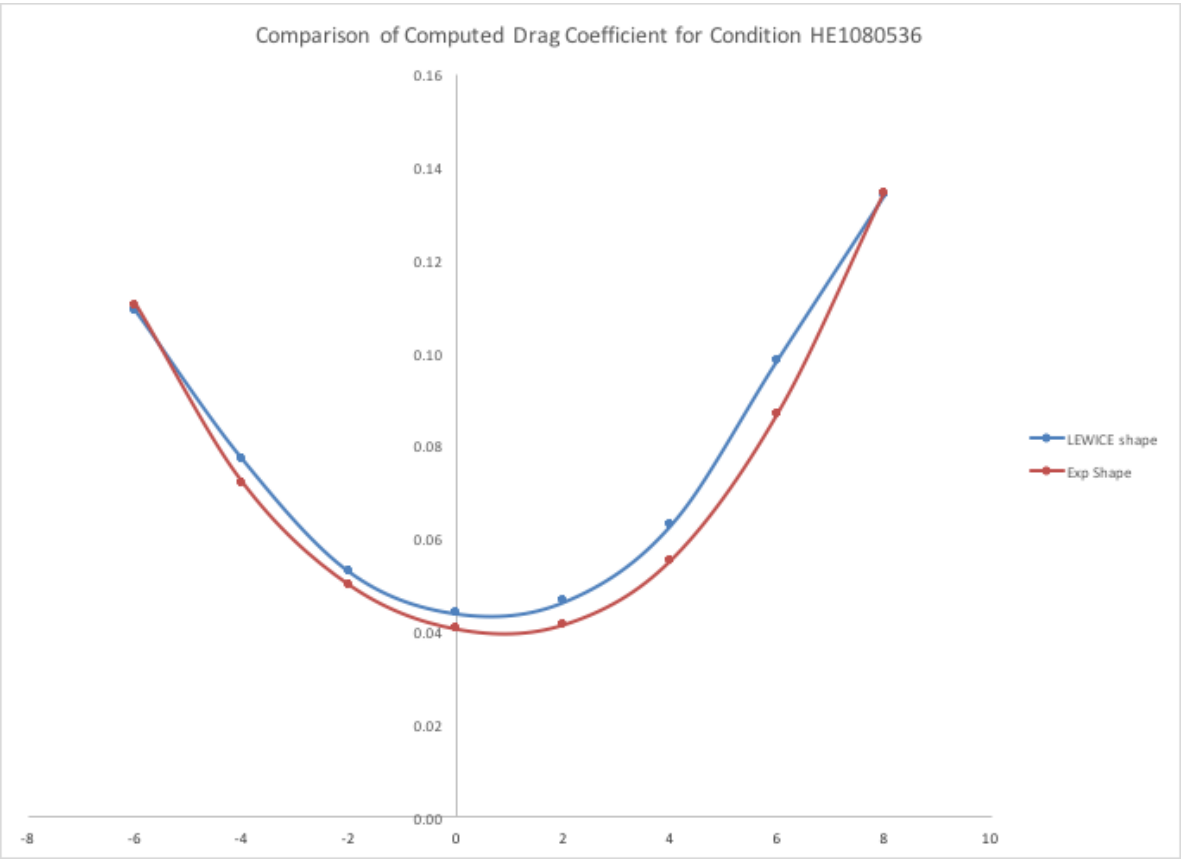

Figure 58: Ice Shape for Condition 11

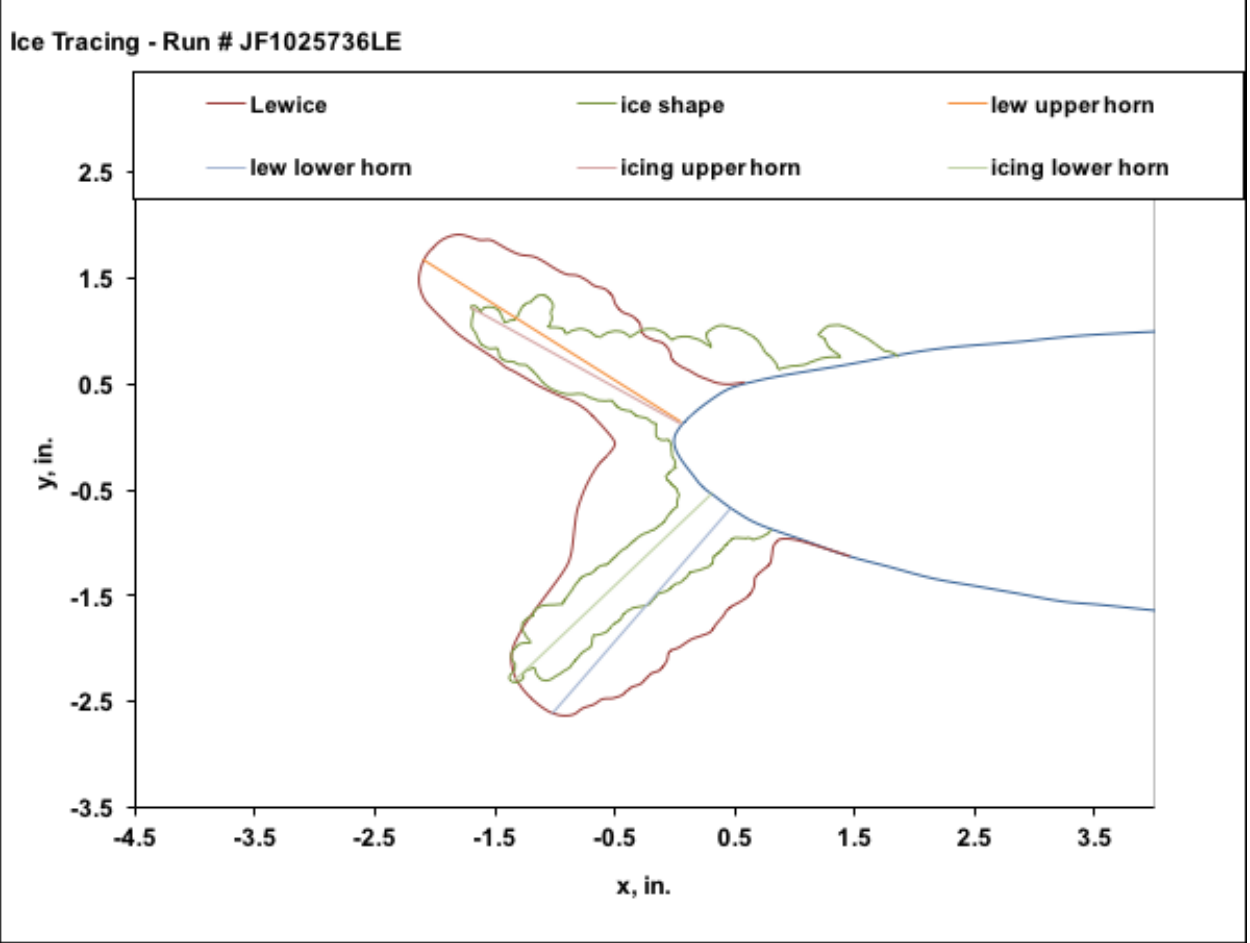


Figure 59: Comparison of Computed Lift for Condition 11

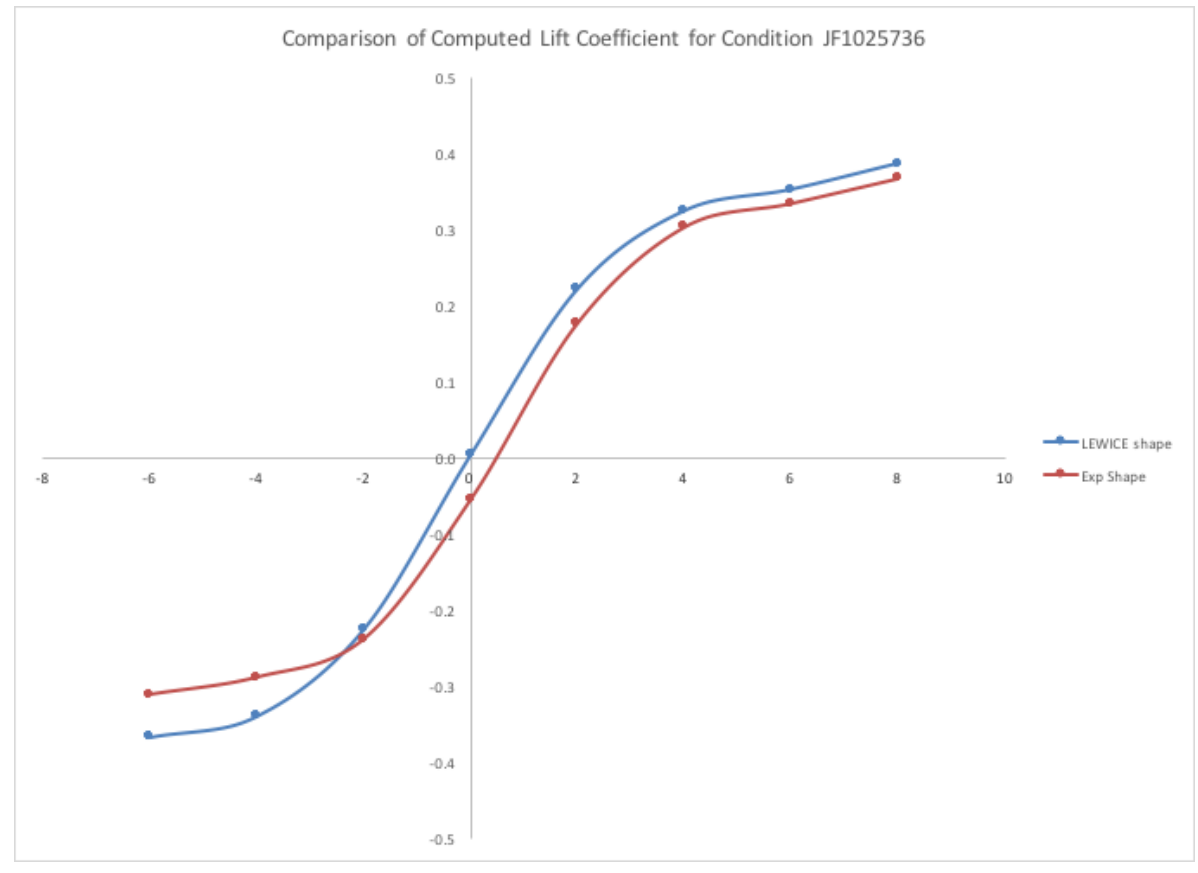

Figure 60: Comparison of Computed Drag for Condition 11

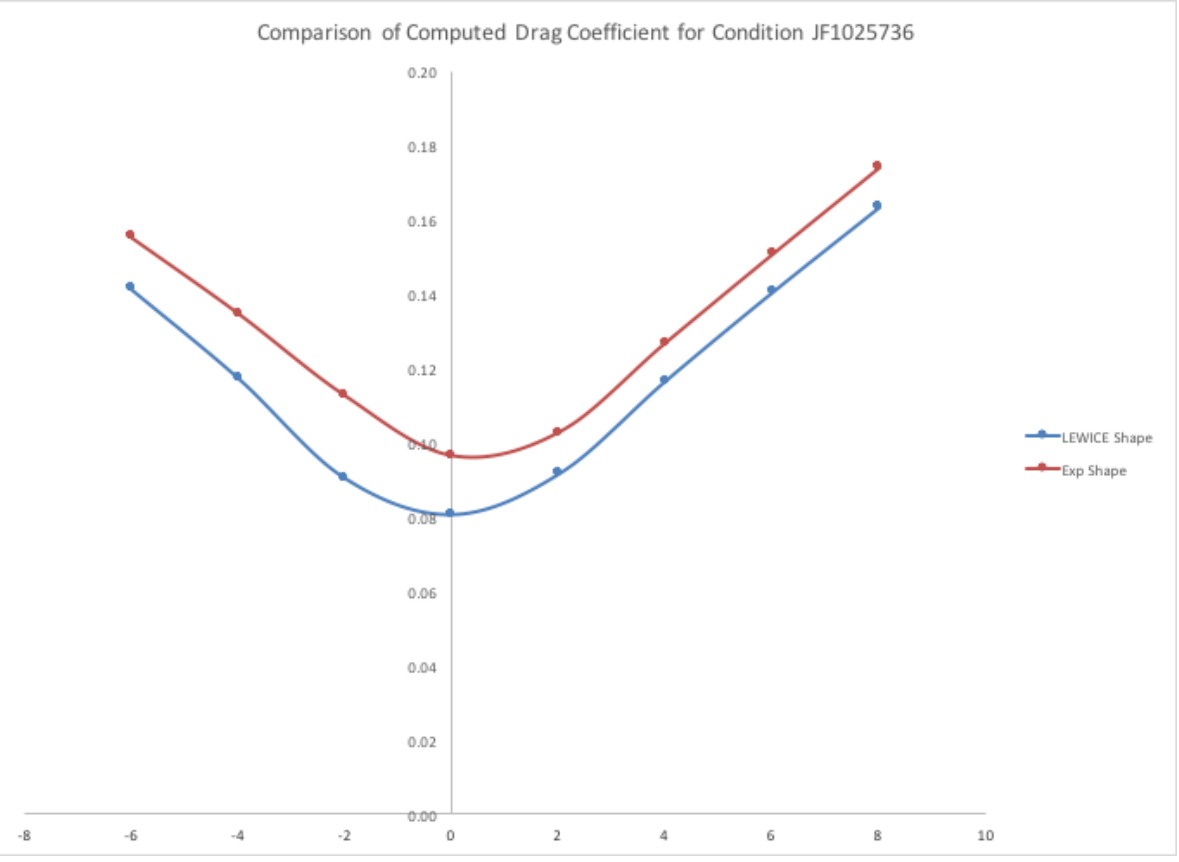

41

American Institute of Aeronautics and Astronautics 
Figure 61: Ice Shape for Condition 12

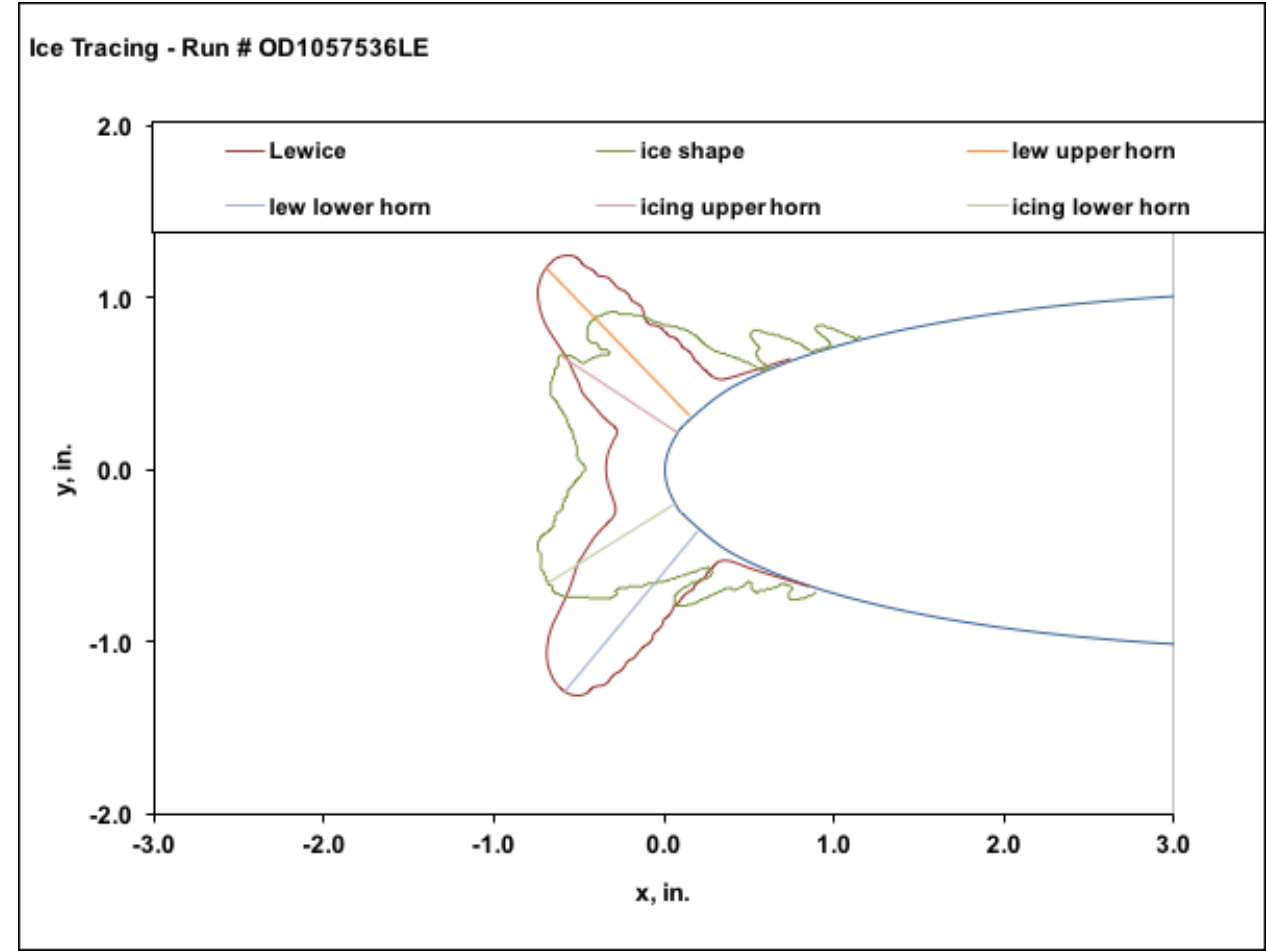

\section{Figure 62: Comparison of Computed Lift for Condition 12}

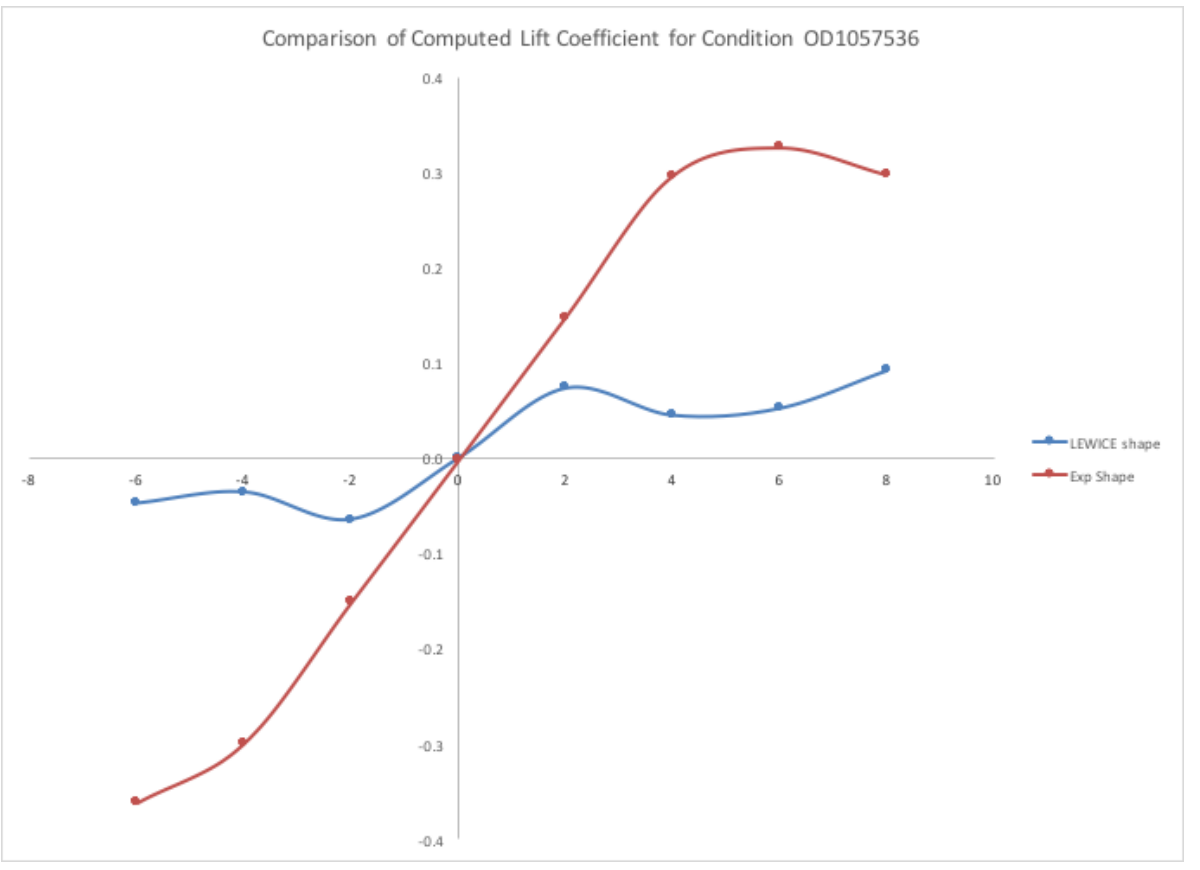


Figure 63: Comparison of Computed Drag for Condition 12

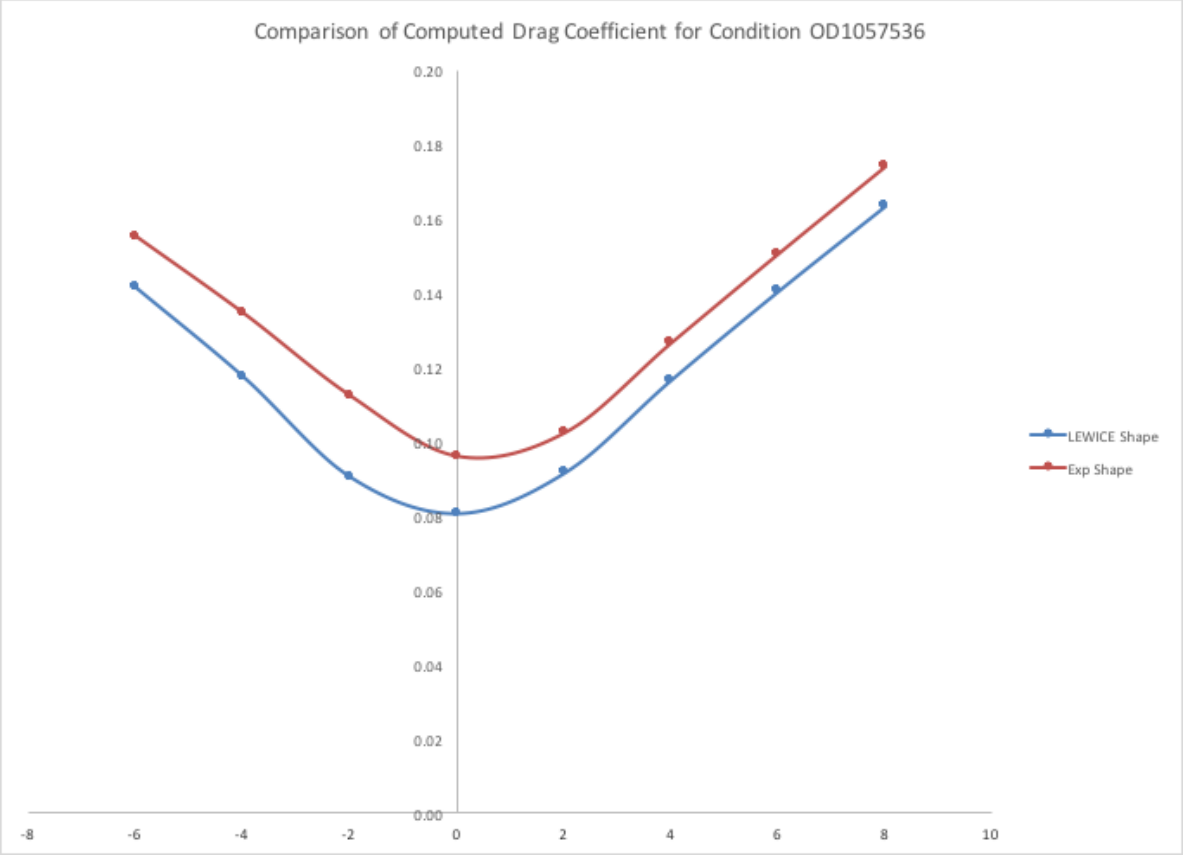

Table 2: Quantitative Comparison

\begin{tabular}{|c|l|c|l|c|c|c|}
\hline Condition & $\begin{array}{l}\text { horn } \\
\text { height } \\
\text { difference } \\
\text { (cm) }\end{array}$ & $\begin{array}{l}\text { horn angle } \\
\text { difference } \\
\text { (deg) }\end{array}$ & $\begin{array}{l}\text { avg } C_{\mathbf{l}} \\
\text { difference } \\
\text { (\%) }\end{array}$ & $\begin{array}{l}\text { avg } \mathbf{C}_{d} \\
\text { difference } \\
\text { (\%) }\end{array}$ & $\begin{array}{l}\text { variation } \\
\text { in } \mathbf{C}_{\mathbf{l}} \text { for } \\
\text { IRT shapes } \\
\text { (\%) }\end{array}$ & $\begin{array}{l}\text { variation } \\
\text { in } \mathbf{C}_{d} \text { for } \\
\text { IRT shapes } \\
\text { (\%) }\end{array}$ \\
\hline $\mathbf{1}$ & 0.9 & 9.5 & 184 & 62 & N/A & N/A \\
\hline $\mathbf{2}$ & 0.2 & 13 & 8 & 22 & N/A & N/A \\
\hline $\mathbf{3}$ & 2 & 23 & 28 & 61 & 10 & 14.7 \\
\hline $\mathbf{4}$ & 1.4 & 7 & 14 & 37 & N/A & N/A \\
\hline $\mathbf{5}$ & 0.1 & 25 & 12 & 7 & N/A & N/A \\
\hline $\mathbf{6}$ & 0.1 & 10 & 26 & 50 & N/A & N/A \\
\hline $\mathbf{7}$ & 0.5 & 9 & 30 & 60 & N/A & N/A \\
\hline $\mathbf{8}$ & 0.1 & 38 & 9 & 8 & N/A & N/A \\
\hline $\mathbf{9}$ & 1.2 & 30 & 10 & 68 & 8.3 & 15 \\
\hline $\mathbf{1 0}$ & 0.7 & 34 & 22 & 39 & 11 & N/A \\
\hline $\mathbf{1 1}$ & 0.6 & 12 & 12 & 11 & N/A & N/A \\
\hline $\mathbf{1 2}$ & 0.4 & 18 & 76 & 97 & N/A & N/A \\
\hline
\end{tabular}

